5-1-1969

\title{
Rheological Study of Concentrated Silica Suspensions
}

Prakash N. Mishra

How does access to this work benefit you? Let us know!

Follow this and additional works at: https://commons.und.edu/theses

\section{Recommended Citation}

Mishra, Prakash N., "Rheological Study of Concentrated Silica Suspensions" (1969). Theses and Dissertations. 591.

https://commons.und.edu/theses/591

This Thesis is brought to you for free and open access by the Theses, Dissertations, and Senior Projects at UND Scholarly Commons. It has been accepted for inclusion in Theses and Dissertations by an authorized administrator of UND Scholarly Commons. For more information, please contact und.commons@library.und.edu. 
RIEOLOGICAL STUDY OF CONCENTRATHD SILICA SUSPENSIONS

by

Prakash N. Mishra

B. Tech. in Chemical Engineering, 1.1.T. Bombay, 1966

A Thesis

Submitted to the Faculty

of the

University of North Dakota

in partial fulfillment of the requirements

for the Degree of

Master of Science

Grand Forks, North Dakota 


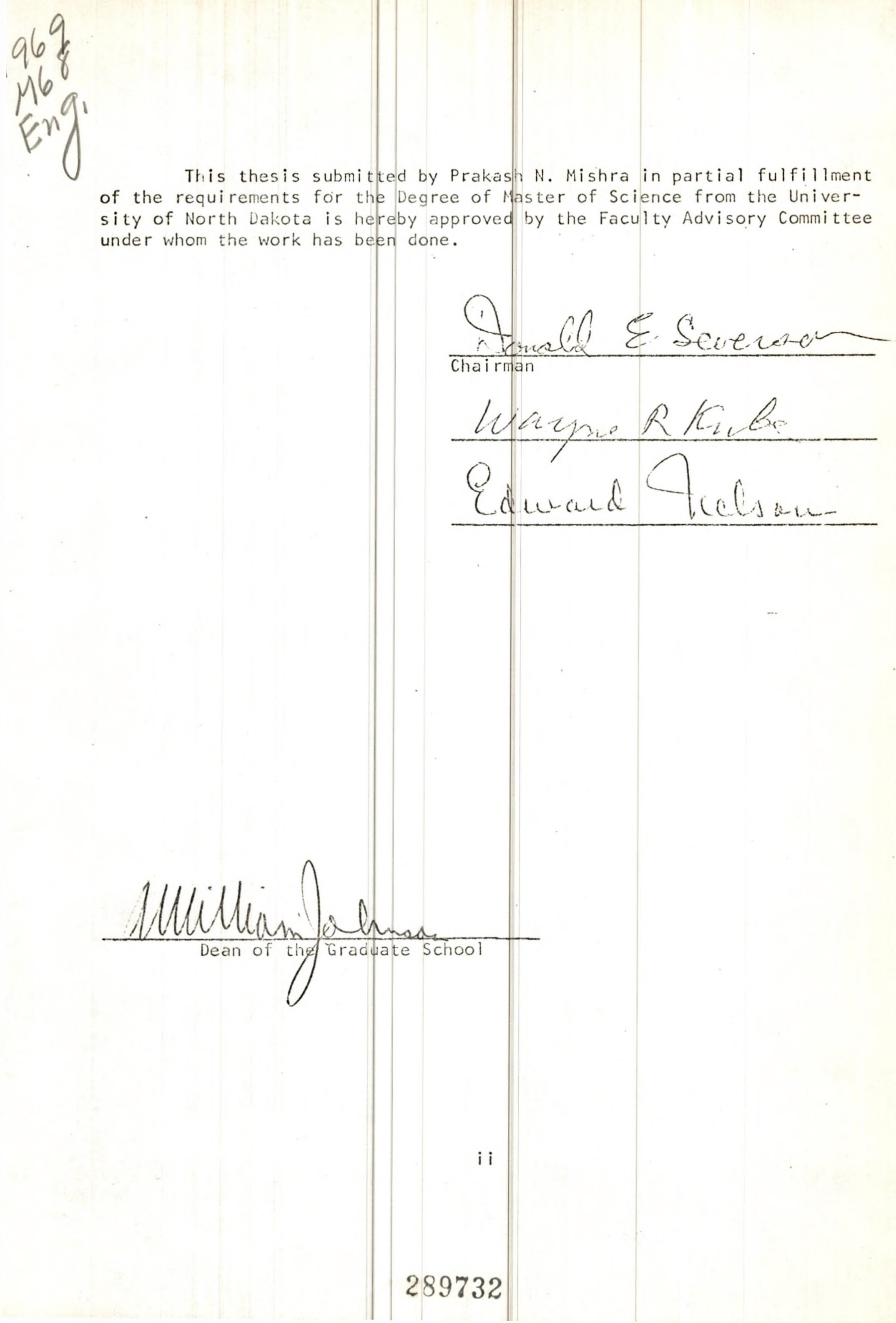




\section{Permission}

Title Rheological Study of Concentrated Silica Suspensions

Department Chemical Engineering

Degree Master of Science

In presenting this thesis in partial fulfillment of the requirements for a graduate degrea from the University of North Dakota, I agree that the Lilhrary of this University shall make it freely available for inspection. I further agree that permission for extensime copying of this thesis for scholarly purposes may be granted by the professor who supervised my thesis work or, in his absence, by the chairman of the Department or the Dean of the College in which my thesis work was done. It is understood that any copying or publication or other use of this thesis or part thereof for financial gain shall not be allowed within my written permission. It is also understood that due recognition shall be $g$ iven to me and to the University of North Dakota in any scholarly use which ma be made of any material in my thesis.

signature Pratenoh Nowion Migha- 


\section{ACKNOWLEDGEHENTS}

The author expresses appreciation to Professor D. E. Severson for his aid in directing and editing this thesis. Appreciation is extended to Professor W. R. Kube and Professor E. O. Nelson for their advice and constructive criticisms.

The author is also very grateful to Professor A. M. Cooley, Professor D. R. Skidmore and Professor T, C. Owens for their kind help during the course of preparation of this thesis.

Very special. thanks are due to Mr. L. T. O'Neil for his help in numerous ways.

Appreciation is also extended to all the people, too numerous to mention, for their kind help and advice in the research and preparition of this thesis. Without their assistance the work could not have been done. 


\section{TABLE OF CONTENTS}

ACKNOWLEDGEMENTS ....................... . iv

LIST OF TABLES.............................. . . . . vi

LIST OF FICURES . . . . . . . . . . . . . . . . . . . vii

ABSTRACT . . . . . . . . . . . . . . . . . . . . . . . $\mathrm{ix}$

Chapter

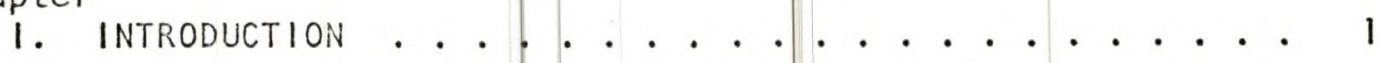

II. PREVIOUS WORK AND LiteratURE SURV:Y. . . . . . . . . . . . 3

II. THECRETICAL APPROACH TO THE PROBL:M . . . . . . . . . . . . 11

IV. MATERIALS, APPARATUS AND EXPERIMEMTAL PROCEDURES . . . . 18

V. RESLLTS . . . . . . . . . . . . . . . . 25

VI. DISCUSSION AND ANALYSIS OF RESULTS . . . . . . . . . . 30

VII. CONCLUSIONS............................ 66

VIII. SUGGESTIONS FOR FURTHER EXPERIMENTATION . . . . . . . . 68 APPENDICES

A. TANGENTIAL ANNULAR FLOW OF A BINGHAM PLASTIC . . . . . 70

B. TANGENTIAL ANNULAR FLOW OF A POWER LAW FLUID . . . . . . 74

C. MATERIAL PROPERTIES................... . . 77

D. EQUIPMENT SPECIFICATIONS ............... 82

E. SAMPLE DATA FOR A PARTICULAR RUN . . . . . . . . . . 88

F. EXPERIMENTAL DATA ................. . 89

G. SAMPLE CALCULATIONS.................... . . . 99

H. VAlues of PARAMETERS . . . . . . . . . . . . 105

LIST OF SYMBOLS . . . . . . . . . . . . . . . . . . . 112

LIST OF REFERENCES . . . . . . . . . . . . . . . . . . . . 115 
Table

Page

1. Particle Size Distribution for Silica........ . 19

2. Data for Lignite-water Suspension . . . . . . . . 64

3. Chemical Analysis of Silica........... . . 78

4. Physical Characteristics of Silica . . . . . . . 79

5. Analysis of Lignite ............... . 80

6. Ash fnalysis of Lignite............... . 81

7. Brookfield Viscometer Specifications . . . . . . . 83

8. Zeta-Meter Specifications ............. 84

9. Sample Data for a Particular Run . . . . . . . . 87

10. Complete Apparent Viscosity Data . . . . . . . . . 90

11. Averaged Electrophoretic Mobility Data . . . . . . . 96

12. Complete Electrophoretic Mobility Data . . . . . . . 97

13. Apparent Viscosity Data for Different Particle Sizes . 98

14. Torque-angular Velocity Data ............ 106

15. Plastic Viscosity and Yield Stress Data........ . 110

16. Power Law Model Parameters Data . . . . . . . . . 111 


\section{LIST OF FIGURES}

Figure

Page

1. Concept of the Zeta Potential ............. 14

2. Effect of Rotational Speed on Apparent Viscosity . . . 26

3. Effect of Solids Concentration on Apparent Viscosity . . 27

4. Effect of pH on Electrophoretic Mobility ........ 29

5. Effect of Angular Velocity on Torcue at $\mathrm{pH}=4.0 . .31$

6. Effest of Angular Velocity on Torcue at $\mathrm{pH}=5.0$. . . 32

7. Effect of Angular Velocity on Torque at $\mathrm{pH}=6.0$. . . 33

8. Effect of Angular Velocity on Torque at $\mathrm{pH}=7.0$. . . 34

9. Effect of Angular Velocity on Torque at $\mathrm{pH}=8.0$. : . 35

10. Effect of Angular Velocity on Torque at $\mathrm{pH}=9.0 . .36$

11. Effect of Angular Velocity on Torcue at $\mathrm{pH}=10.0 . .37$

12. Effect of Solids Concentration on Plastic Viscosity . . . 39

13. Effect of $\mathrm{pH}$ on Plastic Viscosity.......... . 40

14. Effect of Electrophoretic Mobility on Plastic Viscosity. 41

15. Effect of Solids Concentration on Yield Stress . . . . 42

16. Effect of $\mathrm{pH}$ on Yield Stress . . . . . . . . . . 43

17. Effect of Electrophoretic Mobility on Yield Stress . . 44

18. Logarithmic Torque-Angular Velocity Plot at $\mathrm{pH}=4.0$. 46

19. Logarithmic Torque-Angular Velocity Plot at $\mathrm{pH}=5.0$. 47

20. Logarithmic Torque-Angular Velocity Plot at $\mathrm{pH}=6.0$. 48

21. Logarithmic Torque-Angular Velocity Plot at $\mathrm{pH}=7.0 .49$ 
Figure

Page

22. Logarithmic Torque-Angular Velocity Plot at $\mathrm{pH}=8.0$. 50

23. Logarithmic Torque-Angular Velocity Plot at $\mathrm{pH}=9.0 .51$

24. Logarithmic Torque-Angular Velocity Plot at $\mathrm{pH}=10.0 .52$

25. Effect of Solids Concentration on Power Law Model Parameter ' $m$ '. . . . . . . . . . . 54

26. Effect of $\mathrm{pH}$ on Power Law Model Parameter ' $\mathrm{m}$ ' . . . . 55

27. Effest of Electrophoretic Mobility on Power Law Model Parameter ' $\mathrm{m}^{\prime}$.............. 56

28. Effect of Solids Concentration on Power Law Model Parameter ' $n$ '............ 57

29. Effect of $\mathrm{pH}$ on Power Law Model Parameter ' $n$ ' . . . . 58

30. Effect of Electrophoretic Mobility on Power Law

Model Parameter ' $n$ '. . . . . . . . . . . . 59

31. Effect of Rotational Speed on Apparent Viscosity

for Different Particle Sizes ........... 61

32. Effect of $\mathrm{pH}$ on Apparent Viscosity for Different

Particle Sizes............... 62

33. Torque-Angular Velocity Plot for $20 \%$ by Volume

Lignite-Water Suspension . . . . . . . . . . 65 


\section{ABSTRACT}

Concentrated suspensions of silica in water were investigated using a rotational viscometer and a Zeta-Meter. The viscometric data was analyzed for shear dependence, solids concentration dependence and $\mathrm{pH}$ dependence. The data for electrophoretic mobility was analyzed for $\mathrm{pH}$ dependence.

The experimental data was applied to the Bingham plastic model and the power law model and the power law model was found to describe the experimental data more closely than the Bingham plastic model. The parameters for these two models were correlated to solids concentration, $\mathrm{pH}$ and electrophoretic mobility.

Effect of particle size on apparent viscosity was also studied but no correlations were attempted.

A model was proposed for the relationship between $\mathrm{pH}$ and electrophoretic molility.

A suspension of lignite in water was found to fit the Bingham plastic model. 


\section{CHAPTEF I \\ INTRODUCTION}

Interest in the hydraulic transport of solids by pipelines has increased in scope and volume in the past few years. One of the major industries where this mode of transportation has been used is the coal industry and a big project is taking shape, at present, in the southwestern part of the United States (1). A 273-mile pipeline will conviy 660 tons/hr. of slurried coal from a Peabody Coal Company mine at Kayenta, Arizona, to a forthcoming $\$ 191$ pillion Southern California Edison power plant on the Colorado River in southern Nevada.

Previously, this type of operation was used successfully in Ohio by the Consolidation Coal Company, but was closed due to reduction in freigh: rates through unitized rail transportation (2). Similar efforts have been made, with varying degrees of econonic success in France, England and Russia (2). Other materials, such as phosphates, metal ores, 1 imestone and fertilizers, provide an economic avenue for the transportation of their slurries by pipelines. Another application of slurry transportation has come about by the development of slurry-fueled nuclear reactors $(3)$.

Rheology of concentrated suspensions is an area of major interest from the point of view of design of equipment for siurryhandling industries. Generally, the suspensions exhibit non-Newtonian behavior as compared to the Newtonian behavior of the suspending media (4). The rheqlogical behavior of suspensions becomes complicated 
because of the hydrodynamic effect between particles and the difficulty in representing the random arrangements of these particles by a simple model. Concentrated suspensions can be glassified into settling and non-settling suspensions. The degree of settling for a given system depends on the Van der Wals forces of attraction and the forces of repulsion due to surface charges on the particles (5). Laminar flow can be used for the transportation of non-settling suspersions, whereas turbulent transport must be resorted to for settling suspensions (6). Classical work on the rheology of dilute suspensions was done by Einstein, as discussed by Frisch and simha (7). However, the present work is concerned with concentrated suspensions, the industrial application of which is more important. The primary objective of this research was to study the effect of a change in the surface, charge of the particles on the viscosity of concentrated suspensions. Other variables studied were solids concentration, particle size and shear rate. Various researchers have proposed that the Binghim plastic model would best describe a zoncentrated suspension; other workers have suggested the power law model. Both of these theories were investigated and a semiempirical relationship was sought for the correlation of the variables. 


\section{CHAPTER :/}

\section{PREVIOUS WORK AND LITERATURE SURVEY}

Eirstein made the first theoretidal approach to the viscosities of suspensions and arrived at the following relationship for dilute suspensions of spherical particles, as discussed by Frisch and Simha (7):

$$
\mu_{s}=\mu_{0}(1+2.5 \phi)
$$

where $\mu_{s}$ is the absolute viscosity of the suspension, poises,

$\mu_{0}$ is the absolute viscosity of the suspending medium, poises and $\phi$ is the volume fraction occupied by the solids.

The above equation (2.1) is based on the following assumptions:

1. Solic particles are rigid spheres.

2. Suspension is dilute enough to render the inter-particle interaction negligible.

3. Solid particles are large compared to the molecules of the suspending medium, so that the suspending medium can be treated as a continuous fluid.

4. Particle size is uniform.

5. Density of the solid particles equals the density of the suspending medium.

6. No slip exists between the solid particles and the suspending medium.

7. Flow is sufficiently slow.

8. Solid particle diameter is small compared to the characteristic length of the viscosity measurement apparatus so that wall 
effects are negligible.

Experimental data of various workers were higher than values predicted by equation (2.1) for aqueous suspensions. An explanation was offered by Einstein stating that a hydration shell is present around the solid particles, thus changing the effective value of $\phi$, as discussed by Schaller (8).

The main difficulty with equation (2.1) is that it is valid on'y for very small values of $\phi$. In fact, it was derived for an infinitely dilute suspension and hence its applicability to concentrated suspensions is extremely questionable.

Many workers have attempted to provide an equation which fits the experimental data for viscosities of concentrated suspensions. Eilers has proposed the following empirical equation, as reported by Chong (9):

$$
\frac{\mu_{s}}{\mu_{0}}=\left[1+\frac{2 \cdot 5 \phi}{2\left(1-\phi / \phi_{\infty}\right)^{2}}\right]^{2}
$$

where $\phi_{\infty}$ is the volume fraction of the solids when $\mu_{s} / \mu_{0}$ approaches an infinite value. For the maximum packing density of spherical particles, $\phi_{\infty}$ is 0.74 . Eilers experimented with bitumen suspensions and the results agreed with the values predicted by equation (2.2). Ting and Luebbers (10) worked out a similar treatment and their results agree with Eilers' results up to a solids concentration of $35 \%$ by volume.

Vand (II) derived a theoretical equation based on the assumptions that no mutual forces exist among the solid particles and that Brownian movement is not present. Vand's equation has the following form:

$$
\ln \frac{\mu_{s}}{\mu_{0}}=\frac{k_{1} \phi+r_{2}\left(k_{2}-k_{1}\right) \phi^{2}+\cdots-}{1-Q \phi}
$$

where $k_{1}$ is the Einstein shape factor, dimensionless, 
$k_{2}$ is the shape factor of collision doublets, dimensionless,

$r_{2}$ is the collision time constant, dimensionless,

and $Q$ is the hydrodynamic interaction constant, dimensionless.

When equation (2.2) is expanded into a power series, the

result is:

$$
\frac{\mu_{s}}{\mu_{0}}=1+2.5 \phi+7.349 \phi^{2}+\ldots .
$$

Vand tested the validity of this equation and concluded that the theory was valid for his experimental results up to the second power of $\phi$, which was the extent of his theoretical development.

Robinson put forth the idea of a "free volume" of liquid through which the particles can pass each other and proposed that this "free volume" is generally less than the actual volume of the liquid, as discussed by Eirich (12). This is due to the fact that some of the liquid gets trapped between the solid particles when the solids concentration is sufficiently high.

Mooney (13) extended Robinson's ahalysis and considered the effective volume of solids. He proposed the following functional equation:

$$
\frac{\mu_{s}}{\mu_{0}}=\exp \left[\frac{2 \cdot 5 \phi}{1-a_{1} \phi}\right]
$$

where $a_{1}$ is a crowding factor, dimensionless.

Williams investigated the effect of particle size on the viscosity of suspensions of fine glass spheres, as reported by Shaheen (14). The particle size was in the colloidal range and the solids concentration was high. The experimental results differed from the values predicted by Vand's theoretical equation. Williams attributed the difference to the complex nature of colloids. 
Ting and Luebbers (10) used a Brookfield Synchro-Lectric viscometer to study suspensions of glass spheres in a liquid medium of nearly equal density. Thixotropic shear thinning was observed and this was explained by stating that the packing of the solid particles undergoes a change on continuous shearing.

Eveson, Ward and Whitmore studied suspensions of Plexiglas spheres in an aqueous lead nitrate solution and a glycerol solution, using a modified Couette-type viscometer, as discussed by Shaheen (14). Shear dependence was observed for apparent viscosity at solids concentrations greater than $10 \%$ by volume.

Eveson studied a suspension of Plexiglas spheres in a liquid with matching density and presented data for relatively dilute slurries: showing effects of particle size and discontinuous size distribution, as discussed by Shaheen (14).

Moreland (15) investigated suspensions of coe! particles in mineral oil using a Brookfield viscometer and found that the apparent viscosity depended on spindle speed and type of spindle used, indicating non-Newtonian behavior for these suspensions.

Chong (9) studied suspensions of glass spheres in a viscous liquid using an orifice jet viscometer and presented data for the effect of solids concentration which agreed with values predicted by Eilers' equation.

Ford (16) discussed most of the important theoretical and empirical relationships for the viscosities of suspensions. A very common approach has been to develop Einstein's equation into a series as follows:

$$
\frac{\mu_{s}}{\mu_{0}}=1+a \phi+b \phi^{2}+\cdots \cdot \cdot
$$


where $a$ and $b$ are dimensionless constants.

Most of the equations suggested, theoretical and empirical, are of the form of equation (2.6).

Thomas (4) surveyed a large cross-section of the literature data pertaining to concentrated suspensions and concluded that most of the typical equations of the form of equation (2.6) terminate the series at $\phi^{2}$, giving rise to large percentage errors. Thomas suggested the following equation:

$$
\frac{\mu_{s}}{\mu_{0}}=1+2.5 \phi+10.05 \phi^{2}+0.062 \exp \left[\frac{i .875 \phi}{1-1.595 \phi}\right]
$$

The literature data scatter about $\pm 20 \%$ at $\phi=0.20$ to about $\pm 75 \%$ at $\phi=0.50$ from values predicted by equation (2.7). Thomas further proposed the following equation for concentrated suspensions:

$$
\frac{\mu_{s}}{\mu_{0}}=1+\left(\frac{54}{5 f^{3}}\right)\left[\phi^{2} /\left(1-0 / \phi_{\infty}\right)^{3}\right]
$$

where $f$ is a dimensionless factor and is expected to vary between 1 and 2 for the entire range of solids concentrations.

A major limitation of the foregoing equations is that they do not take into account variables other than the solids concentration. Among these variables are particle size, shear rate and the electrical charge on the solid particles. Some work has been done in trying to relate the effect of electrical charge on the particle and the viscosity of the suspension through the use of the zeta potential defined on page 15 .

Schaller (8) investigated the literature in this area and presented a comprehensive review on the electroviscous effects. He experimentally investigated the electroviscous effects in monodisperse polystyrene latexes and found that electrophoretic mobility decreased 
with increase in ionic strength. Electroviscous effects were marked for smaller particles and non-Newtonian behavior was exhibited at low ionic strength. Newtonian flow was observed for high ionic strengths.

Huber and Penzkofer (17) studied the effect of $\mathrm{pH}$ on the viscosity of suspensions and compared these data with the results of a theoretical approach using the zeta potential. The study was related to aqueous clay dispersions and showed that the viscosity decreased with increase in $\mathrm{pH}$. It was also suggested that a decrease in particle size results in an increase in viscosity, while an increase in the electrical charge on the particle causes a decrease in viscosity. In other words, an increase in zeta potential will decrease the viscosity since interparticle repulsion will increase.

0ttewill (18) investigated the electroviscous effects in concentrated sols of silver iodide and concluded that experimental data can be represented adequately by the foliowing equation at constant shear rate:

$$
\frac{\mu_{s}}{\mu_{0}}=1+b_{1} \phi+b_{2} \phi^{2}
$$

where the constants $b_{1}$ and $b_{2}$ are dependent on the ionic strength. It was also pointed out that at high ionic strengths the behavior of the sol would approach a purely hydrodynamic one.

For dilute suspensions, Ottewill (18) suggested the following general equation for the viscosity of a suspension in which electroviscosity is evident:

$$
\frac{\mu_{s}}{\mu_{0}}=1+2.5 \phi\left(1+f^{\prime}\right)
$$

where $f^{\prime}$ is the electroviscous contribution. 
Several researchers have given treatments of electroviscosity leading to theoretical expressions for $f^{\prime}$ involving the zeta potential and the thickness of the double layer around the solid particles.

Conway and Dobry-Duclaux (19) presented an extensive treatment on the viscosity of suspensions of electrifally charged particles and concluded that electroviscosity arises due to the following three factors, each of which can be termed as an electroviscous effect:

1. The equilibrium spherical symmetry of the double layer is distorsed under the influence of a velocity gradient.

2. Overlapping of double layers occurs between particles at high solids concentrations.

3. The shape of the solid particle undergoes a change when it undergoes ionization on dispersion in water.

They further proposed that the viscosity of such suspensions can be written in the form of the following equation:

$$
\frac{\mu_{s}}{\mu_{0}}=1+\left[k_{1}+k_{2}+k_{3}\right]
$$

where $K_{1}, K_{2}$ and $K_{3}$ are the factors corresponding to the three electroviscous effects and each is a function of $\phi$. A power series was. written for the viscosity of such suspensions in the following form:

$$
\frac{\mu_{s}}{\mu_{0}}=1+c_{1} \sqrt{ } \phi+c_{2} \phi+c_{3} \phi^{2}+\cdots \cdot-
$$

where $c_{1}, c_{2}$ and $c_{3}$ are dimensionless constants.

Separation of the three electroviscous effects is difficult, but has been attempted to a varying degree of success by various workers.

Sennett and 0livier (20) have explained the concept of zeta potential in relation to colloidal dispersions in a comprehensive 
manner. They include an explanation of how hydrophobic colloids acquire the electrical charge on the surface and how the zeta potential is affected by the presence of different types of ions in the dispersion. A more extensive explanation of the concept of zeta potential and electrophoretic mobility is given by Ove.beek (2i), where the nature of the double layer and the electrokinetic effects are discussed in detail. The fact remains that the zeta potential calculation can be done in a meaningful manner only for very low values of zeta potential and can seldom be used for correlations. 


\section{CHAPTER $/ 11$}

\section{THEORETICAL APPROACH TO THE PROBLEM}

The problem of the rheological behavior of concentrated suspensions, in this case silica-water suspensions, requires theoretical analysis. Since non-Newtonian flow properties are exhibited and electroviscosity is evident, it is necessary to present theoretical equations for non-Newtonian flow and to explain the electrical charge on the solid particles. A method for the correlation of this electrical charge and the rheological properties is also required.

1. SHEAR LEPENDENCE OF CONCENTRATED SUSDENSIONS

Bird et. al. (22) have pointed ost that concentrated suspensions exhibit non-Newtonian flow behavior. Various rheological equations of state have been suggested for different systems depending on the nature of shear dependence exhibited.

A Newtonian fluid is defined by the following equation for its shear stress-shear rate behavior:

$$
\tau=-\mu_{0} \gamma
$$

where $\tau$ is the shear stress in dynes $\mathrm{cm}^{-2}$,

$\gamma$ is the shear rate in $\sec ^{-1}$,

and $\mu_{0}$ is the viscosity of the fluid in poises $\left(\mathrm{gm} \mathrm{cm}^{-1} \mathrm{sec}^{-1}\right)$. Hence, for a Newtonian fluid the viscosity is independent of the shear rate.

One of the non-Newtonian rheological equations of state is as follows:

$$
\tau=-\mu_{p} \gamma+\tau_{0}
$$


where $\mu_{p}$ is the plastic viscosity of the fluid in poises, and $\tau_{0}$ is the yield stress for the fluid in dynes $\mathrm{cm}^{-2}$.

Equation (3.2) is valid for suspensions of nuclear fuels in heavy water (22) and is known as the Bingham plastic model. Caldwell and Babbitt (23) state that this model is valid for sludges and clay suspensions.

Another equation describing non-Newtonian flow is:

$$
\tau=-m \gamma^{n}
$$

where ' $\mathrm{m}$ ' is a material characteristic parameter with units $\mathrm{gm}^{-1} \mathrm{sec}^{-n}$

and ' $n$ ' is a dimensionless material characteristic parameter.

Equation (3.3) is known as the power law model and is valid for claywater suspersions and napalm-kerosene suspensions (22). Shaheen (14) found this model to be valid for concent rated suspensions of styrenedivinyl benzene beads in water.

2. USE OF THE BROOKFIELD VISCOMETER

When the Brookfield viscometer is used with the UL Adapter, the fluid is in tangential annular flow between an inner rotating cylinder and a stationary outer cylinder. The scale reads the apparent Newtonian viscosity and the calibration is based on the torque resulting from a given speed of cylinder rotated. If $\mu_{a}$ is the apparent viscosity scale reading at an angular velocity $\omega$ (radians $\sec ^{-1}$ ), then the torque $T$ is given by the following equation derived in Brodkey (24):

$$
T=\frac{4 \pi h \mu_{a} \omega}{\left(r_{1}^{-2}-r_{2}^{-2}\right)}
$$

where $r_{1}$ is the radius of the inner cylinder in $\mathrm{cm}$, $r_{2}$ is the radius of the outer cylinder in $\mathrm{cm}$, 
$h$ is the height of the inner cylinder in $\mathrm{cm}$,

and $T$ is the torque on the inner cylinder in $\mathrm{gm} \mathrm{cm}$.

The adaptation of concentric cylinder viscometer data to pipe

flow has been made by Christiansen et. al. (25), Black (26) and

Bowles et. al. (27).

Appendix A and Appendix B show the derivation of the torqueangular velocity relationship for a Bingham plastic and a power law fluid, respectively. For a Bingham plastic

$$
\omega=\frac{T}{4 \pi h \mu_{p}}\left(r_{1}{ }^{-2}-r_{2}{ }^{-2}\right)+\frac{\tau_{0}}{\mu_{p}} \ln \frac{1}{r_{2}}
$$

For a power law fluid

$$
\omega=\left(\frac{T}{2 \pi h m}\right)^{1 / n} \cdot \frac{n}{2} \cdot\left(r_{1}^{-i / n}-r_{2}^{-2 / n}\right)
$$

3. ELECTROPHORETIC MOBILITY AND ZETA POTENTIAL

The concept of zeta potential is illustrated in Figure 1 for an electronegative particle, as is the silica used in the present research. The particle is electronegative since it has an excess of negative charges at its surface. Most colloids and suspensoids are electronegative and this phenomenon has been the subject of much investigation.

Using the model of Figure 1 , it can be said that the negative surface attracts a surrounding layer of positive ions, which may originate from the colloid itself or from the suspending medium. The oppositely charged ions are drawn to the particle by electrostatic attraction. The system comprising the surface of the particle and the neutralizing counter ions is termed the "double layer".

Some of the counter ions are very strongly attached to the surface forming the "Stern layer", while the rest of the counter ions 


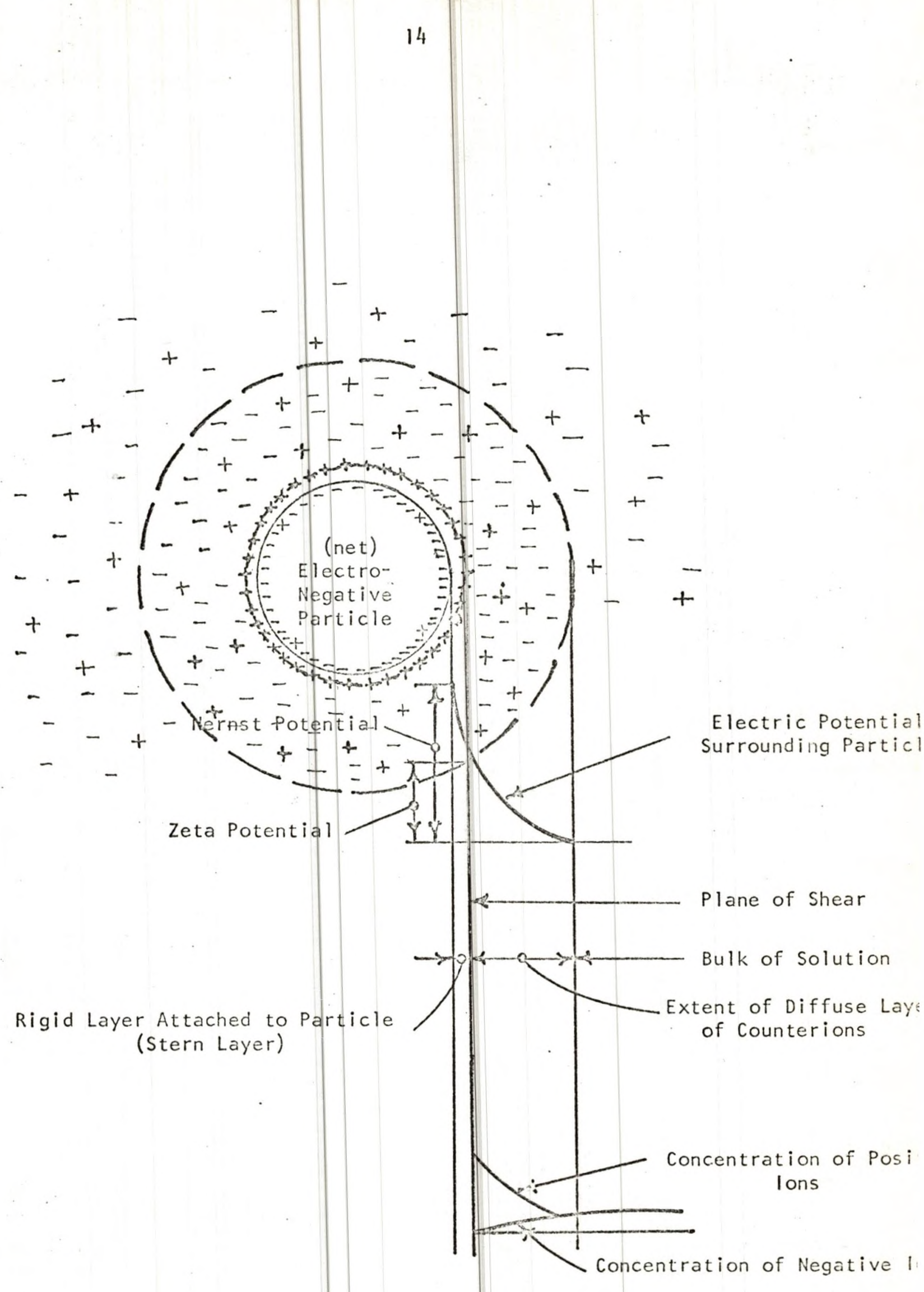

FIGURE I CONCEPT OF THE ZETA POTENTIAL

[From Zeta-Meter Manual (28)] 
are further away and form the diffuse part of the double layer. There is no clear distinction between the Stern layer and the diffuse layer.

The zeta potential is the potential difference between the surface and the diffuse part of the double layer and hence it is related to the net electrical charge on the particle.

When a liquid containing such charged particles is placed in an electric field, the electronegative particles are attracted to the positive electrode and the counter ions to the negative electrode. The force on the particle increases with the net electrical charge on the particle. Friction between the particle and the surrounding liquid containing the diffuse part of the double layer slows down the motion of the particle towards the electrode. Hence, the terminal velocity cf the particle in a given electric field increases with increase in the net electrical charge on the particle and with the extent of the diffuse part of the double layer. The terminal velocity of the particle under unit field strength is called its electrophoretic mobility.

Zeta potential can be calculated from the electrophoretic mobility of the particles only for low values of zeta potential. This is so because all the available relationships between zeta potential and electrophoretic mobility involve the dielectric constant and the viscosity of the suspending medium in the double layer around the particle, and the estimation of these quantities for high surface potential is extremely difficult.

The formation of the double layer requires that the surface of the solid particle be charged. Sennett and 0livier (20) have offered three possible mechanisms for the acquisition of this charge: 
1. The crystal lattice of the solid may contain a net positive or negative charge arising from interior defects or lattice substitutions; the net charge is therefore compensated by an equivalent ionic charge at the surface. In contact with water, the compensating ions dissociate to form the counter ions of the double layer.

2. When sparingly soluble solids with ionic lattices are dispersed in water, an equilibrium exists between the ions making up the surface of the crystal and the same constituent ions in solution. Their concentrations in solution are determined by the solubility product for the material. The potential of the solid will thus be fully determined by a thermodynamic (adsorption) equilibrium, in accold with a Nernst equation. Using a colloidal Agl as an example,

$$
\begin{aligned}
\Psi_{0}(\mathrm{Agl}) & =A+(\mathrm{RT} / \mathrm{F}) \text { ln } \mathrm{C}_{\mathrm{Ag}^{+}} \\
\text {or } \Psi_{0}(\mathrm{Agl}) & =A-(\mathrm{RT} / \mathrm{F}) \text { ln } \mathrm{C}_{1}^{-}
\end{aligned}
$$

where $A$ and $B$ are constants, $\Psi_{0}$ is the potential of the solid surface with respect to the bulk liquid, $F$ is the Faraday charge, and $C$ is the concentration (activity) of the particular ion in solution. Thus, if excess silver ions are added to the solution, $\Psi_{0}$ will become more positive. The potential determining ions for a given solid are usually apparent from its chemical composition. For most metallic oxides and hydroxides, $\mathrm{H}^{+}$or $\mathrm{OH}^{-}$ions are potential determining.

3. A third mechanism by which the surface charge may originate or be affected is by the adsorption of specific ions from the solution. 
Specific ions may be strongly adsorbed or chemisorbed by formation of a surface complex or compound. This mechanism is seldom responsible for the total charge on the surface.

\section{PRESENT WORK}

The present work is an investigation of the rheological properties of suspensions of silica in water and of lignite in water. Apparent viscosities were measured with the Brookfield viscometer at various rotational speeds and value of $\mathrm{pH}$ and the electrophoretic mobility of the particles was measured by the use of a Zeta-Meter. The experimental data was applied to the Bingham plastic model and to the power law model. The variation of electrophoretic mobility and the parameters of the two models with $\mathrm{pH}$ and solids concentration was investigated. The variation of apparent viscosity with ave age particle size was also studied. 


\section{CHAPTER IV}

\section{MATERIALS, APPARATUS AND EXPERIMENTAL PROCEDURES}

This chapter presents details of experimental procedures, apparatus used and materials used. In the present work, apparent viscosity is the term used to signify the viscosity of the suspension as measured by a Brookfield viscometer at a certain shear rate and is not the true viscosity of the suspension. Electrophoretic mobility is the te $\mathrm{m}$ used for the terminal velocity at which the solid particles travel in an electrophoresis cell under a unit potential gradient.

\section{MATERIALLS}

The suspensions in this series of experiments were prepared by mixing spherical silica particles with demineralized water. The silica had an average specific gravity of 2.65 and was obtained from 111 inois Minerals Company, Cairo, lllinois. Three different grades of silica were used and their particle size distribution is given in Table 1. A typical chemical analysis of the silica is given in Table 3 in Appendix $C$, and some typical physical characteristics are given in Table 4 in Appendix C.

The demineralized water was prepared by passing tap water through a Barnstead Demineralizer containing a mixed resin bed cartridge. The $\mathrm{pH}$ of the demineralized water was 5.6 (average), which is low due to the adsorption of carbon dioxide from the atmosphere. 


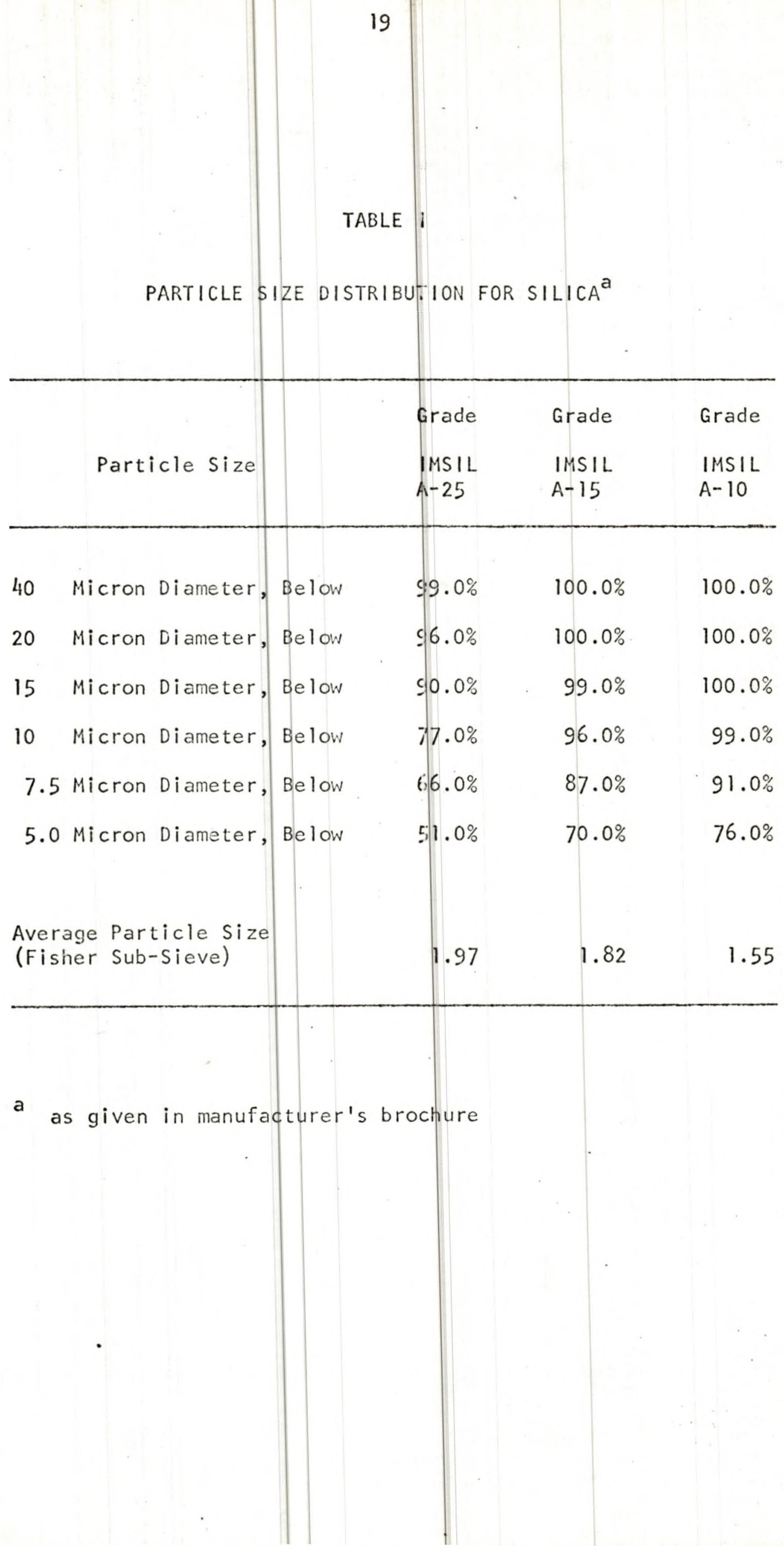


Some experimentation was also performed on lignite in water suspensions. The lignite, obtained from the Velva mine, McHenry County, North Dakota, was pulverized and the -325 mesh screen size fraction used in the test. The proximate and ultimate analyses of the lignite are given in Table 5 in Appendix $C$ and the analysis of the lignite ash in Table 6 in Appendix $C$. The specific gravity of the sample used was 1.2 and the moisture content when used was $14.9 \%$.

\section{APPARATUS}

Apparent viscosities were measured using a Brookfield Synchro* Lectric viscometer with the UL Adapter. The instrument specifications are given in Table 7. in Appendix D. The UL Adapter consists of two concentric cylinders with a small clearance and is used for measuring low viscosities. The inner cylinder is rotated, while the outer cylinder is held staticnary. The radius of the inner cylinder is $1.25 \mathrm{~cm}$ and the radius of the outer cylinder is $1.4 \mathrm{~cm}$. The height of the inner cylinder is $9.6 \mathrm{~cm}$. The fluid volume required to fill the clearance volume between the two cylinders is $22 \mathrm{ml}$.

The apparent viscosity measurements were carried out in a water bath controlled at a temperature of $20 \pm 0.5^{\circ} \mathrm{C}$ by an E.H. Sargent and Company, Type NS1-12, thermostat.

The $\mathrm{pH}$ of the suspensions was measured with a Beckman Zeromatic pH Meter, Model 96 .

A Clay Adams Company Safety Head Centrifuge was used for separation of the liquid from the solids in a suspension for the measurement of electrophoretic mobility. Glass centrifuge tubes were used for this.

The electrophoretic mobility of the solid particles in suspension 
was measured by a Zeta-Meter manufactured by the Zeta-Meter Company, the specifications for which are given in Table 8 in Appendix D. The ZetaMeter consists of (28):

1. A continuously variable (0 to 500 volts) DC power supply with reversible polarity switch and a precision voltmeter and micro-ammeter. This unit has a variable voltage outlet for the microscope illuminator.

2. An electric timer measuring to tenths of a second, with a fast acting contact switch.

3. A clear plastic electrophoresis cell with plastic sol-chambers and two types of iridium-hardened platinum electrodes.

4. A heat adsorbing cell holder for reflecting a beam of light through the cell tube at an angle to remove the direct light from the optics of the microscope.

5. A special illuminator to produce a thin beam of intense blue-white light of controlled intensity for illuminating colloids.

6. A stereoscopic microscope with a special mechanical stage and ocular micrometer for measuring the rate of travel of discrete particles in the electrophoresis cell.

The electrophoresis cell used was Cell No. $465 \times 5$, supplied by the Zeta-Meter Company.

\section{PROCEDURE}

The silica in water suspensions were prepared by placing a known weight of silica in a $400 \mathrm{ml}$ beaker and adding the required volume of demineralized water to obtain the desired solids concentration. The 
mixture was first stirred thoroughly with a glass rod and then with a magnetic stirrer for 30 minutes. The $\mathrm{pH}$ of the suspension was adjusted to the desired level by adding IN HCl O:- IN NaOH dropwise. Next a sample of the suspension was taken for apparent viscosity measurements and another fo: electrophoretic mobility mecsurements. The remaining sus. pension was kept stirred with a magnetic stirrer and the required changes were made in its $\mathrm{pH}$ level as required.

The suspension was transferred cirectly to the UL Adapter which was then $f$ itted to the viscometer head. The UL Adapter was lowered into the water bath, and the viscometer rotated at the desired speed. No readings were taken during the first two minutes after which readings were taken every 30 seconds. Ten readings were taken and then the ro:ational speed was changed. After this change in rotational speed no readings were aken for 60 seconds. Readings were then taken again at 30 second intervals. After five readings at this level the speed was changed again. In this manner, measurements of apparent viscosity were made at four different rotational speeds. All readings were taken within a period of 20 minutes from the beginning, since after this time interval appreciable amounts of silica were noticed to settle out in the UL Adapter. To show that thixotropy was not present to an appreciable degree, measurements were made in a random manner of speed changes.

The sample of the suspension taken for electrophoretic mobility measurements was transferred to glass centrifuge tubes and centrifuged at 3400 revolutions per minute for 30 minutes. The supernatant 1 iquid was transferred to a $50 \mathrm{ml}$ beaker and one drop of the original suspension added. The electrophoretic mobility measurements were made on this diluted suspension to ease the tracking of particles in the electrophoresis 
cell. This procedure is recommended by Riddick (29) for concentrated suspensions.

The electrophoresis cell was filled carefully with the diluted suspension so as to avoid trapping air tubbles in the system and then placed on the cell holder. The illuminator was then adjusted to direct a thin beam of intense blue-white light in the proper manner. Next the "positioning line" of the cell was brought into clear focus and made to coincide with the reference line of the ocular micrometer. The DC power supply was then connected to the electrodes and a suitable voltage applied. The DC polarity switch was thrown into the correct position to move the negatively charged silica particles towards the anode. Discrete particles situated on or near the appropriate counting line (depending upon the objective employed) were then timed in their traverse of one or two ocular micrometer divisions by holding down the snap-switch attached to the timer cable. Twenty particles were tracked in their normal direction of travel and then the $D C$ polarity switch was reversed and twenty more particles were tracked in the opposite direction. This was done five times in each direction and then the average time of travel for a particle over one ocular micrometer division was computed. More precise details of the procedure can be found in the Zeta-Meter manual.

Table 9 in Appendix E shows an example of measurements made of apparent viscosity and of electrophoretic mobility of a silica in water suspension.

An aqueous slurry of lignite was prepared in a similar manner, except that the required amount of lignite" was added in small portions to the demineralized water in a $400 \mathrm{ml}$ beaker to aid wetting. Also, it was noted that the settling velocity of pulverized lignite was considerably 
higher than that of silica and hence the apparent viscosity measurements had to be made in a shorter time duration with the UL Adapter. The remainder of the procedure was similar to that used for silica in water suspensions.

The rotational speeds $60,30,12$ and 6 revolutions per minute of the Brookfield viscometer were checked with a stop watch and found to be correct with a reproducibility of \pm 0.2 second. 


\section{EFFECT OF SHEAR RATE ON APPARENT VISCOSITY}

The apparent viscosity of silica in water suspensions investigated shows a dependence on the shear rate. Table 10 in Appendix $F$ shows all the apparent viscosity data for silica $(99 \%$ below 10 micron diameter) in water suspensions. Figure? is a plot of the apparent viscosity of a $15 \%$ by volume silica in water suspension as a function of the rotational speed of the inner cylindis of the UL Adapter. The different curves in the above mentioned, lot are obtained for different values of $\mathrm{pl}$ for the suspension and they all show that the apparent viscosity decreases with increasing shear rate. This clearly indicates ronNewtonian behavior, though the degree of deviation from Newtonian behavior depends on the $\mathrm{pH}$ of the suspension.

\section{EFFECT OF SOLIDS CONCENTRATION ON THE APPARENT VISCOSITY}

Figure 3 is a plot of apparent viscosity as a function of the solids concentration by volume at a given shear rate and is based on the data of Table 10 in Appendix F. The different curves are for different $\mathrm{pH}$ levels of the suspension. This plot shows that an increase in solids concentration leads to an increase in the apparent viscosity. On extrapolation to zero solids concentration the apparent viscosity equals that of water as expected. 


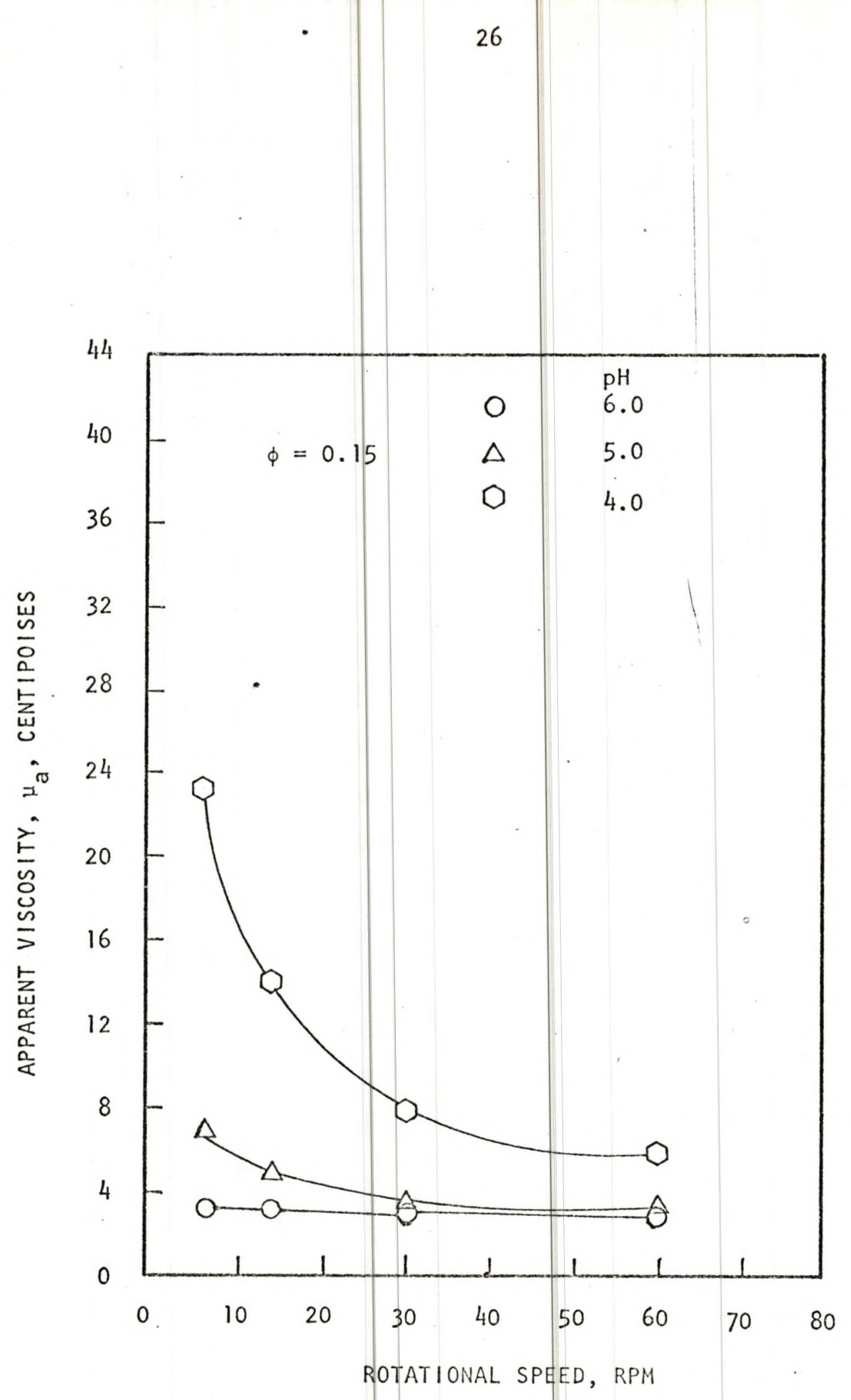

FIGURE 2 EFFECT OF ROTATIONAL SPEED ON APPARENT VISCOSITY 


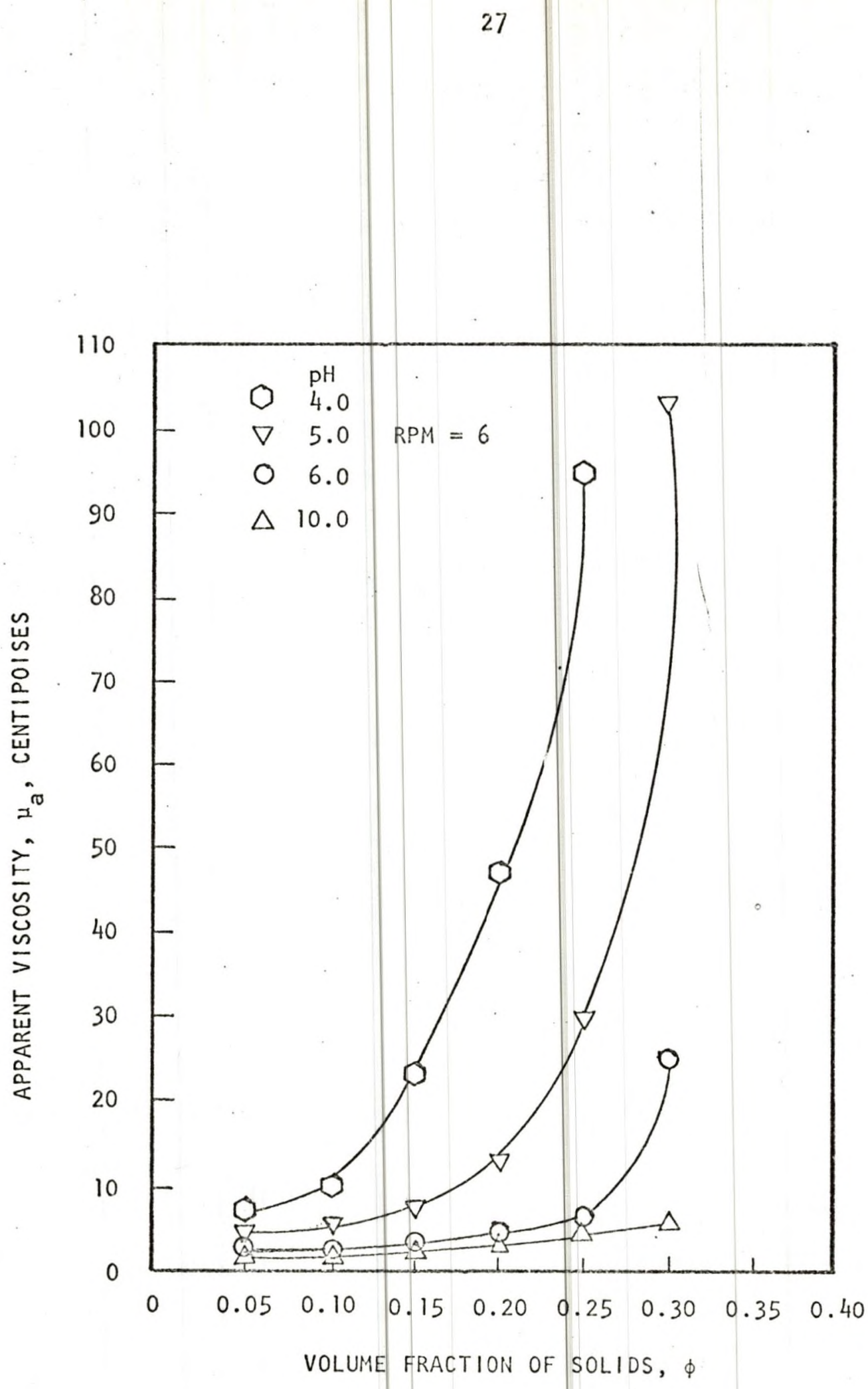

FIGURE 3 EFFECT OF SOLIDS CONCENTRATION ON APPARENT VISCOSITY 
3. EFFECT OF PH ON ELECTROPHORETIC MOBILITY

Table 11 in Appendix F gives the values of the electrophoretic mobility at different $\mathrm{pH}$ levels for the silica in water suspensions. The values of zeta potential calculated from these values of electrophoretic mobility are also listed in the same table. This data is shown in the form of a plot in Figure 4 . It is evident that in the $\mathrm{pH}$ range 4 to 10 the electrophoretic mobility increases monotonically with increasing pH. The experimental technique was based on the assumption that the electrophoretic mobility is independent of the solids concentration. The data for electrophoretic mobility measurements for each solids concentration is given in Table 1\% in Appendix F. Table il presents the average values of the electrophoretic mobilities only. This was done because the values differed at different solids concentrations by very small amounts. Appendix $G$ shows sample calculations of electrophoretic mobility and zeta potential. 


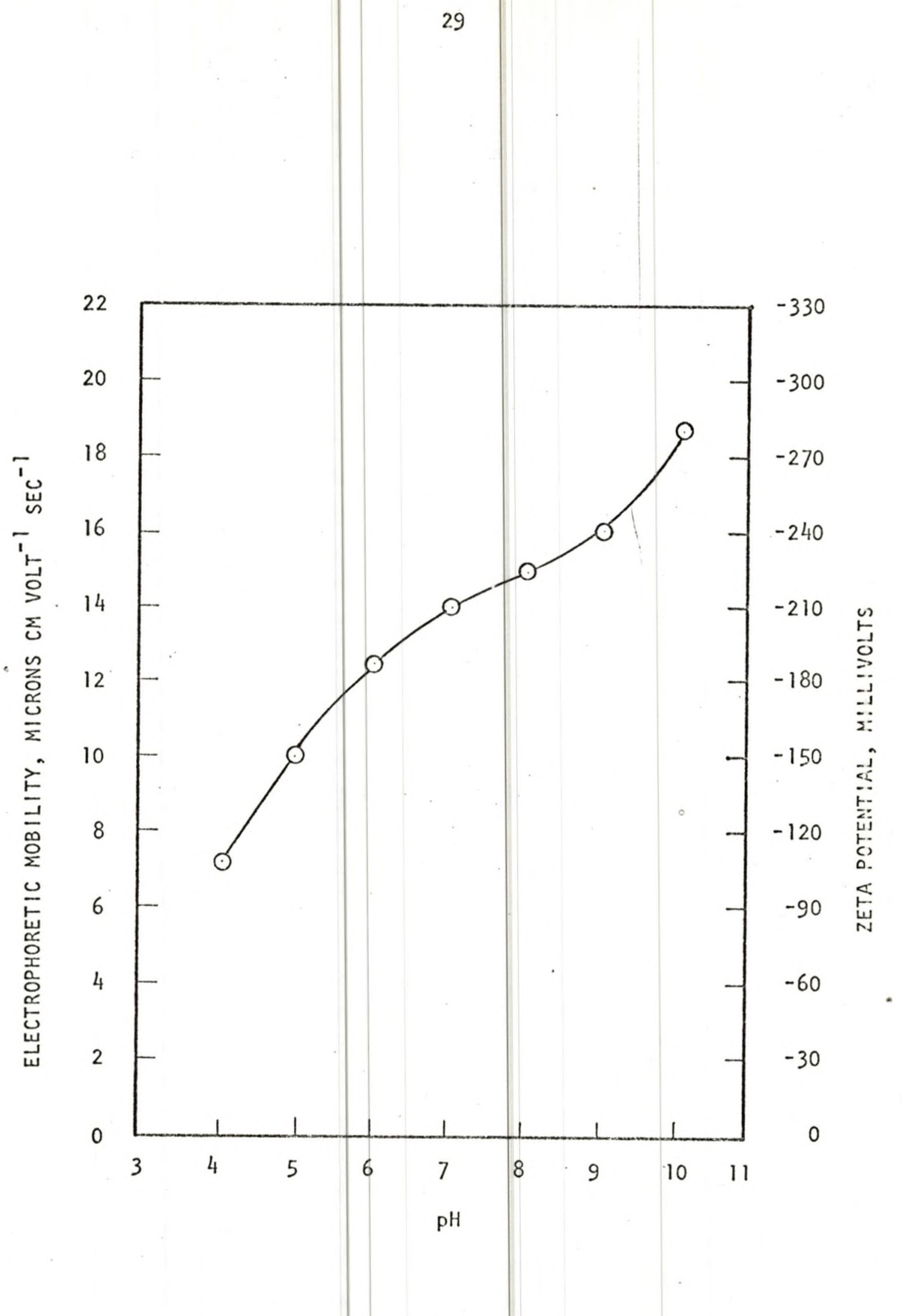

F.IGURE 4 EFFECT OF PH ON ELECTROPHORETIC MOBILITY 


\section{CHAPTER VI}

\section{DISCUSSION AND ANALYSIS OF RESULTS}

In the previous chapter the non-Newtonian behavior of the silica in water suspensions and the lignite in water suspensions was clearly established. The data can now be applied to the Bingham plastic model and the power law model and the dependence of the constants of the two models c:an be analysed.

\section{BINGHAM PLASTIC MODEL ANALYSIS}

Figures 5 to 11 are plots of torque as a function of angular velocity of the inner cylinder of the UL Adapter. The torque is calcuiated from equation (3.4) using the apparent viscosity, the dimensions o: the UL Adaper and the angular velocity of the inner cylinder. A sample calculation of torque and angular velocity is given in Appendix G. Table 14 in Appendix $H$ contains the calculated values of torque and of angular velocity.

For a Bingham plastic, the torque-angular velocity plots should be a straight line with a slope equal to the plastic viscosity and the intercept on the torque axis is the yield torque, as shown by equation (3.5). In Figures 5 to 11 , straight 1 ines have been drawn through the two highest angular velocity data points and the values of the yield stress and the plastic viscosity have been computed on the basis of these straight lines. It is observed that the lower angular velocity data points do not always fall on the straight line. The deviation is minimum at lowest solids concentration and highest pH, and increases with increasing 


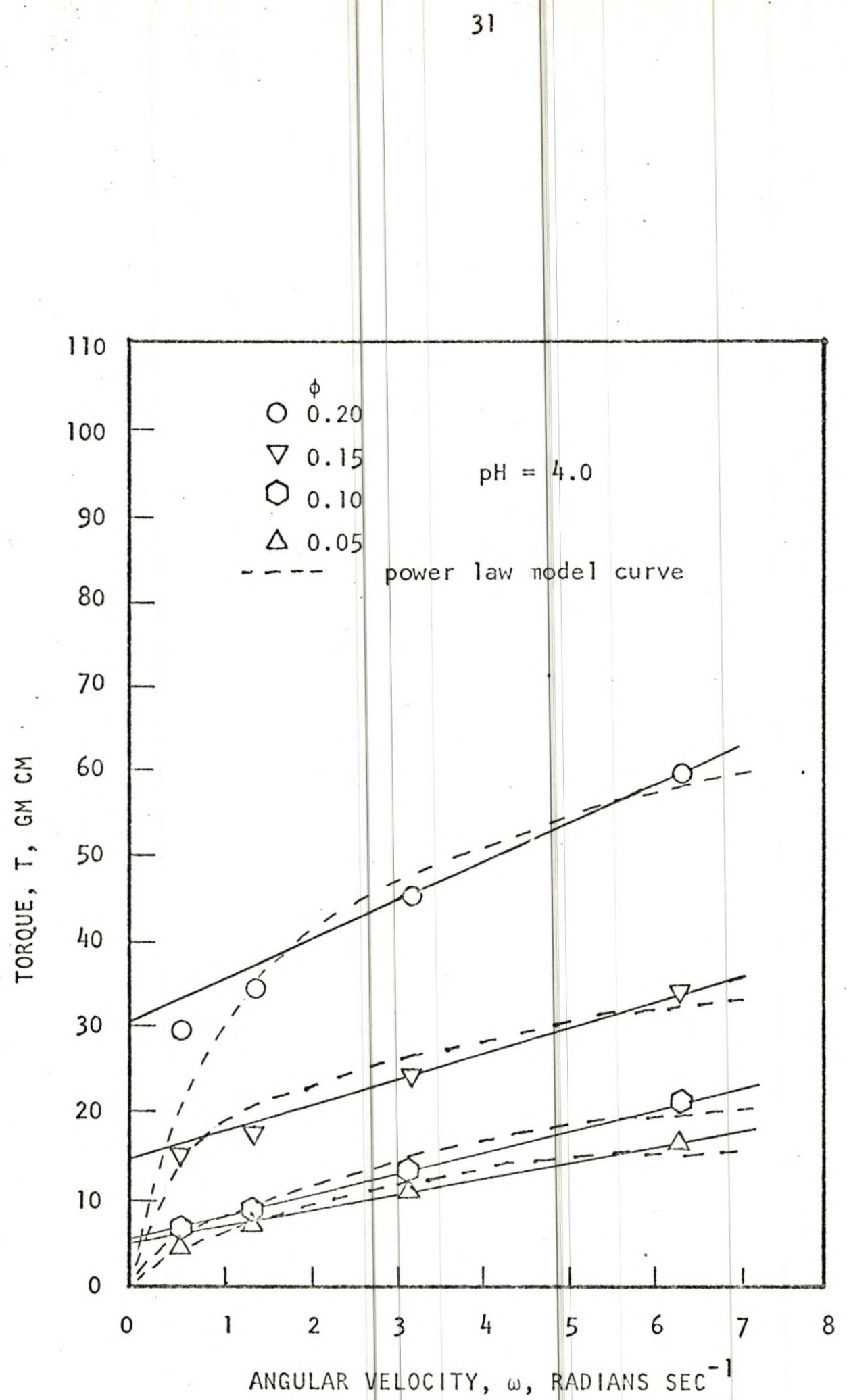

FIGURE 5 EFFECT OF ANGULAR VELOCITY ON TORQUE AT $\mathrm{pH}=4.0$ 


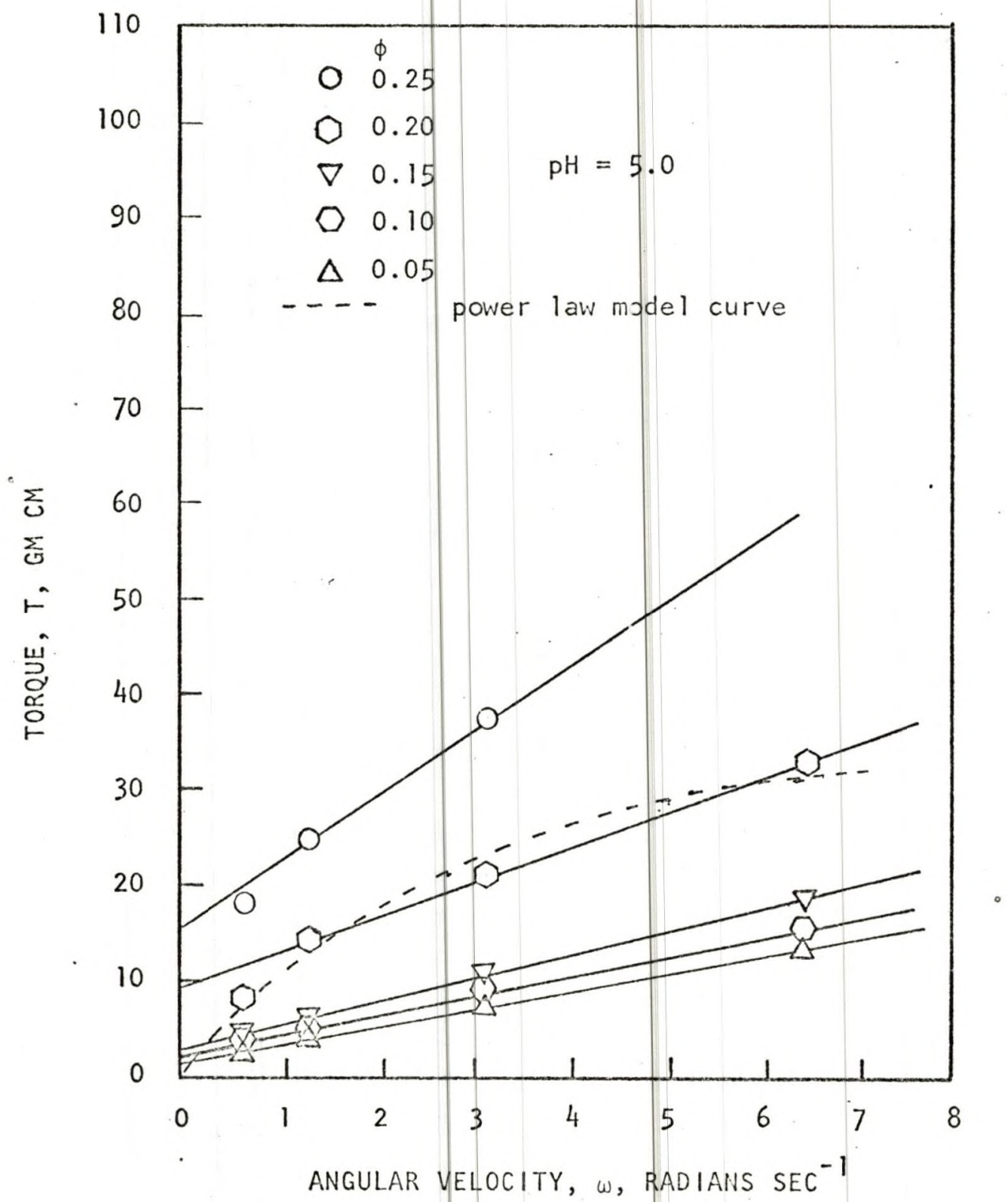

FIGURE 6 EFFECT OF ANGULAR VELOCITY ON TORQUE AT $\mathrm{pH}=5.0$ 


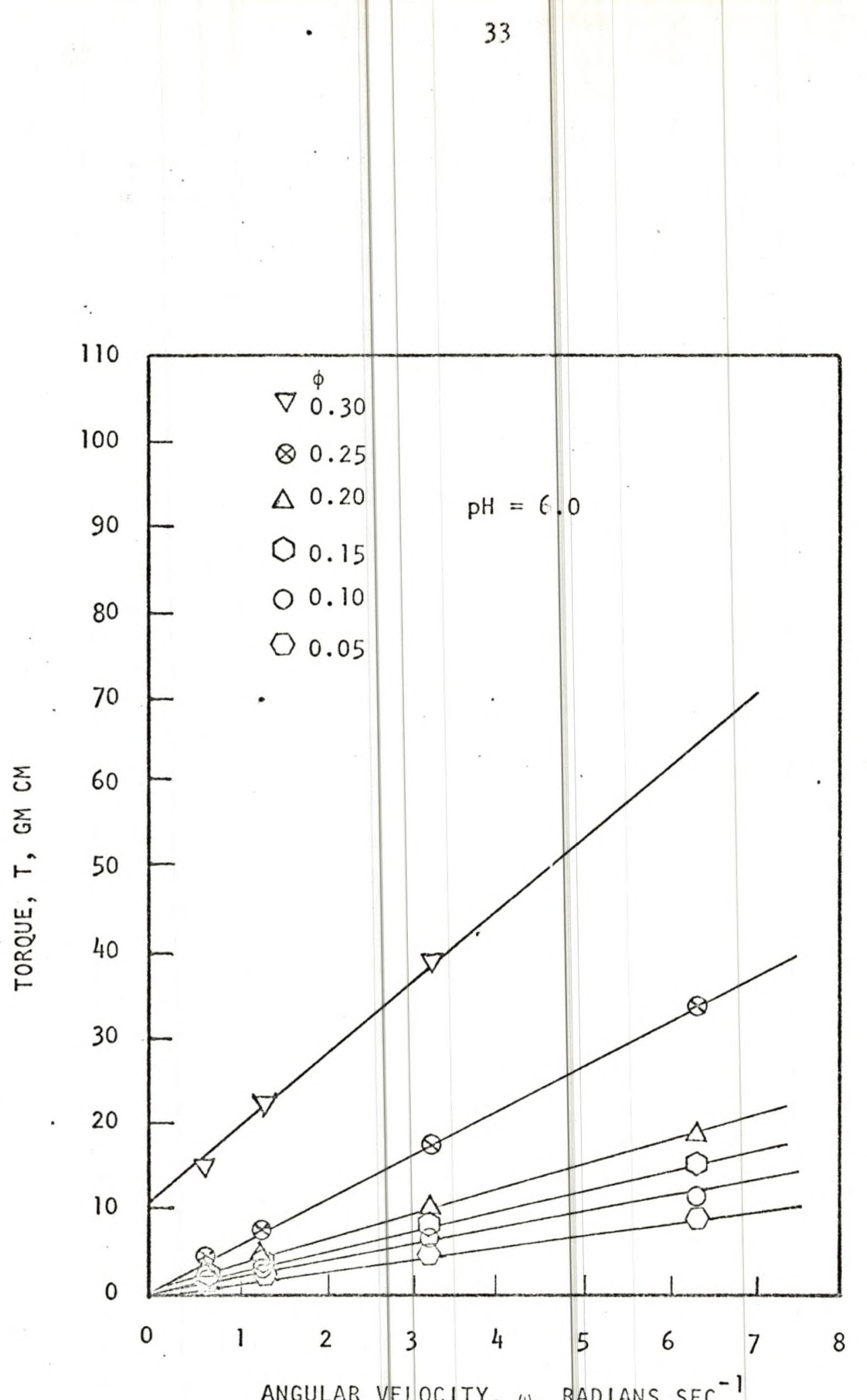

ANGULAR VELOCITY, $\omega$, RADIANS SEC -1

FIGURE 7 EFFECT OF ANGULAR VELOCITY ON TORQUE AT $\mathrm{pH}=6.0$ 


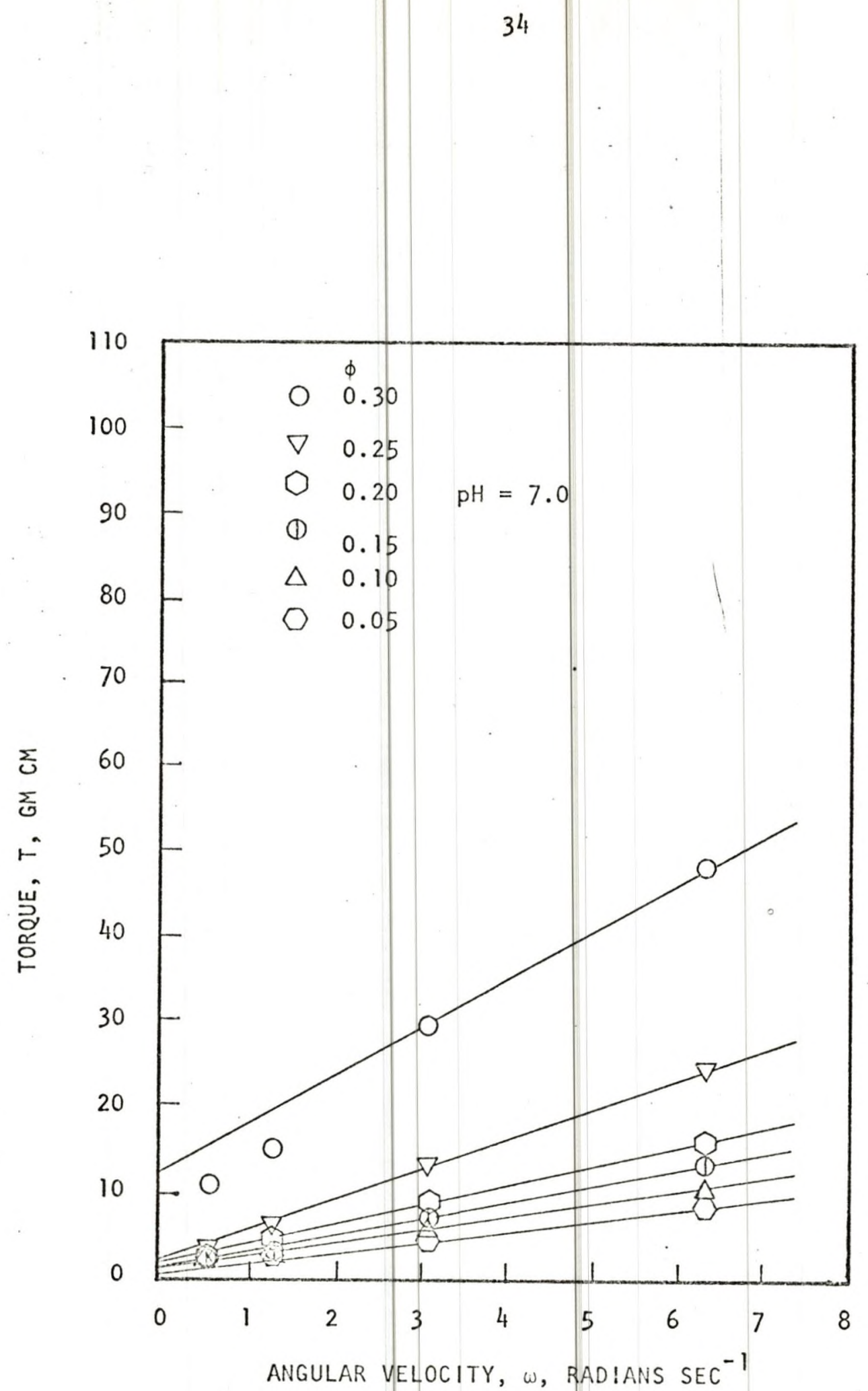

FIGURE 8 EFFECT OF ANGULAR VELOCITY ON TORQUE AT $p H=7.0$ 


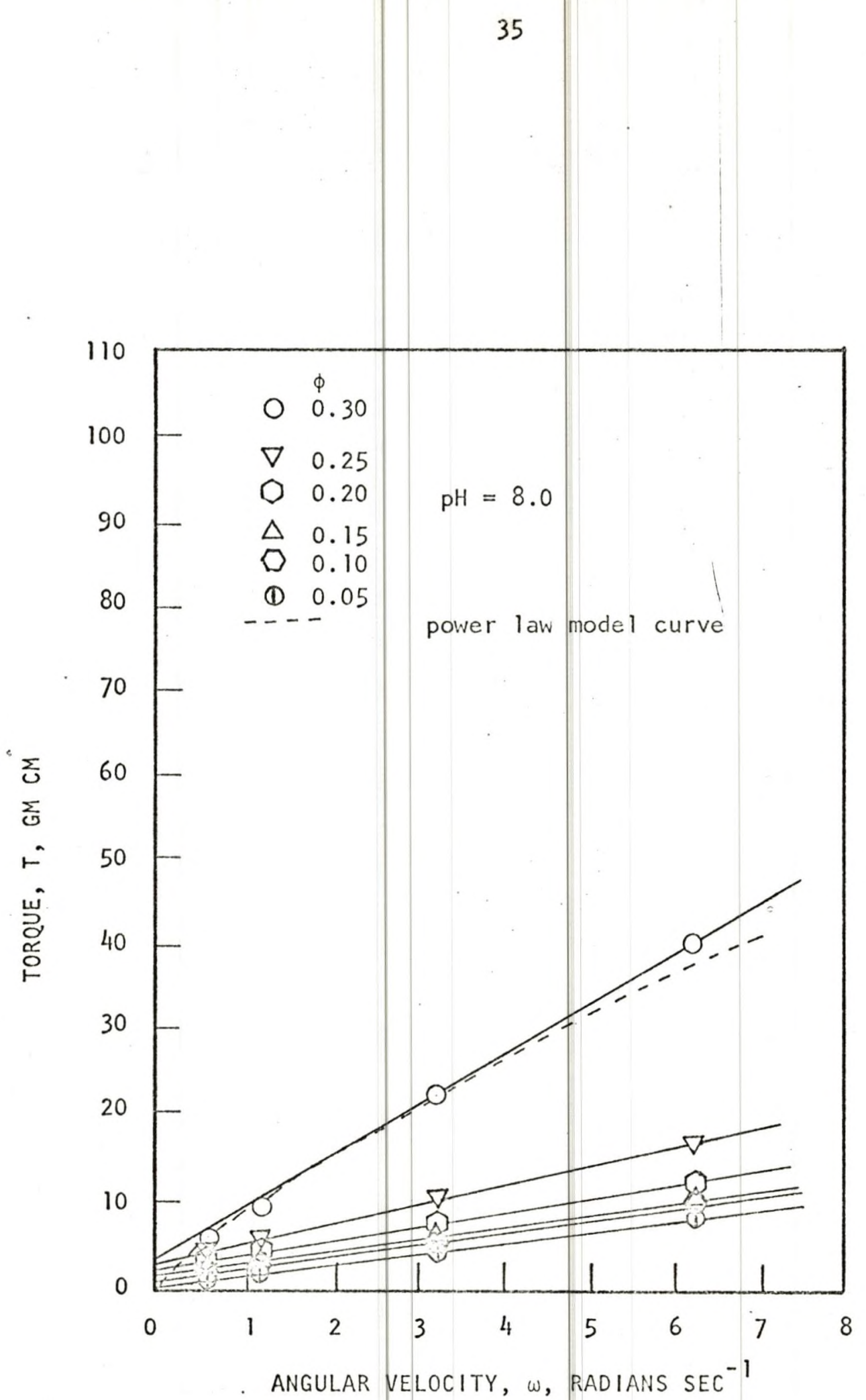

FIGURE 9 EFFECT OF ANGULAR VELOCITY ON TORQUE AT $\mathrm{pH}=8.0$ 


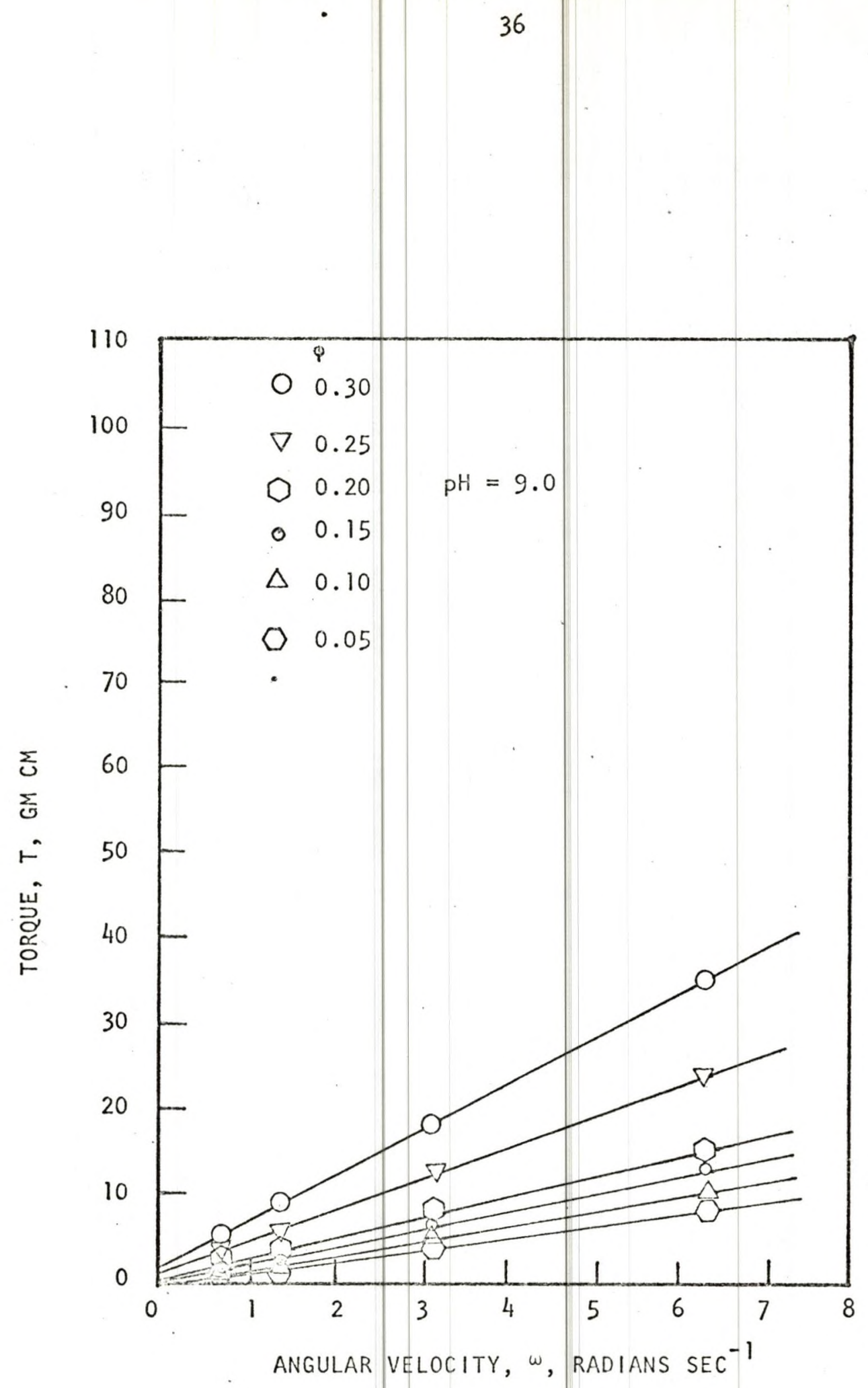

FIGURE 10 EFFECT OF ANGULAR VELOCITY ON TORQUE AT $\mathrm{pH}=9.0$ 


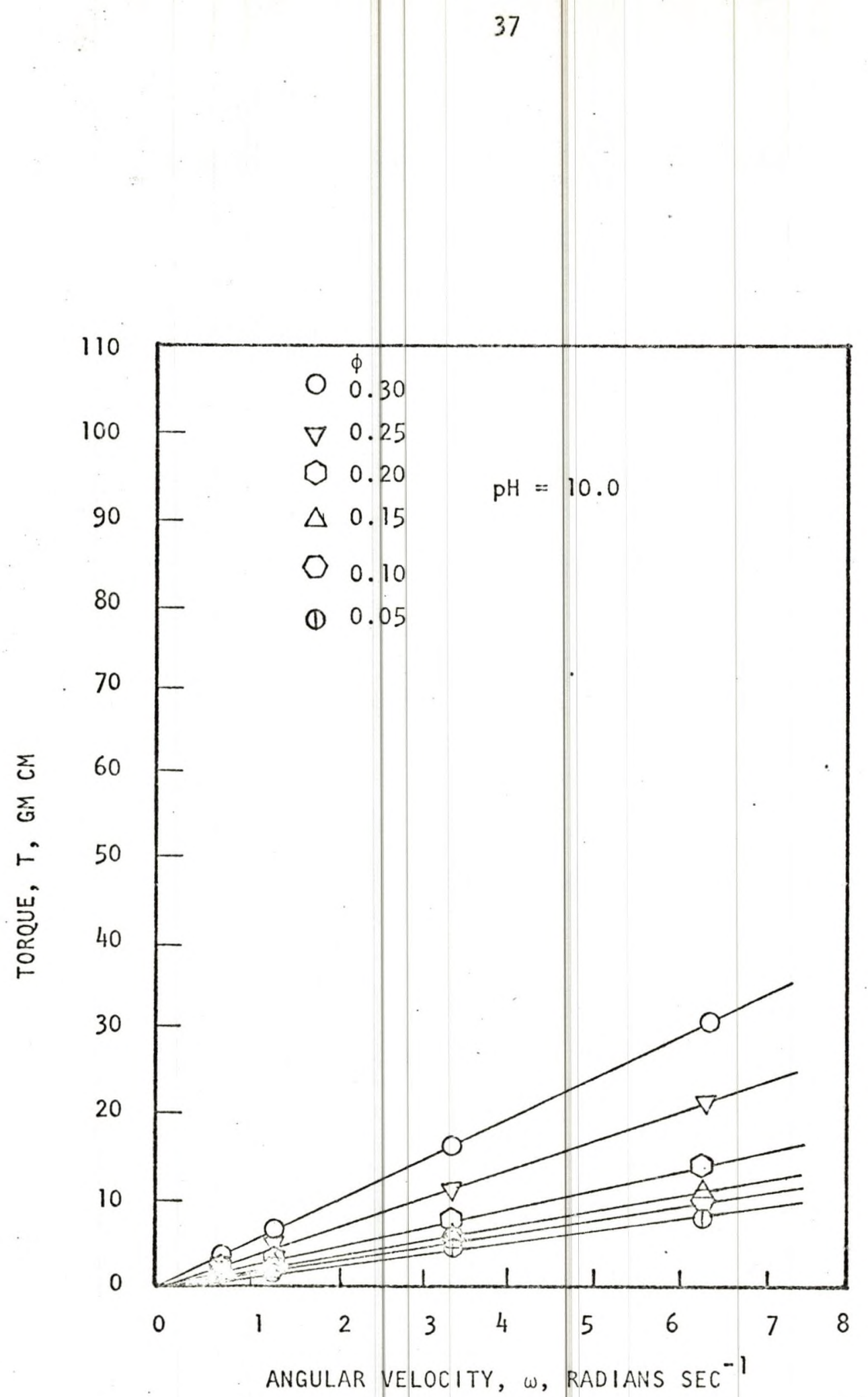

FIGURE 11 EFFECT OF ANGULAR VELOCITY ON TORQUE AT $\mathrm{pH}=10.0$ 
solids concentration and decreasing pH. It is evident that these suspensions approach Newtonian behavior at high values of $\mathrm{pH}$ where the yield torque approaches zero.

Table 15 in Appendix $H$ contains the calculated values of plastic viscosity and yield stress. Sample calchlations for these quantities are shown in Appendix G. Figures 12 to 17 are plots of yield stress and plastic viscosity as functions of solids concentration, $\mathrm{pH}$ and electrophoretic mobility. These plots show that plastic viscosity and yield stress increase monotonically with increasing solids concentration and decrease monotonically with increasirg pH and electrophoretic mobility. Extrapolation of the plastic viscosity curve to zero solids shows that the plastic viscosity approactes a value close to that of the viscosity of water. The plastic viscosity-pH and the plastic viscosityelectrophoretic mobility plots show that the rate of change of plastic viscosity is smaller at a high $\mathrm{pH}$ than at a low $\mathrm{pH}$. Also, the change in the slope of these curves is greater for a high solids concentration than for a low solids concentration.

The yield stress-solids concentration plots should go to zero at zero solids concentration. Also, for low $\mathrm{pH}$ values the curve is steep. but tends to level off as the pH increases. At pH values of 9 and 10 , the yield stress values are extremely low, which again indicates that these suspensions approach Newtonian behavior at high values of $\mathrm{pH}$. The yield stress-pH and the yield stress-electrophoretic mobility plots show that the yield stress is large at low pH and electrophoretic mobility but drops very rapidly to small values as the $\mathrm{pH}$ and electrophoretic mobility increase. 


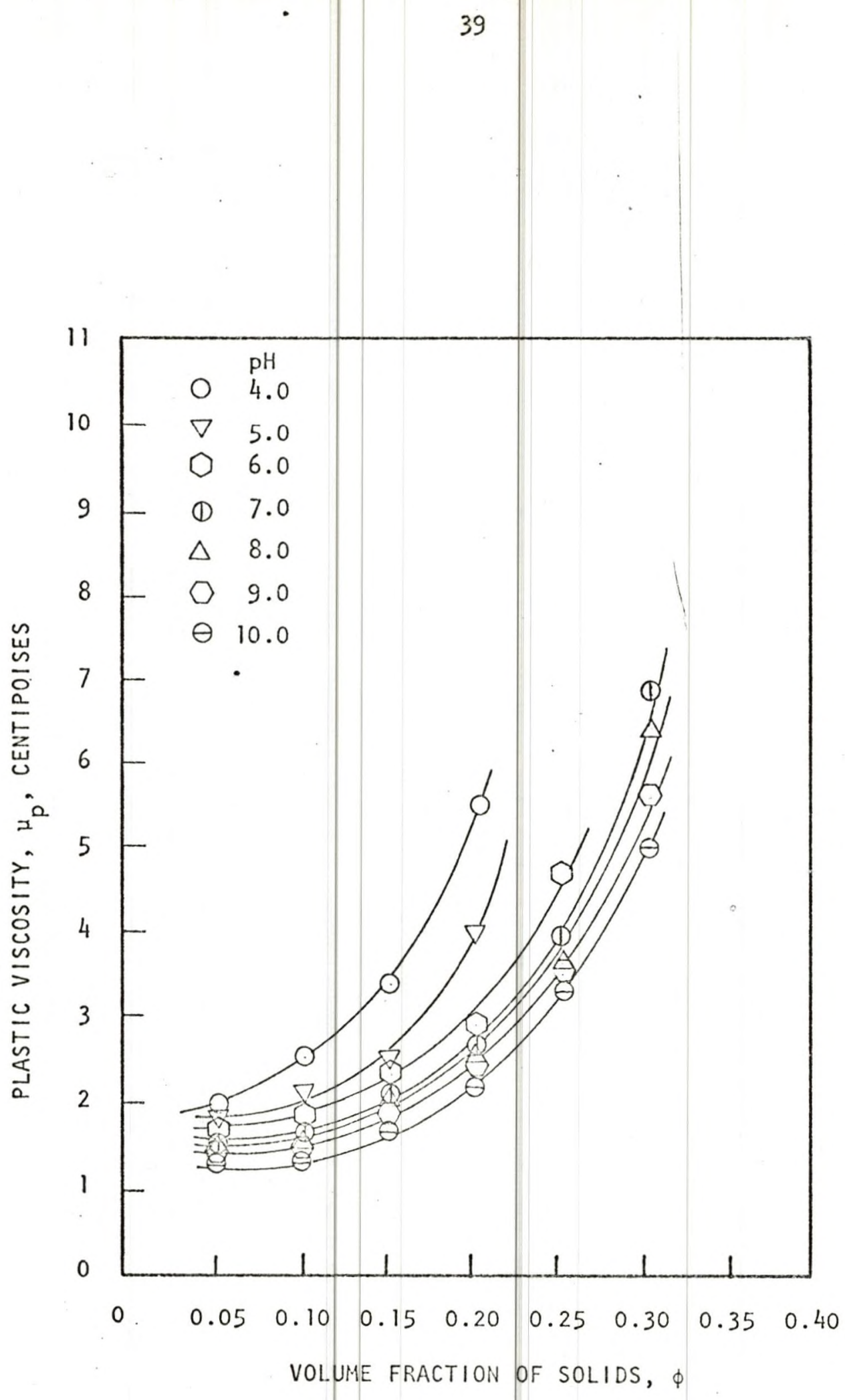

FIGURE 12 EFFECT OF SOLIOS CONCENTRATION ON PLASTIC VISCOSITY 


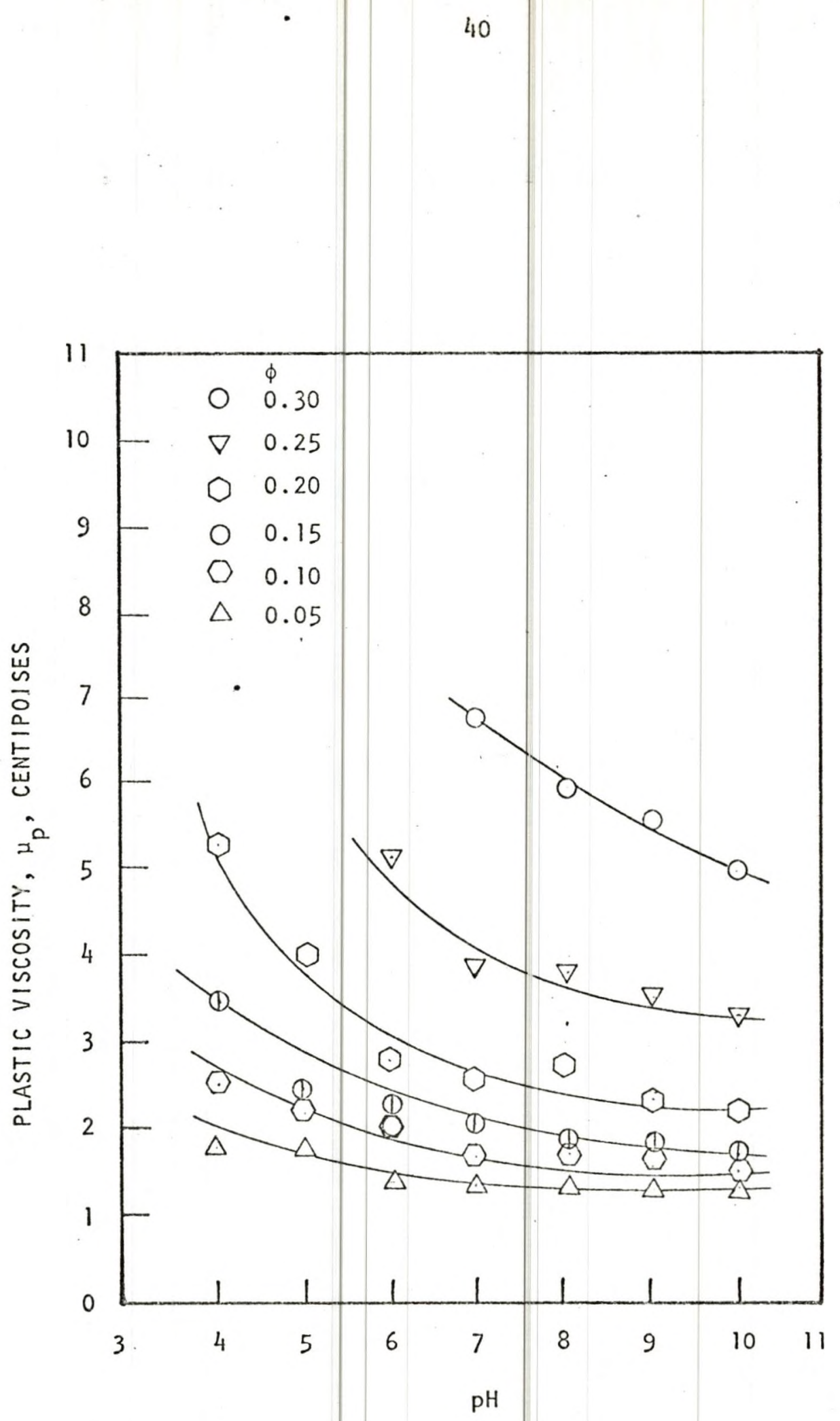

FIGURE 13 EFFECT OF PH ON PLASTIC VISCOSITY 


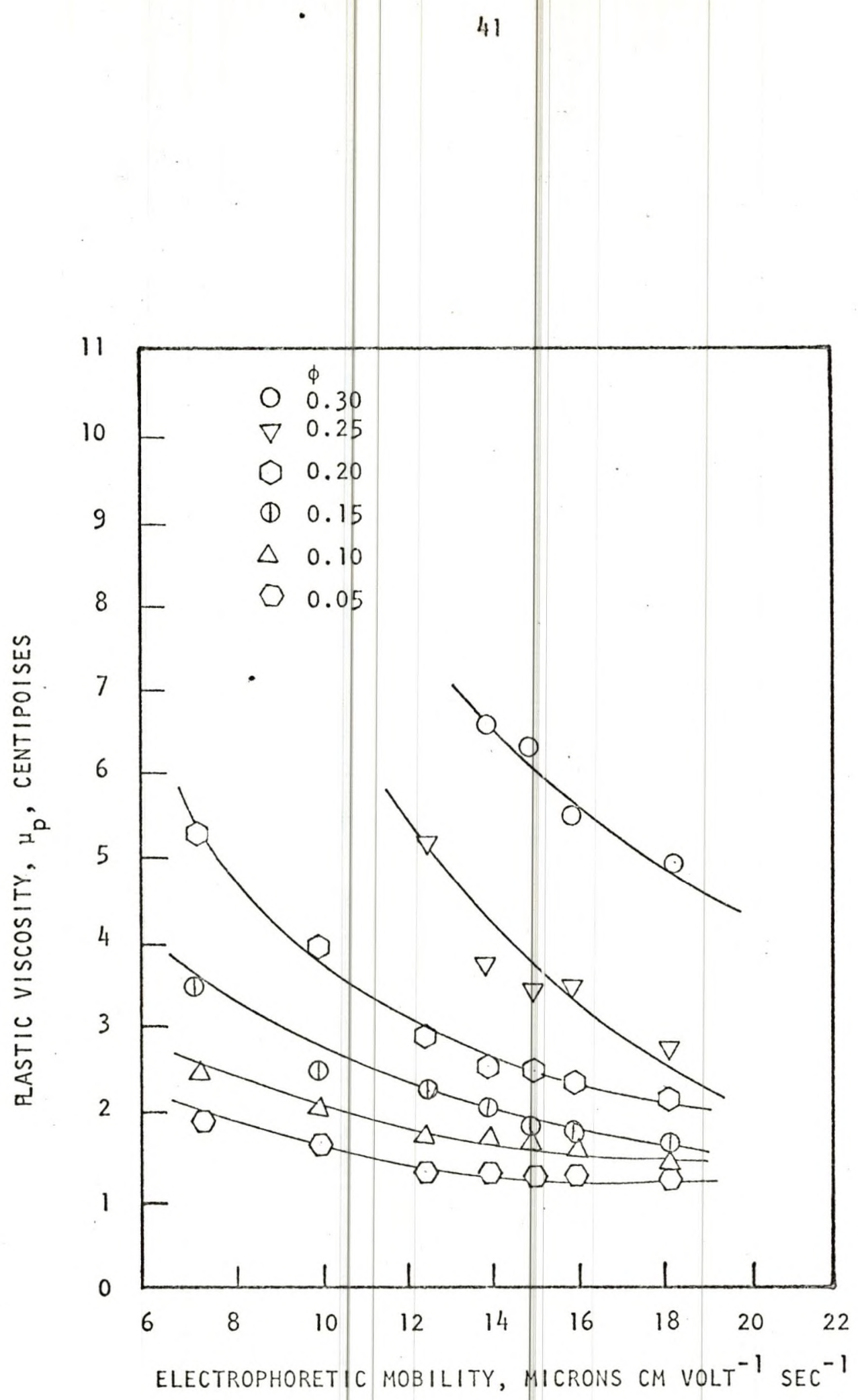

FIGURE 14 EFFECT OF ELECTROPHORETIC MOBILITY ON PLASTIC VISCOSITY 


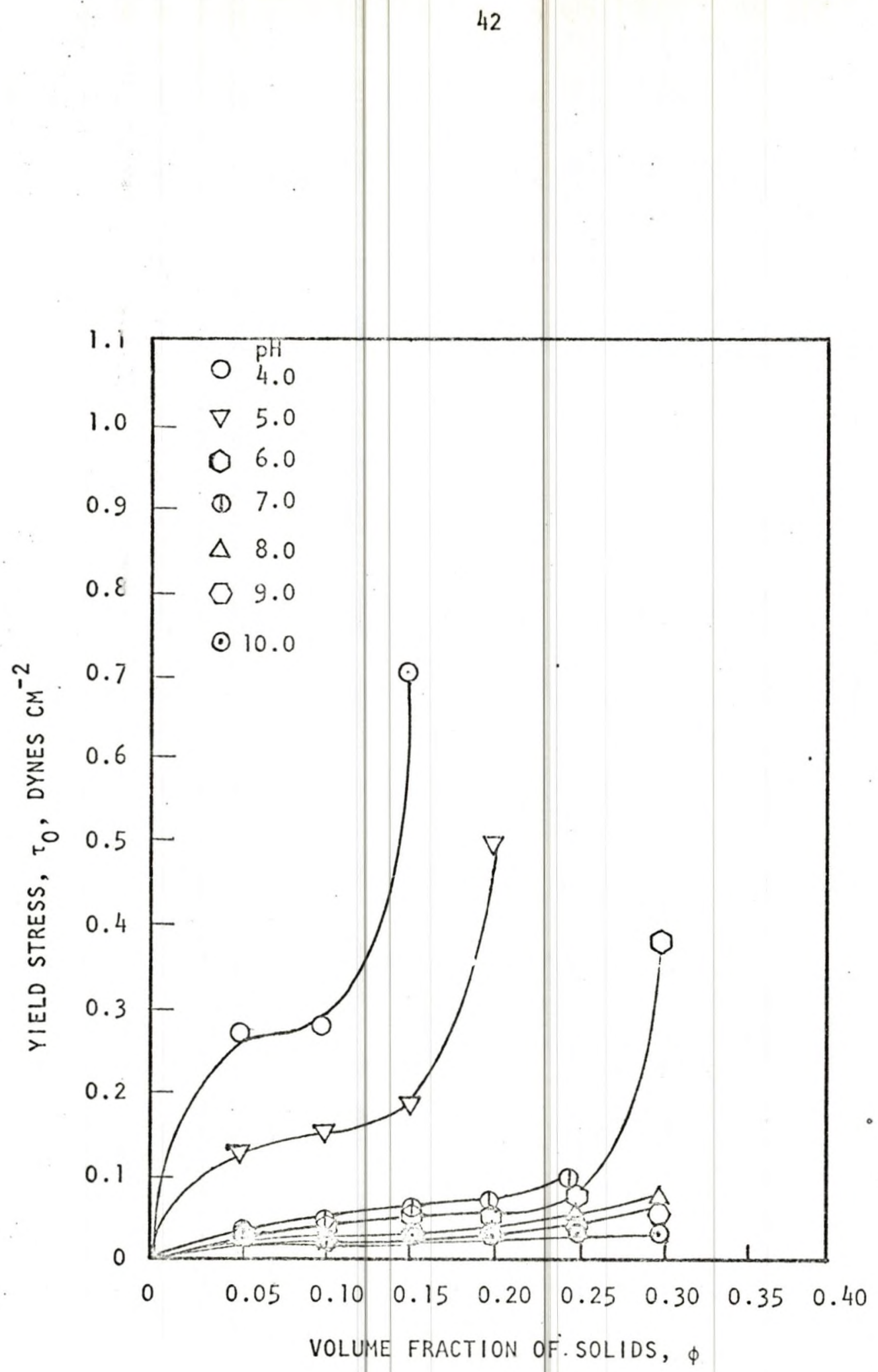

FIGURE 15 EFFECT OF SOLIDS CONCENTRATION ON YIELD STRESS 


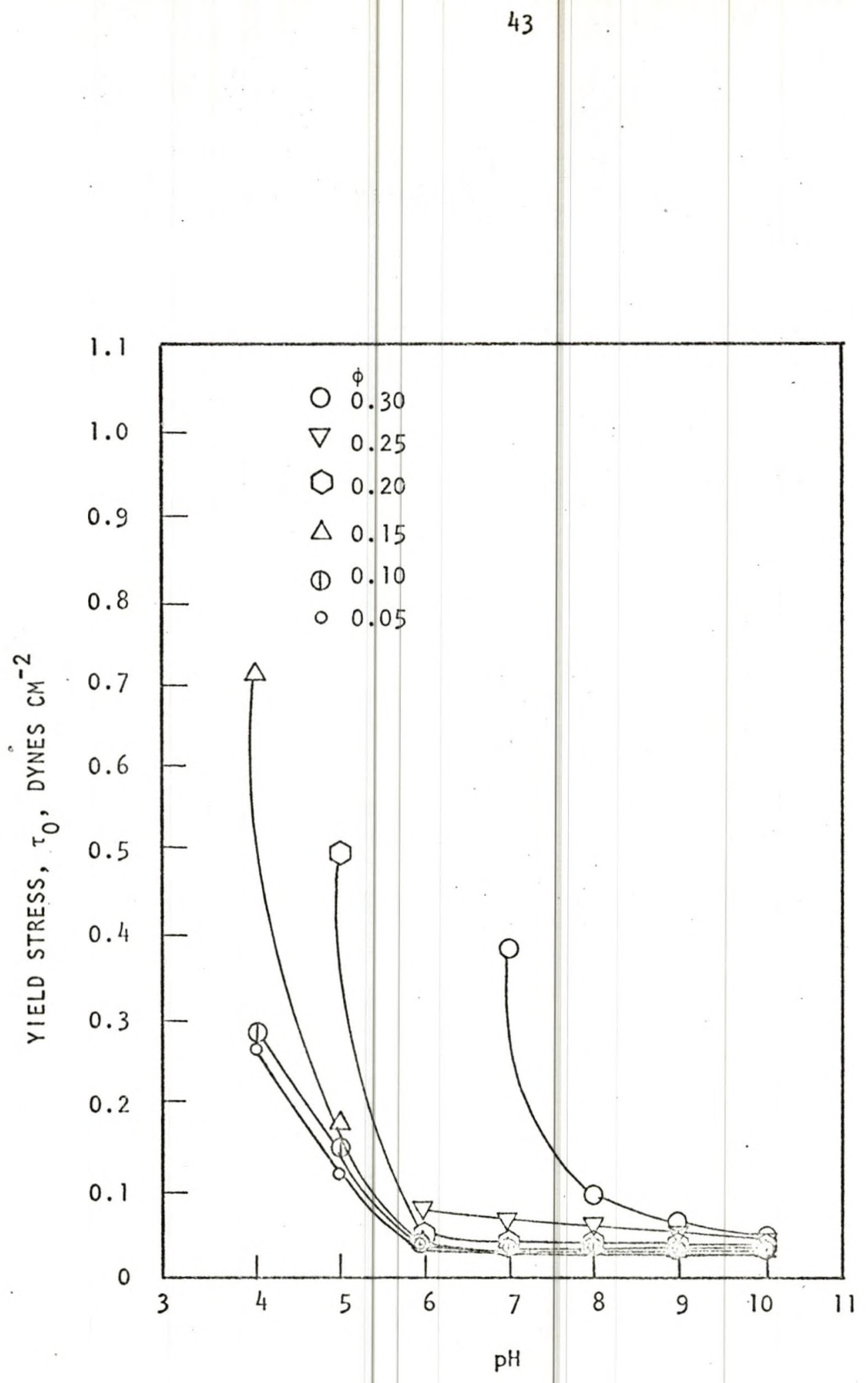

FIGURE 16 EFFECT OF PH ON YIELD STRESS 


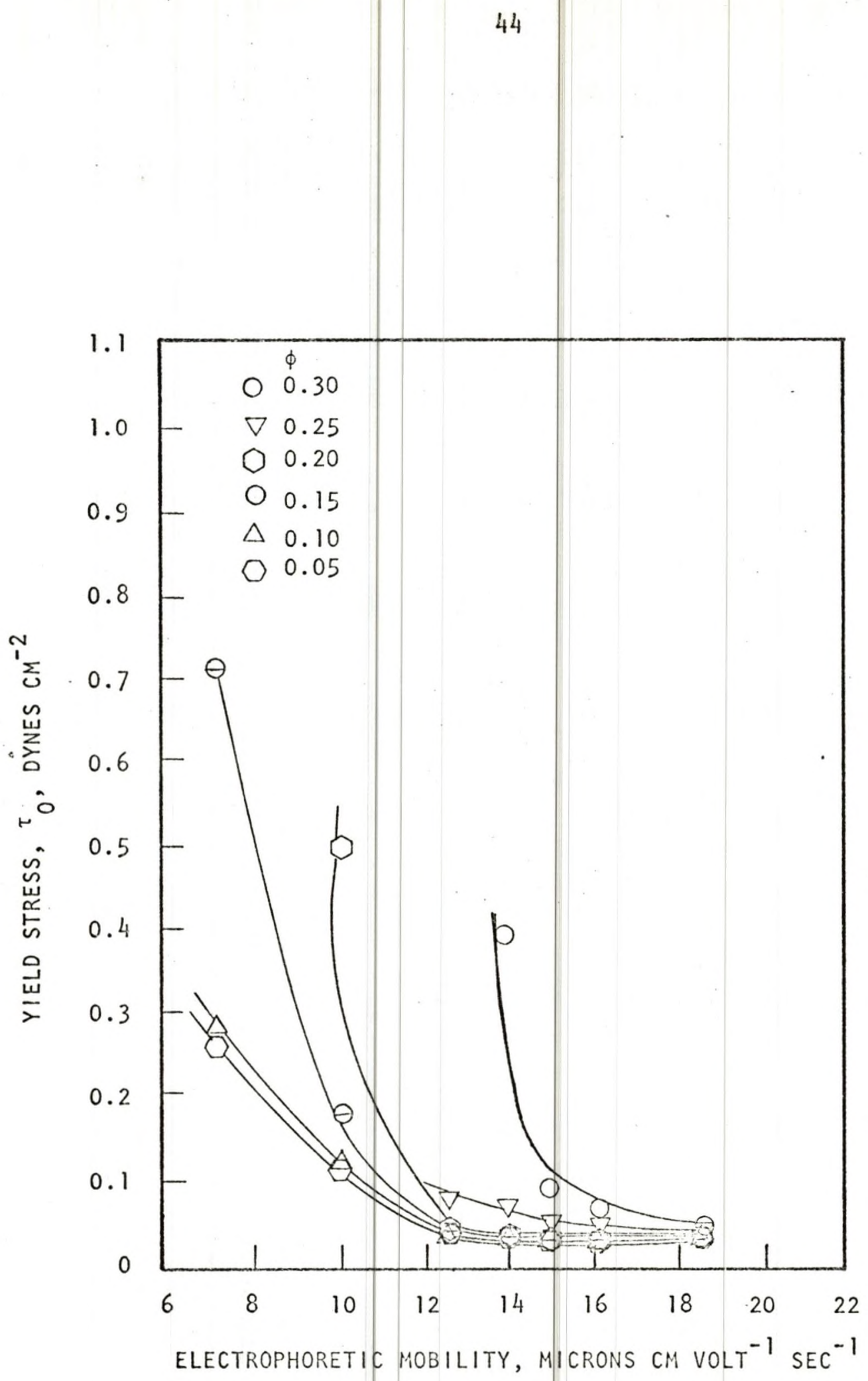

FIGURE $\cdot 17$ EFFECT OF ELECTROPHORETIC MOBILITY ON YIELD STRESS 
2. POWER LAW MODEL ANALYSIS

Not all the data points on the torque-angular velocity plots fall on a straight line at all solids concentration for all values of $\mathrm{pH}$. The relation between torque and angular velocity for a power law fluid, as derived in Appendix B, suggests a straight line plot for torque-angular velocity data on logarithmic coordinates. Figures 18 to 24 are p'ots of the torque-angular velocity data for silica in water suspensions using logarithmic coordinates. Since the data falls on straight lines, it can be said that the power law model fits the present experimental data closely. The parameters ' $m$ ' and ' $n$ ' for the power law model can be calculated from the slopes and the intercepts of the straight lines on these logarithmic plots. This has been done and the computed va'ues of ' $\mathrm{m}$ ' and ' $\mathrm{n}$ ' are presented in Table 16 in Appendix $H$. Sample calculations for ' $m$ ' and ' $n$ ' are presented in Appendix $G$. Some of the values from the lines drawn on the logarithmic plots have been transferred to some of the torque-angular velocity plots in the regular coordinate system. The dotted curves obtained show a pseudoplastic behavior for the silica in water suspensions indicating that the power law model fits experimental data for the silica in water suspensions investigated more closely than the Bingham plastic model.

Figures 25 to 30 are plots of the power law model parameters ' $m$ ' and ' $n$ ' as a function of solids concentration, $\mathrm{pH}$ and electrophoretic mobility. From the ' $n$ '-solids concentration plot it is evident that ' $n$ ' tends to unity as solids concentration goes to zero, which is as expected since ' $n$ ' is unity for a Newtonian fluid. The values of ' $n$ ' tend to decrease from unity as the solids concentration increases. This is more noticeable at a low $\mathrm{pH}$ than at a high $\mathrm{pH}$. The ' $\mathrm{n}$ '- $\mathrm{pH}$ and the 


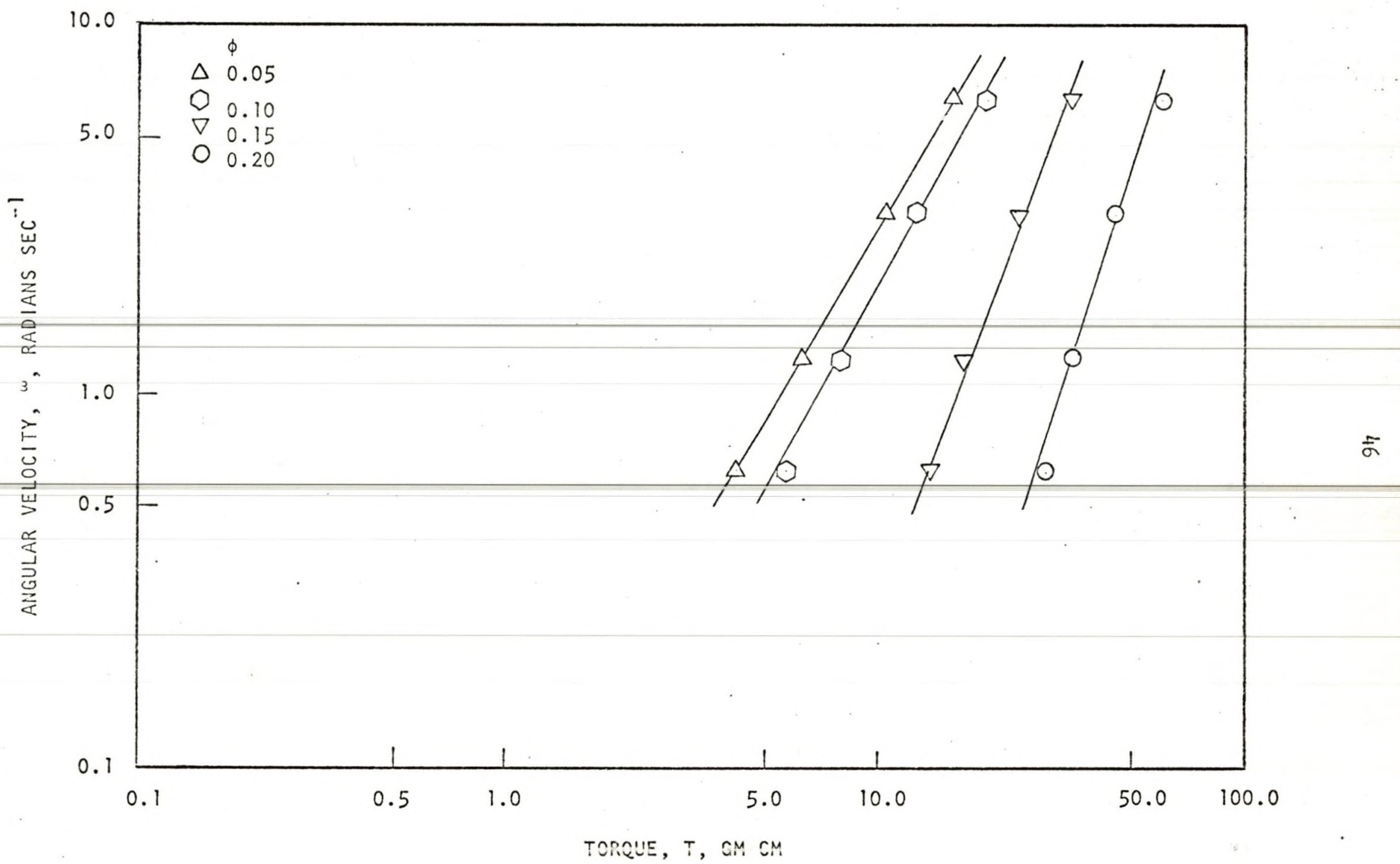

FIGURE 18 LOGARITHMIC TORQUE-ANGULAR VELOCITY PLOT AT $\mathrm{pH}=4.0$ 


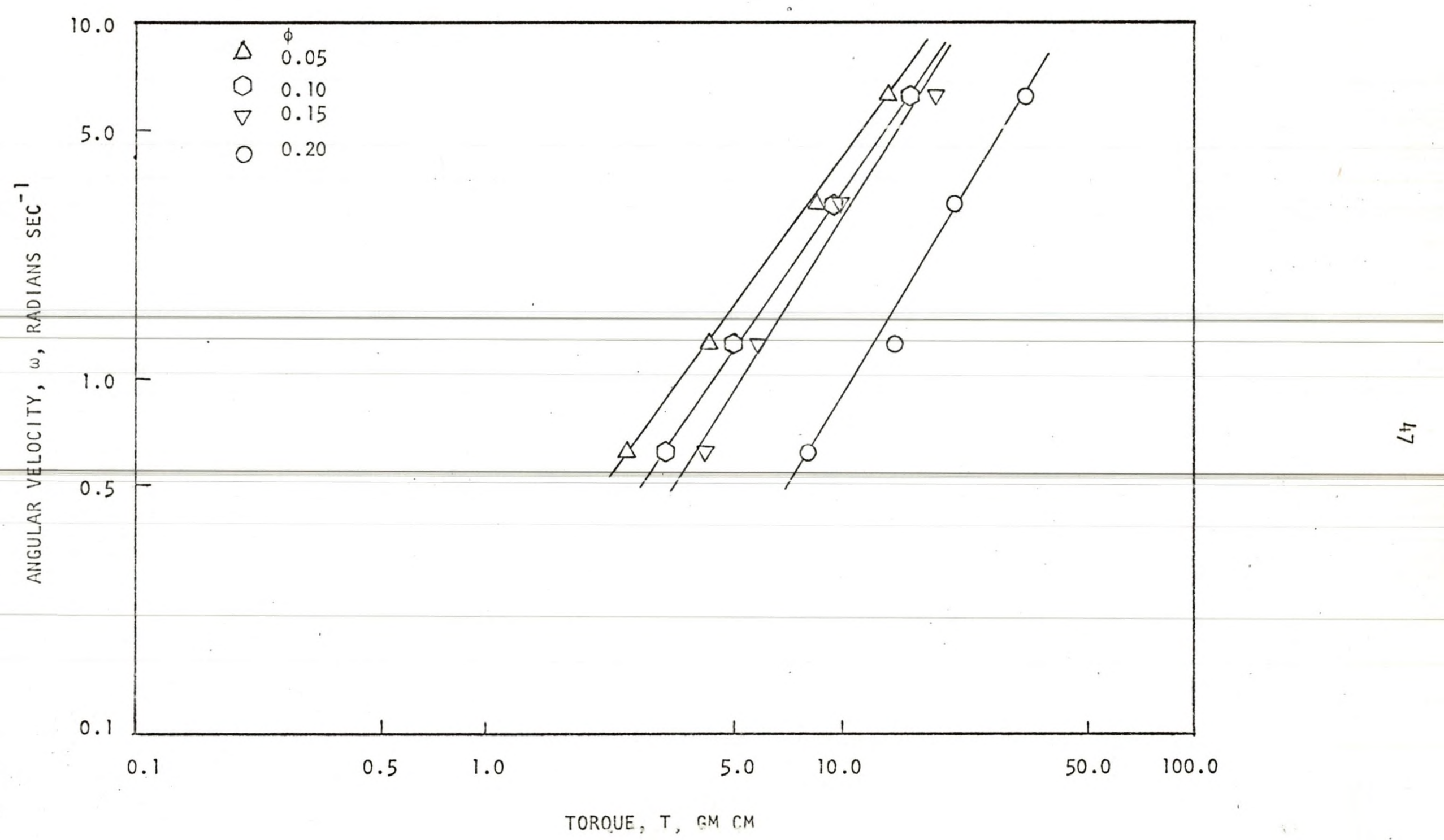

FIGURE 19 LOGARITHMIC TORQUE-ANGULAR VELOCITY PLOT AT $\mathrm{pH}=5.0$ 


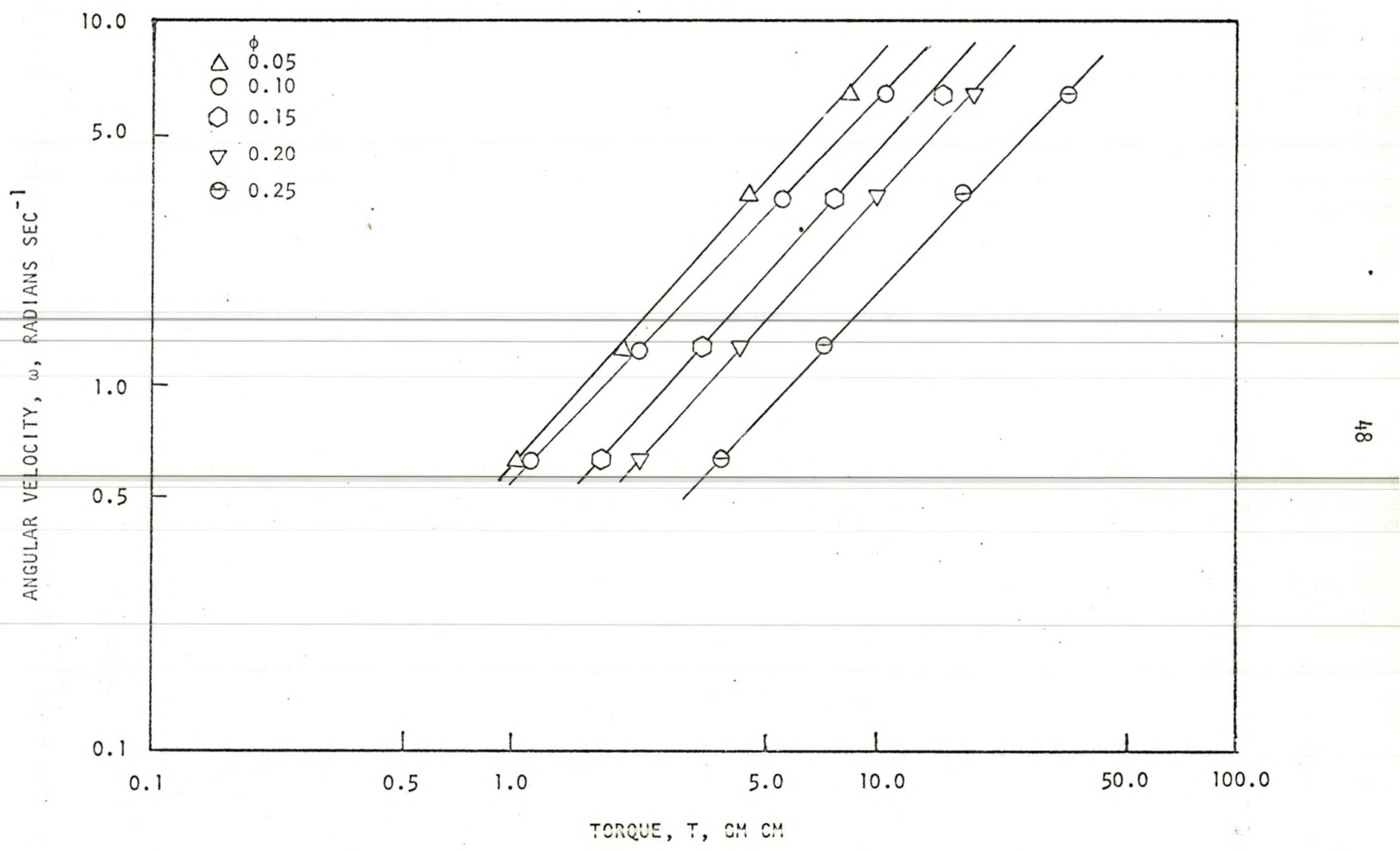

FIGURE 20 LOGARITHMIC TORQUE-ANGULAR VELOCITY PLOT AT $\mathrm{PH}=6.0$ 


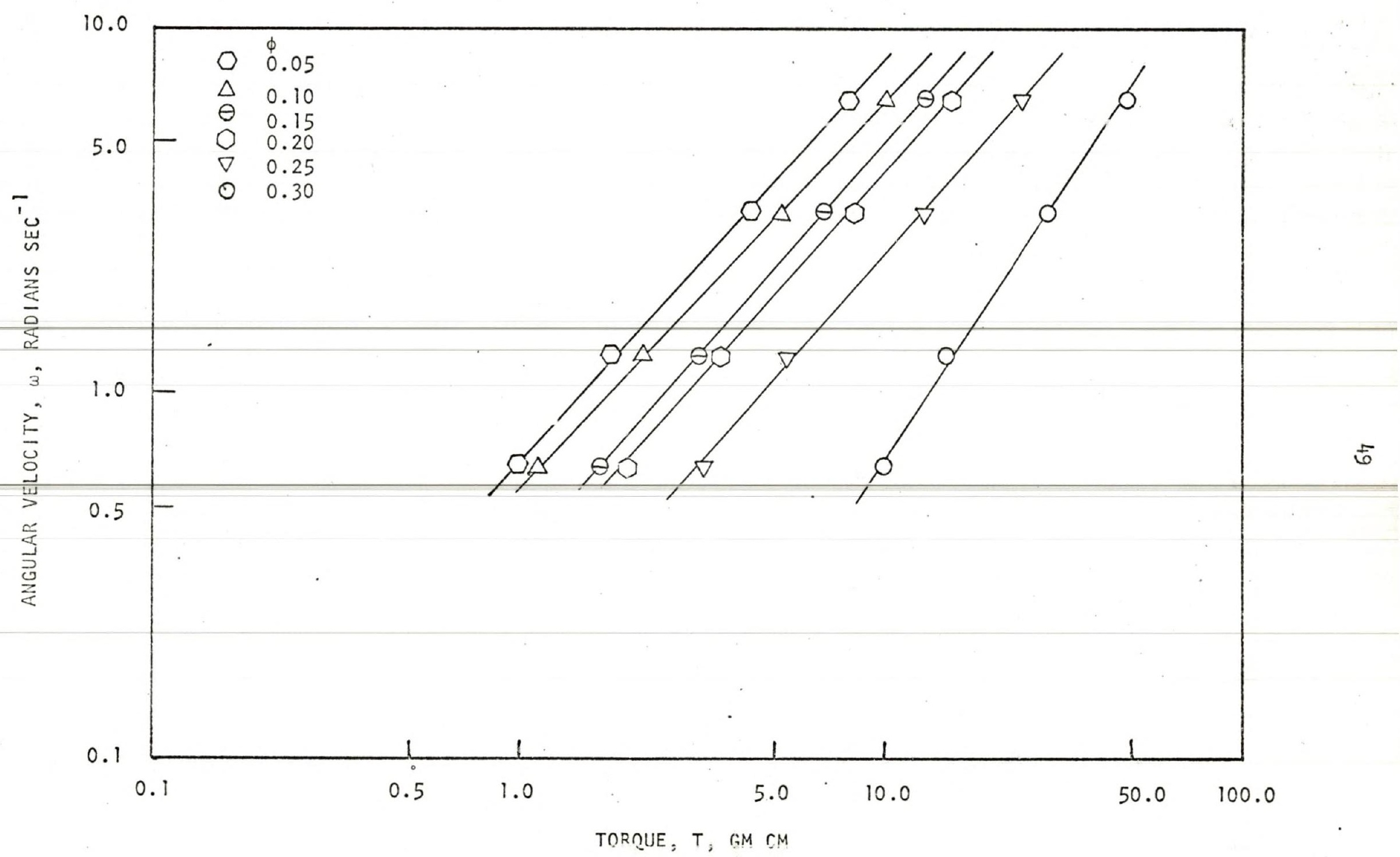

FIGURE 21 LOGARITHMIC TORQUE-ANGULAR VELOCITY PLOT AT $\mathrm{PH}=7.0$ 


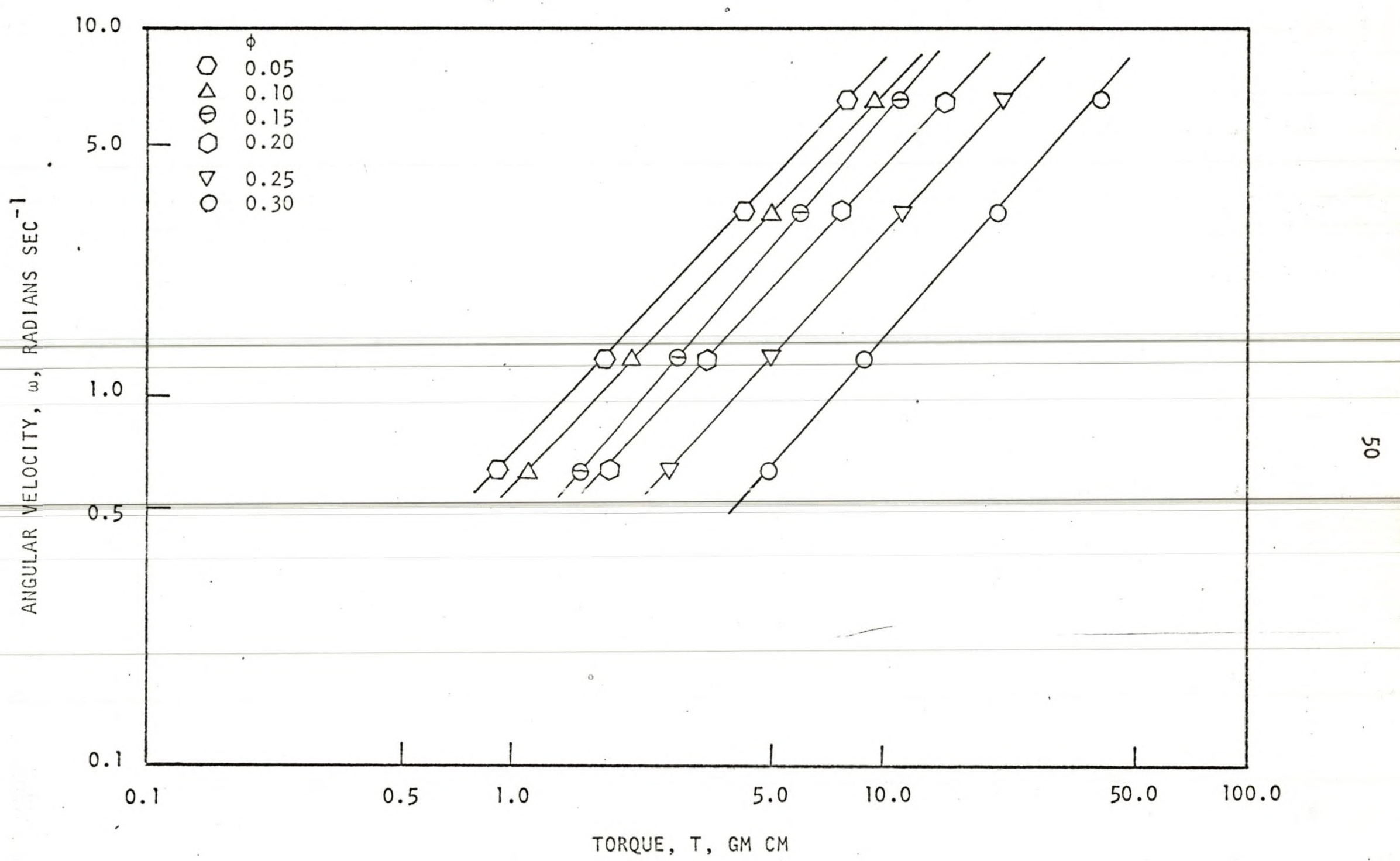

FIGURE 22 LOGARITHMIC TORQUE-ANGULAR VELOCITY PLOT AT $\mathrm{PH}=8.0$ 


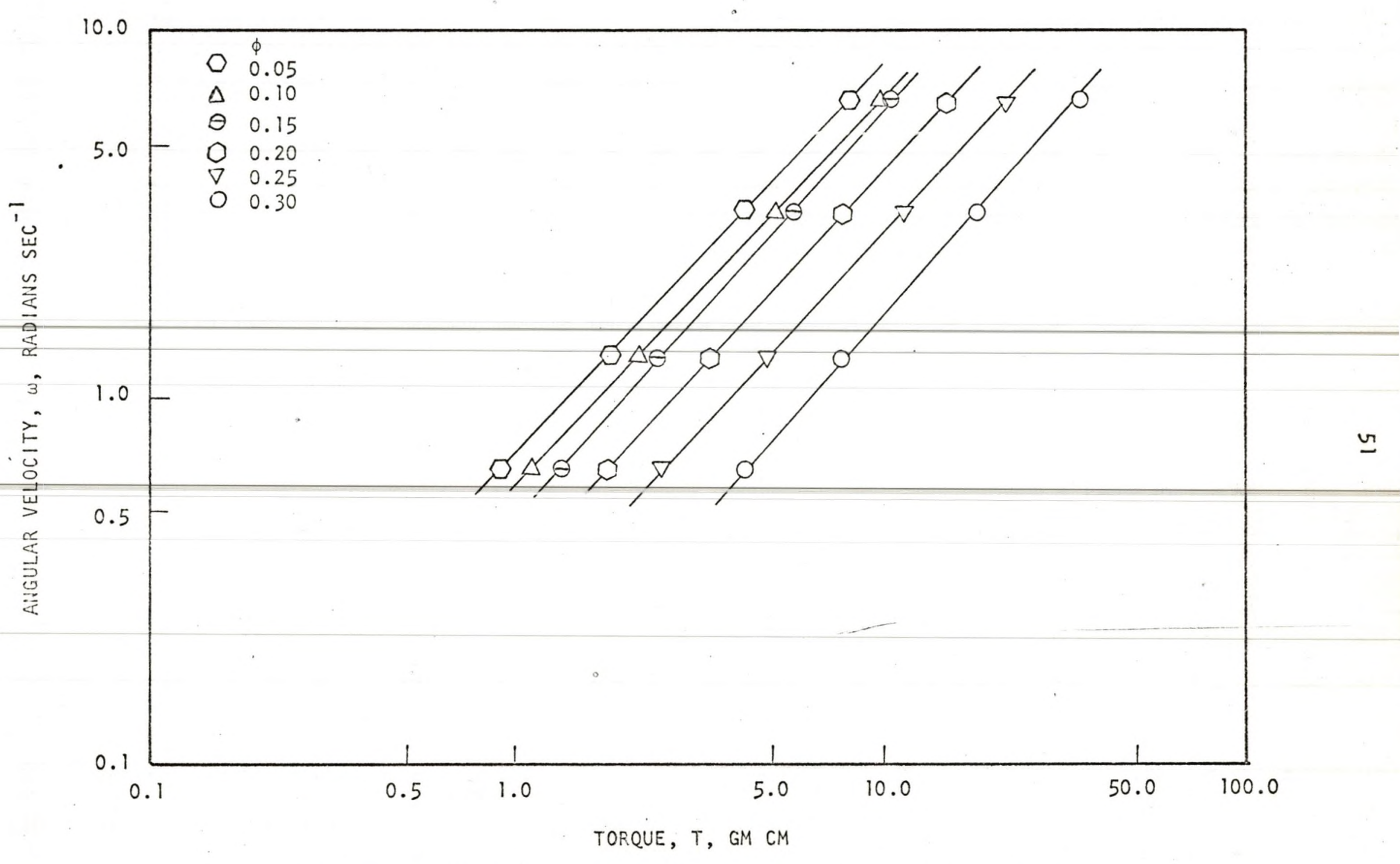

FIGURE 23 LOGARITHMIC TORQUE-ANGULAR VELOCITY PLOT AT PH $=9.0$ 


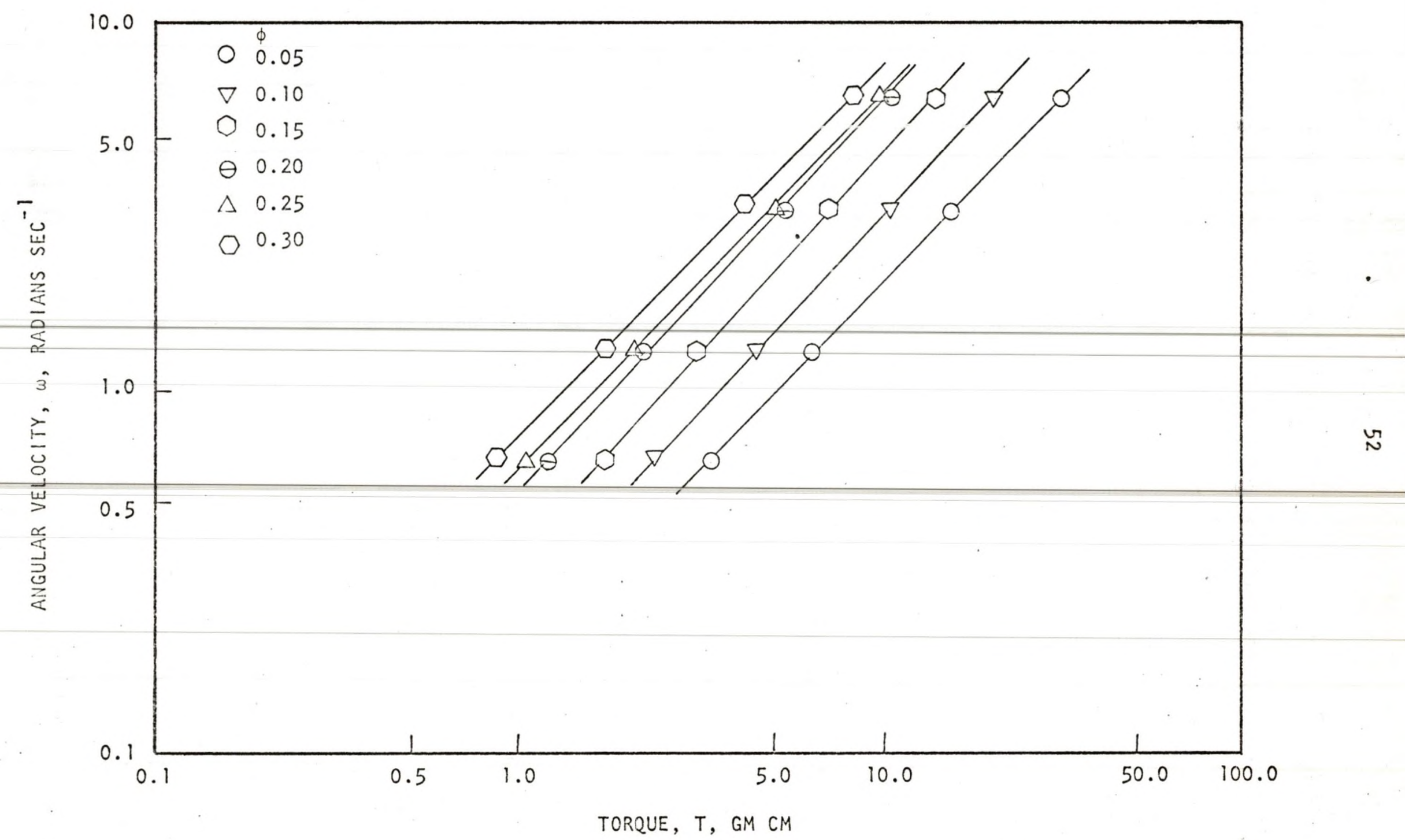

FIGURE 24 LOGARITHMIC TORQUE-ANGULAR VELOCITY PLOT AT PH $=10.0$ 
' $n$ '-electrophoretic mobility plots show that ' $n$ ' increases monotonically towards unity as the $\mathrm{pH}$ and electrophoretic mobility increase. In fact at $\mathrm{pH}$ values of 9 and 10 , the difference between the ' $n$ ' values for different solids concentration is extremely small as compared to the difference at a low pH of 4 . This fact $\exists g a i n$ indicates that these silica in water suspensions tend to Newtonian behavior at high values of $\mathrm{pH}$ and electrophoretic mobility.

Extrapolation of the ' $\mathrm{m}$ '-solids concentration plot should lead to the viscosity of water at zero solids concentration and this is found to be true in the present case. Also, the change in the value of ' $m$ ' with solids concentration is higher at a low pH than at a high pH. The ' $m$ '-pH and the 'm'-electrophoretic mobility plots are similar in nature and indicate that ' $\mathrm{m}$ ' decreases with increase in $\mathrm{pH}$ and electrophoretic mobility. The rate of change of ' $m$ ' with $\mathrm{pH}$ and electrophoretic mobility increases with increase in solids concentration, though at high $\mathrm{pH}$ and electrophoretic mobility there is little difference in values of ' $m$ ' among solids concentrations. At this stage it is interesting to rote that the plots for the power law model parameter ' $m$ ' are similar in appearance to the plots of plastic viscosity for the Bingham plastic model.

\section{EFFECT OF PARTICLE SIZE}

Silica in water suspensions of three different average particle sizes were investigated to determine the effect of particle size on both the rheological properties and the electrophoretic mobility. It was found that the electrophoretic mobility was not dependent on the three different particle sizes investigated. This can be explained by the fact that the change in average particle diameter may not have been sufficient to bring 


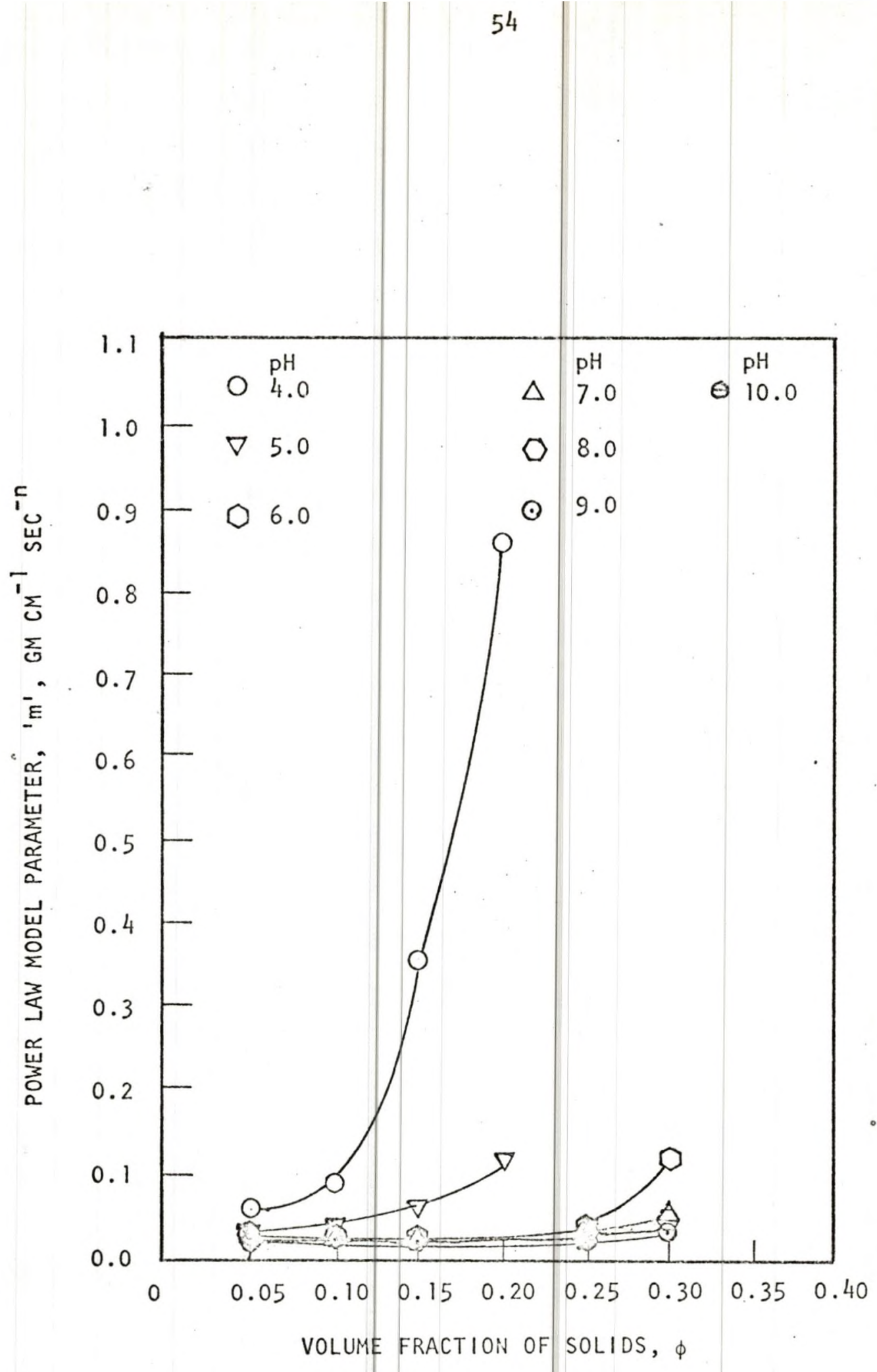

FIGURE 25 EFFECT OF SOLIDS CONCENTRATION ON POWER LAW MODEL PARAMETER 'm' 


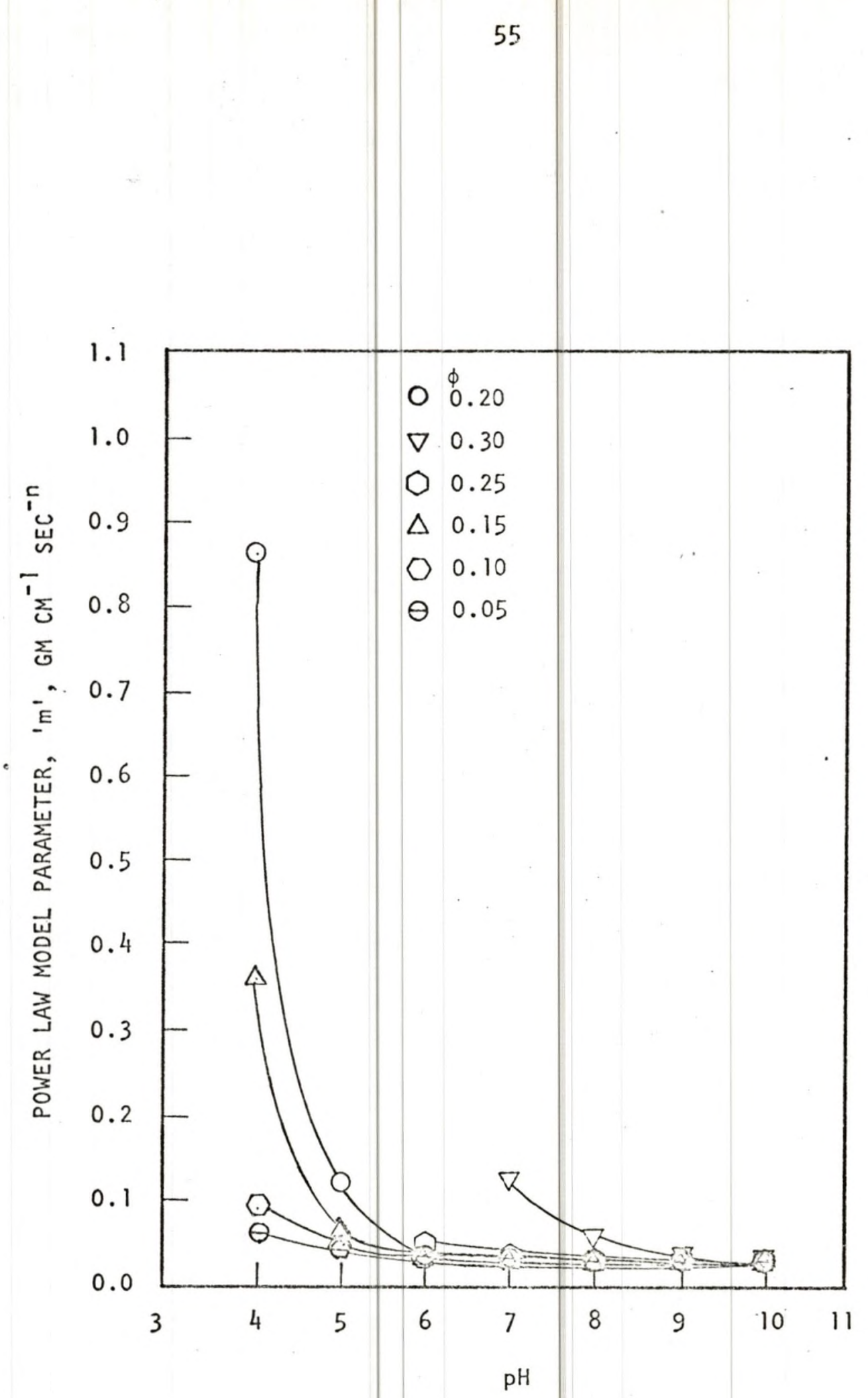

FIGURE 26 EFFECT OF $\mathrm{pH}$ ON POWER LAW MODEL PARAMETER ' $m$ ' 


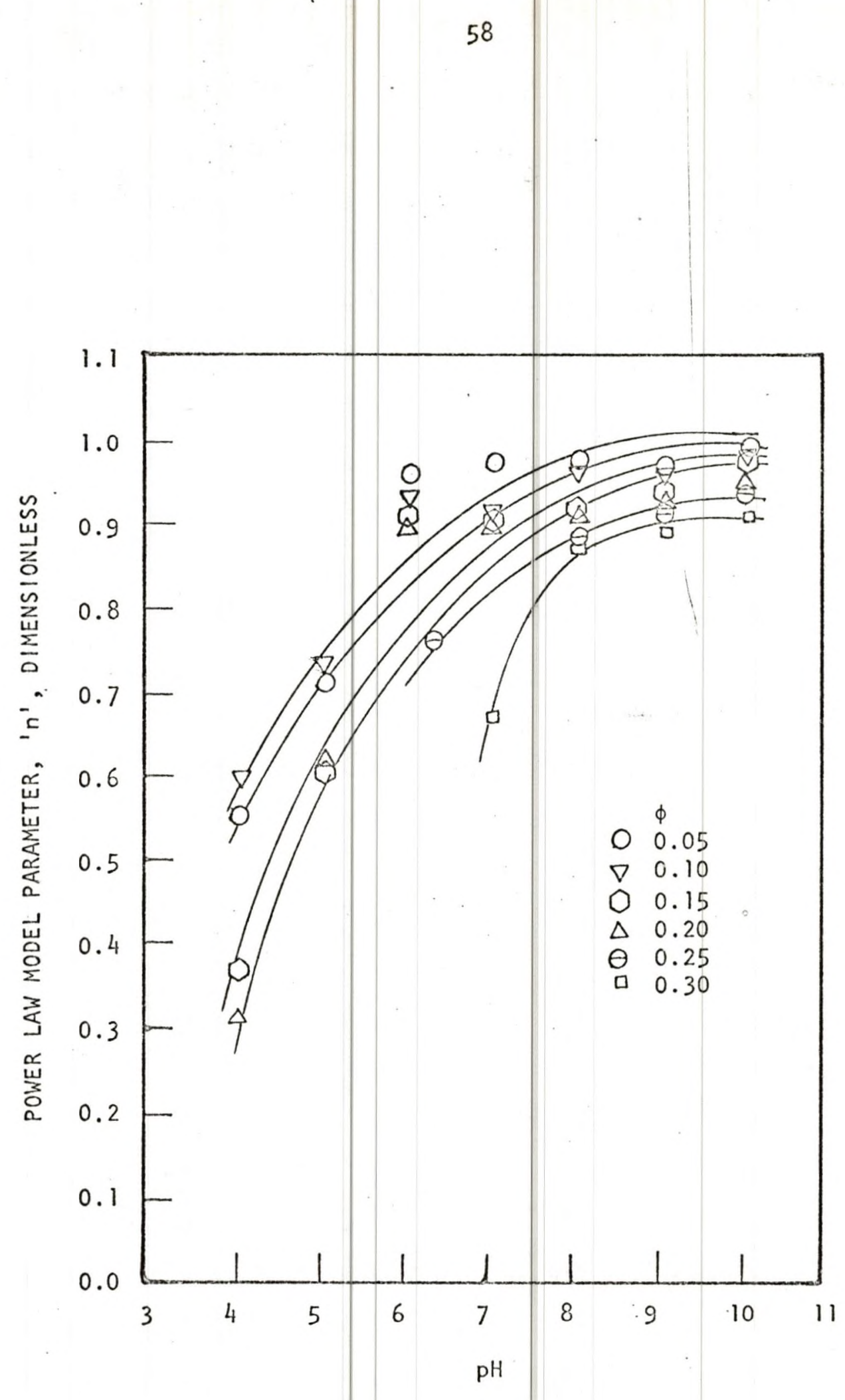

FIGURE 29 EFFECT OF $p H$ ON POWER LAW MODEL PARAMETER ' $n$ ' 


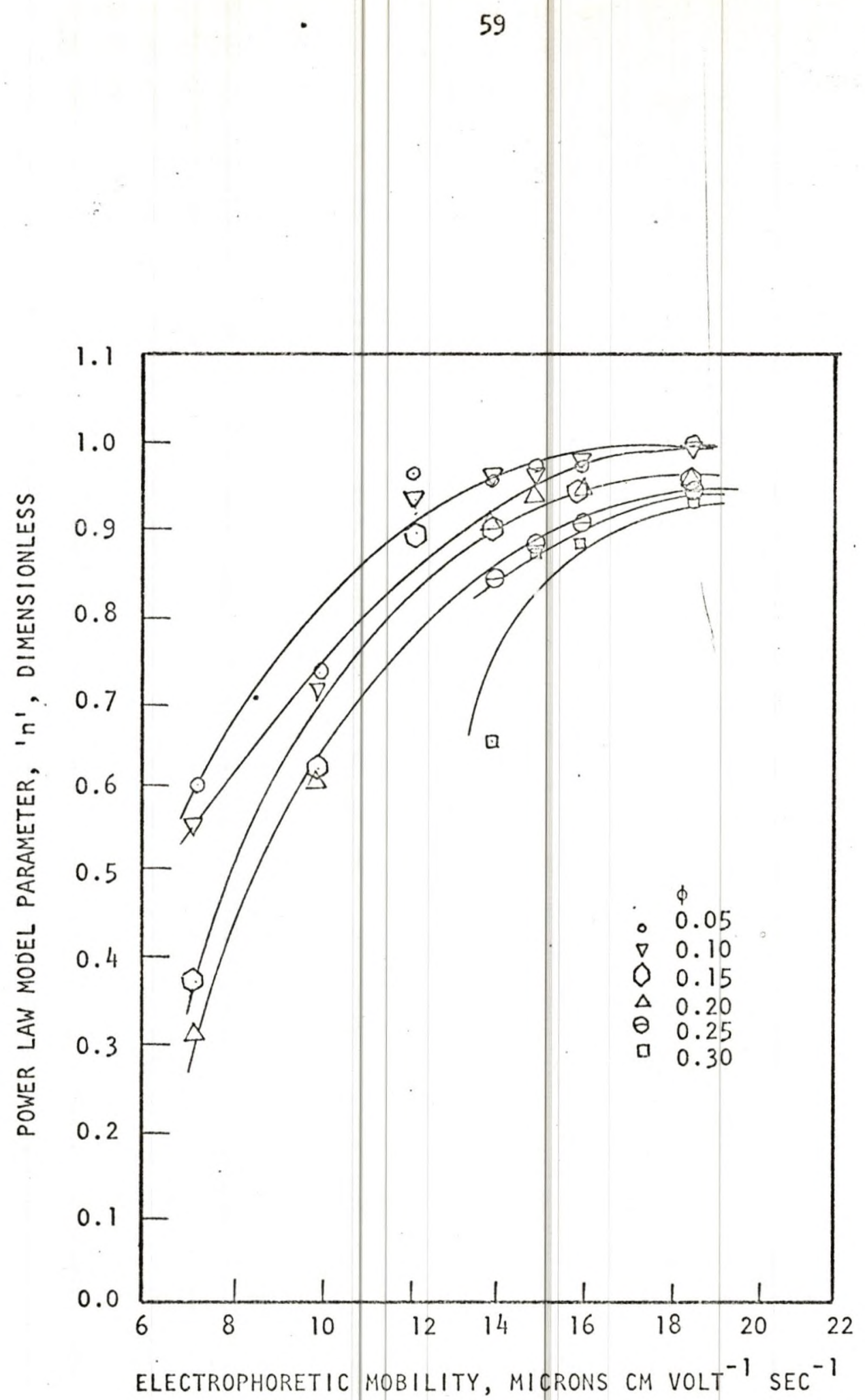

FIGURE 30 EFFECT OF ELECTROPHORETIC MOBILITY ON POWER LAW MODEL. PARAMETER ' $n$ ' 
about an appreciable change in the net electrical charge on the particles.

The data for the effect of particle size on apparent viscosity is given in Table 13 in Appendix F. Figure 31 is a plot of apparent viscosity as a function of rotational speed for different particle sizes at a given solids concentration and a given $\mathrm{pH}$. The curves show the dependence of apparent viscosity on rotational speed for the three particle sizes. Figure 32 is a plot of apparent viscosity as a function of $\mathrm{pH}$ at a given rotational speed and a given solids concentration for the three different particle sizes. These curves show the dependence of apparent viscosity on $\mathrm{pH}$ for the three different particle sizes. 4. PH-ELEC *ROPHORETIC MOBILITY RELATIONSHIP

An explanation for the increase in electrophoretic mobility with increasing $\mathrm{pH}$ is as follows:

At low values of $\mathrm{pH}$ the hydrogen ion concentration in the * double laye about the particle is high, thus reducing the net negative charge on the solid particle, which in turn gives rise to a low electrophoretic mobility. As the $\mathrm{pH}$ rises, the hydrogen ion concentration in the double layer about the particle decreases, thus increasing the net negative charge on the solid particle, which in turn gives rise to a higher electrophoretic mobility.

The above may not be true in all cases and the electrophoretic mobility may tend to be a function of the ionic strength and not the $\mathrm{pH}$. This would depend on the type of ions present in the suspension.

\section{LIGNITE IN WATER SUSPENSION}

The apparent viscosity and the electrophoretic mobility of a $20 \%$ by volume lignite in water suspension was measured and the results 


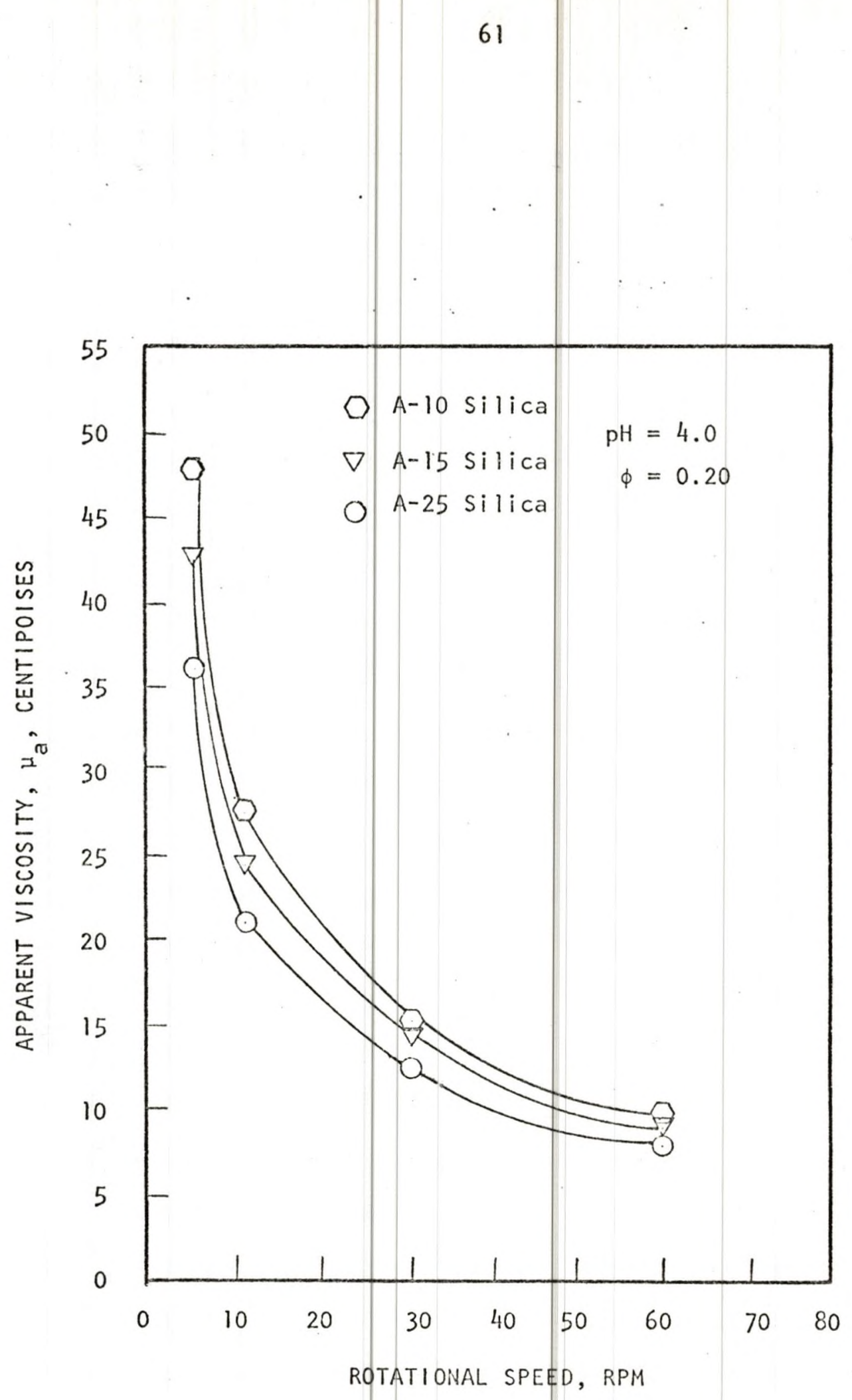

FIGURE 31 EFFECT OF ROTATIONAL SPEED ON APPARENT VISCOSITY FOR DIFFERENT PARTICLE SIZES 


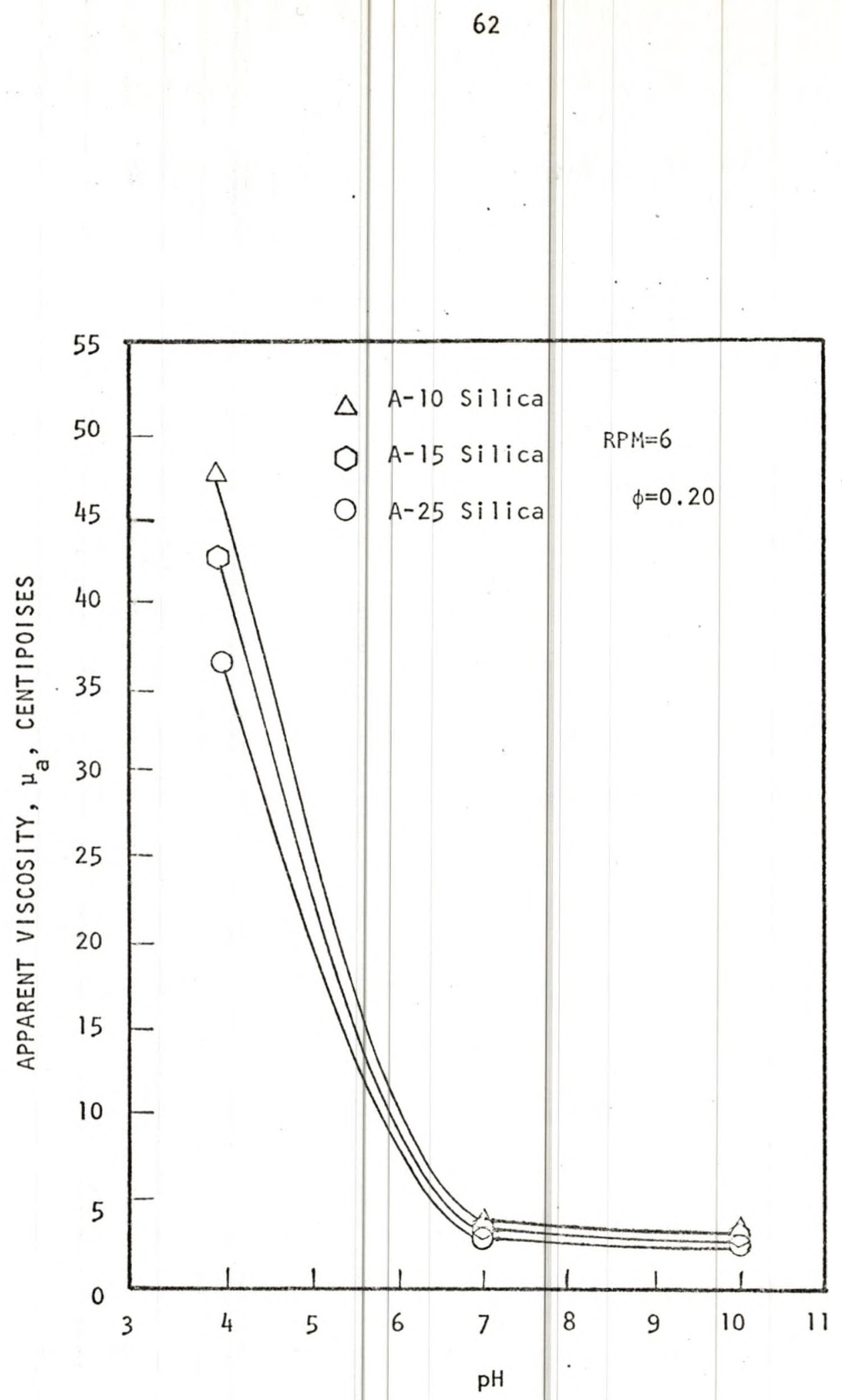

FIGURE 32 EFFECT OF PH ON APPARENT VISCOSITY FOR DIFFERENT PARTICLE SIZES 
are shown in Table 2. These data suggest that the suspension is shear thinning. Figure 33 is a plot of the torque as a function of the angular velocity and all the data points fall on a straight line. This indicates that the lignite in water suspension can be well characterized as a Bingham plastic. The values of the plastic viscosity and the yield stress for this suspension and the values of the torques at various angular velocities are given in Table 2 . 


\section{TABLE 2}

DATA FOR 20\% BY VOLUME LIGNITE-WATER SUSPENSION

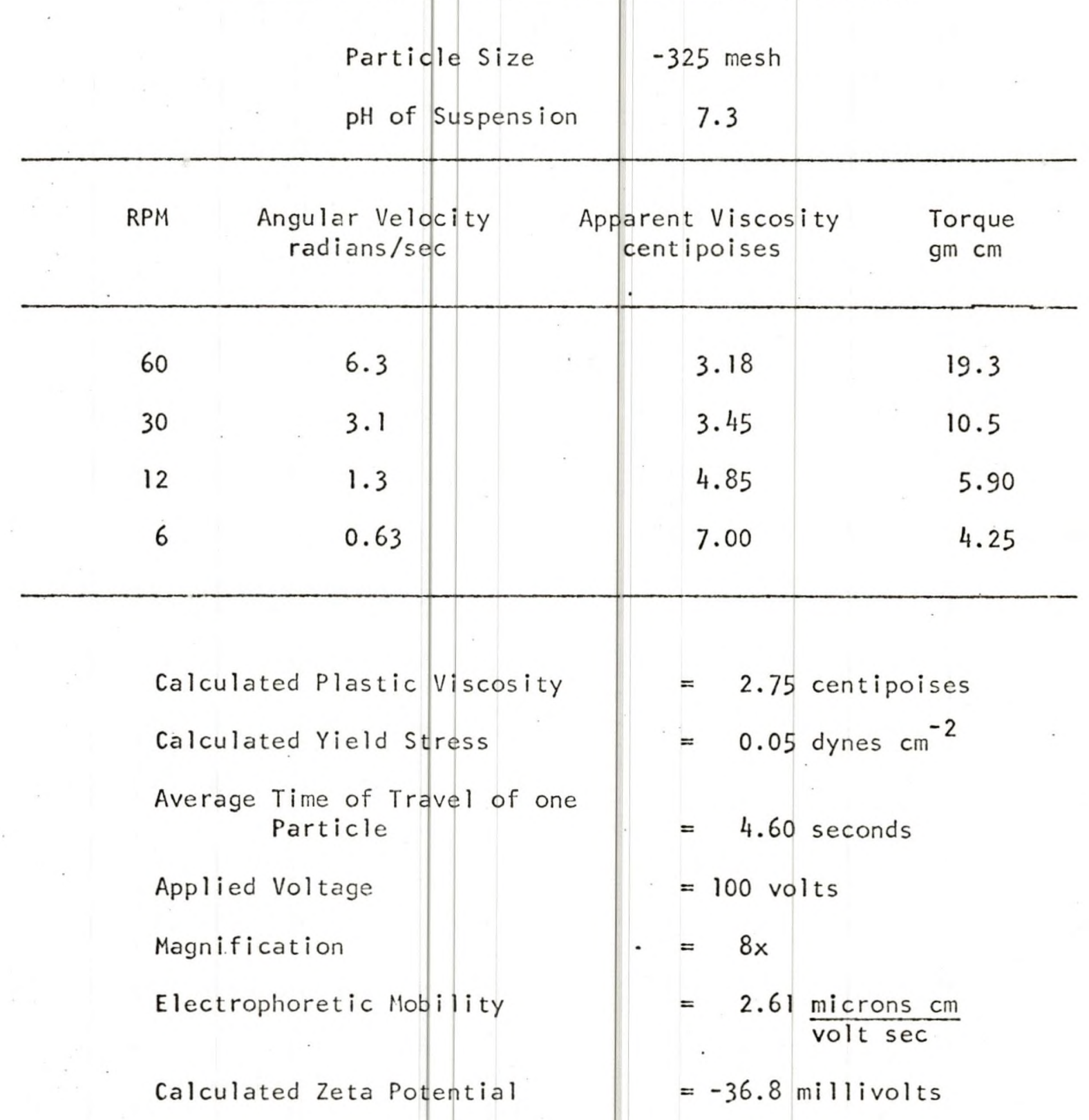




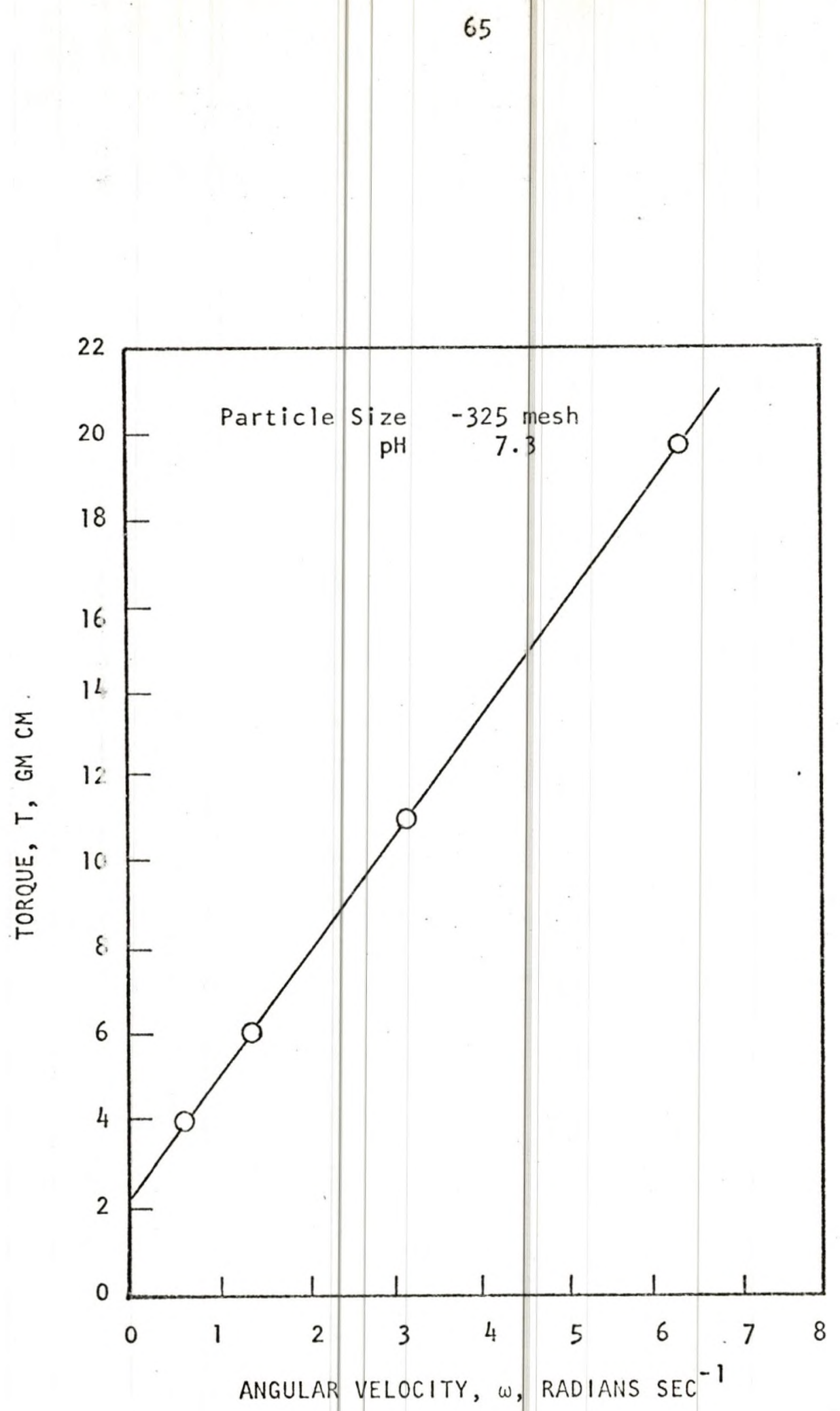

FIGURE 33 TORQUE-ANGULAR VELOCITY PLOT

- FOR 20\% by VOLUME LIGNITE-WATER SUSPENSION 


\section{CHAPTER VII \\ CONCLUSIONS}

This study of the rheological properties of silica in water suspensions has led to the following conclusions:

1. The apparent viscosity of silica in water suspensions decreases with increasing shear rate and henre silica in water suspensions can be classified as shear-thinnin! fluids.

2. At a given shear rate, an increase in solids concentration produces an increase in the apparent viscosity.

3. The power law model fits the experimental data closely, although the Bingham plastic model describes silica in water suspersions well.

4. The electrophoretic mobility of the silica particles in water increases monotonically with increasing $\mathrm{pH}$ for the $\mathrm{pH}$ range 4 to 10 .

5. The plastic viscosity, yield stres\$ and the power law model parameters, ' $m$ ' and ' $n$ ', increase monotonically with increasing solids concentration at a constant $\mathrm{pH}$ and electrophoretic mobility.

6. At constant solids concentration, plastic viscosity, yield stress and ' $m$ ' and ' $n$ ', decrease monotonically with increasing $\mathrm{pH}$ and electrophoretic mobility.

7. At zero solids concentration, the values of plastic viscosity, yield stress, and ' $m$ ' and ' $n$ ', approach values close to that for water. 
8. The values of plastic yiscosity, yield stress and the power law model parameters ' $m$ ' and ' $n$ ', indicate that silica in water suspensions tend toward Newtonian tehavior at the higher values of $\mathrm{pH}$ and electrophoretic mobility.

9. At constant shear rate, $\mathrm{pH}$ and solids concentration, the apparent viscosity decreases with increase in average particle size. Particle size does not affect the electrophoretic mobility over the range investigated.

The following statement can be made about the lignite in water suspension investigated:

Shear-thinning is exhibited by the lignite in water suspension and the Bingham plastic model fits the experimental data closely. 


\section{CHAPTER VIII}

SUGGESTIONS FOR FUTURE EXPERIMENTATION

This study was essentially preliminary in nature and the area of rheology of concentrated silica suspensions needs further investigation.

An important extension of the present study would be to investigate pipe flow for the same suspensions at the same rates of shear and compare results with those of the prasent study. This might lead to a correlation between concentric cylinder viscometer data and pipe flow data for use in the design of pipelines and other equipment for concentrated suspensions.

It would be of interest to investigate the effect of ionic strength of the suspending medium on the electrophoretic mobility and the viscosity of silica in water suspensions. The nature of the ions present in the suspending medium may have a bearing on the electrophoretic mobility of the suspension and the stability of the suspension as well. It might be worthwhile to investigate this.

Effect of particle size should be investigated in greater detail.

The effect of temperature on the suspensions of silica in water may provide another interesting avenue for investigation.

It would be of considerable interest to continue the present line of study over a wider range of solids concentration for silica in water suspensions. Also, other methods of changing the electrophoretic mobility should be studied and the question of whether they lead to 
similar changes in apparent viscosity behavior should be investigated.

Lignite-water suspensions need further experimentation. Investigation over a wide range of solids concentration and $\mathrm{pH}$ is needed. The effects of addition of salts such as sodium chloride and calcium chloride to lignite in water suspensions would be of extreme practical value.

Investigation leading to stabilizing techniques for lignite-water suspensions would be of great interest from the industrial standpoint.

Another interesting line of experimentation lies in the study of lignite-petroleum suspensions. This should include investigation of the viscometric behavior and pipe flow of such suspensions. Effect of temperature should be studied as well. 

TANGENTIAL ANNULAR FLOW OF A BINGHAM PLASTIC

Consider a Bingham plastic between two vertical concentric cylinders with the inner cylinder being rotated at a constant angular velocity. The radius of the outer cylinder is $r_{2}$, radius of the inne. cylinder is $r$, and the height of the inner cylinder is $h$.

Assuming that the velocity components in the radial direction and in the axial direction to be zero and that the angular component of the velocity is dependent on radius alone, the equation of motion for steady state can be written as arrived at by Bird et. al. (22).

$$
0=\frac{1}{r^{2}} \frac{d}{d r}\left(r^{2} \tau_{r}\right)
$$

On integration, equation $(A-1)$ gives

$$
\tau_{r \theta}=\frac{c}{r^{2}}
$$

If the torque at the inner cylincier is known to be $T$, then

$$
T=\left(r^{-r}\right)_{r}=r_{1} \cdot 2 \pi h r_{1} r_{1}
$$

The combination of equations $(A-2)$ and $(A-3)$ yields

$$
\tau_{r \theta}=\frac{T}{2 \pi h r^{2}}
$$

On the assumption that there is plastic flow throughout $\tau_{r}$ greater than $\tau_{0}$ at $r_{2}$ greater than $r$ greater than $r_{1}(A-5)$

The equation of state for a Bingham plastic can be written as

$$
\tau_{r \theta}=-\mu_{p} r \frac{d}{d r}\left(v_{\theta} / r\right)+\tau_{0}
$$


where $\tau_{0}$ is the yield stress

and $\mu_{p}$ is the plastic viscosity.

On combination, equations $(A-4)$ and $(A-6)$ give

$$
\frac{T}{2 \pi h r^{2}}=-\mu p r \frac{d}{d r}\left(v_{\theta} / r\right)+t_{0}
$$

Equation $(A-7)$ can be rewritten as follows:

$$
\frac{T}{2 \pi h r^{3}}=-\mu_{p} \frac{d}{d r}\left(v_{\theta} / r\right)+\tau_{j} / r
$$

On integration, equation $(A-8)$ gives

$$
-\frac{T}{4 \pi h r^{2}}=-\mu_{p}\left(v_{\theta} / r\right)+\tau_{p} \ln r+c_{1}
$$

where $c_{1}$ is the integration constant.

Using the boundary condition

$$
\begin{aligned}
& v_{\theta}=0 \text { at } r=r_{2} \\
& c_{1}=-\frac{T}{4 \pi h r_{2}^{2}}-\tau_{0} \ln r_{2}
\end{aligned}
$$

Substituting the value of $C_{1}$ from equation $(A-10)$ in equation $(A-9)$, the result is

$$
-\frac{T}{4 \pi h r^{2}}=-\mu_{p}\left(v_{\theta} / r\right)+\tau_{0} \ln r-\tau_{0} \ln r_{2}-\frac{T}{4 \pi h r_{2}^{2}}(A-11)
$$

Using the boundary condition

$$
v_{\theta} / r=w \text { at } r=r_{1}
$$

equation $(A-11)$ yields

$$
-\frac{T}{4 \pi h r_{1}^{2}}=-\mu_{p} \omega+\tau_{0} \ln r_{1} / r_{2}-\frac{T}{4 \pi h r_{2}^{2}}
$$


which can be rearranged to give

$$
\omega=\frac{T}{4 \pi h \mu_{p}}\left(r_{1}{ }^{-2}-r_{2}^{-2}\right)+\frac{\tau_{0}}{\mu_{p}} \ln r_{1} / r_{2}
$$

Equation $(A-12)$ can be used to evaluate the plastic viscosity and yield stress from torque-angular velocity data.

For a Newtonian fluid equation $(A-12)$ reduces to

$$
\omega=\frac{T}{4 \pi h \mu_{0}}\left(r_{1}{ }^{-2}-r_{2}^{-2}\right)
$$

where $\mu_{0}$ is the absolute Newtonian viscosity. 
Coisider a power law fluid between two vertical concentric cylinders, with the inner cylinder being rotated at an angular velocity $\omega$. The radius of the inner cylinder is $r$, and its height is $h$. The radius of the outer cylinder is $r_{2}$.

Assuming that the velocity components in the radial and axial directions to be zero and the angular component of the velocity to be dependent on the radius alone, the equation of motion for steady state can be written as arrived at by Bird et. al. (22):

$$
0=\frac{1}{r^{2}} \frac{d}{d r}\left(r^{2} r_{r}\right)
$$

On integration, equation $(B-1)$ gives

$$
\tau_{r \theta}=\frac{c^{\prime}}{r^{2}}
$$

If the torque at the inner cylinder is known to be $T$, then

$$
T=\left(\tau_{r \theta}\right)_{r}=r_{1} \cdot 2 \pi r_{1} h r_{1}
$$

The combination of equations $(B-2)$ and $(B-3)$ yields

$$
\tau_{r \theta}=\frac{T}{2 \pi h r^{2}}
$$

The equation of state for a power law fluid can be written as

$$
\tau_{r \theta}=-m\left[r \frac{d}{d r}\left(v_{\theta} / r\right)\right]^{n}
$$

where ' $n$ ' is a dimensionless material characteristic parameter, and ' $m$ ' is a material characteristic parameter and has the units $\mathrm{gm} \mathrm{cm}^{-1} \mathrm{sec}^{-n}$ 
On combination, equations $(B-4)$ and $(B-5)$ give

$$
\frac{T}{2 \pi h r^{2}}=-m\left[r \frac{d}{d r}\left(v_{\theta} / r\right)\right]^{n}
$$

On integration, equation $(B-6)$ yields

$$
v_{\theta} / r=+(T / 2 \pi h m)^{1 / n} \cdot \frac{n}{2} \cdot r^{-2 / n}+c_{1}^{\prime}
$$

where $c_{1}$ ' can be evaluated by using the poundary condition

$$
\begin{aligned}
& v_{\theta}=0 \quad \text { at } r=r_{2} \\
& c_{1}^{\prime}=-(T / 2 \pi h m)^{l / n} \cdot \frac{n}{2} \cdot r_{2}^{-2 / n}
\end{aligned}
$$

Substitutirg the value of $C_{1}{ }^{\prime}$ in equation $(B-7)$, the result is

$$
v_{\theta} / r=(T / 2 \pi h m)^{1 / n} \cdot \frac{n}{2} \cdot\left(r^{-2 / n}-r_{2}^{-2 / n}\right) .
$$

Using the cther boundary condition.

$$
v_{\theta} / r=\omega \text { at } r=r_{1}
$$

equation (B-9) yields

$$
\omega=(T / 2 \pi h m)^{1 / n} \cdot \frac{n}{2}^{n} \cdot\left(r_{1}-2 / n-r_{2}{ }^{-2 / n}\right)
$$

Equation $(B-10)$ can now be used to evaluate the parameters ' $m$ ' and ' $n$ ' from torque-angular velocity data.

For a Newtonian fluid, equation $(B-10)$ reduces to

$$
\omega=\frac{T}{4 \pi h \mu_{0}}\left(r_{1}{ }^{-2}-r_{2}^{-2}\right)
$$

where $\mu_{0}$ is the Newtonian viscosity (absolute). 
APPENDIX C: 
TABLE ;

CHEMICAL ANALYSIS (TYPICAL) OF SILICA

\begin{tabular}{l|lll}
\hline Item & IMSIL & IMSIL & IMSIL \\
& A-25 & A-15 & A-10 \\
\hline Silca $\left(\mathrm{SiO}_{2}\right)$ & $99.0 \%$ & $99.0 \%$ & $99.0 \%$ \\
Iron Oxide $\left(\mathrm{Fe}_{2} \mathrm{O}_{3}\right)$ & $0.025 \%$ & $0.025 \%$ & $0.025 \%$ \\
Titanium 0xide $\left(\mathrm{TiO}_{2}\right)$ & $0.005 \%$ & $0.005 \%$ & $0.005 \%$ \\
Aluminium 0xide $\left(\mathrm{Al}_{2} \mathrm{O}_{3}\right)$ & $0.009 \%$ & $0.009 \%$ & $0.009 \%$ \\
Calcium 0xide $\left(\mathrm{CaO}_{3}\right)$ & $0.15 \%$ & $0.15 \%$ & $0.15 \%$ \\
Magnesium 0xide $(\mathrm{MgO})$ & $0.008 \%$ & $0.008 \%$ & $0.008 \%$ \\
Lossi on Ignition & $0.30 \%$ & $0.30 \%$ & $0.30 \%$ \\
\hline
\end{tabular}

a Specified in manufacturer's brochure 


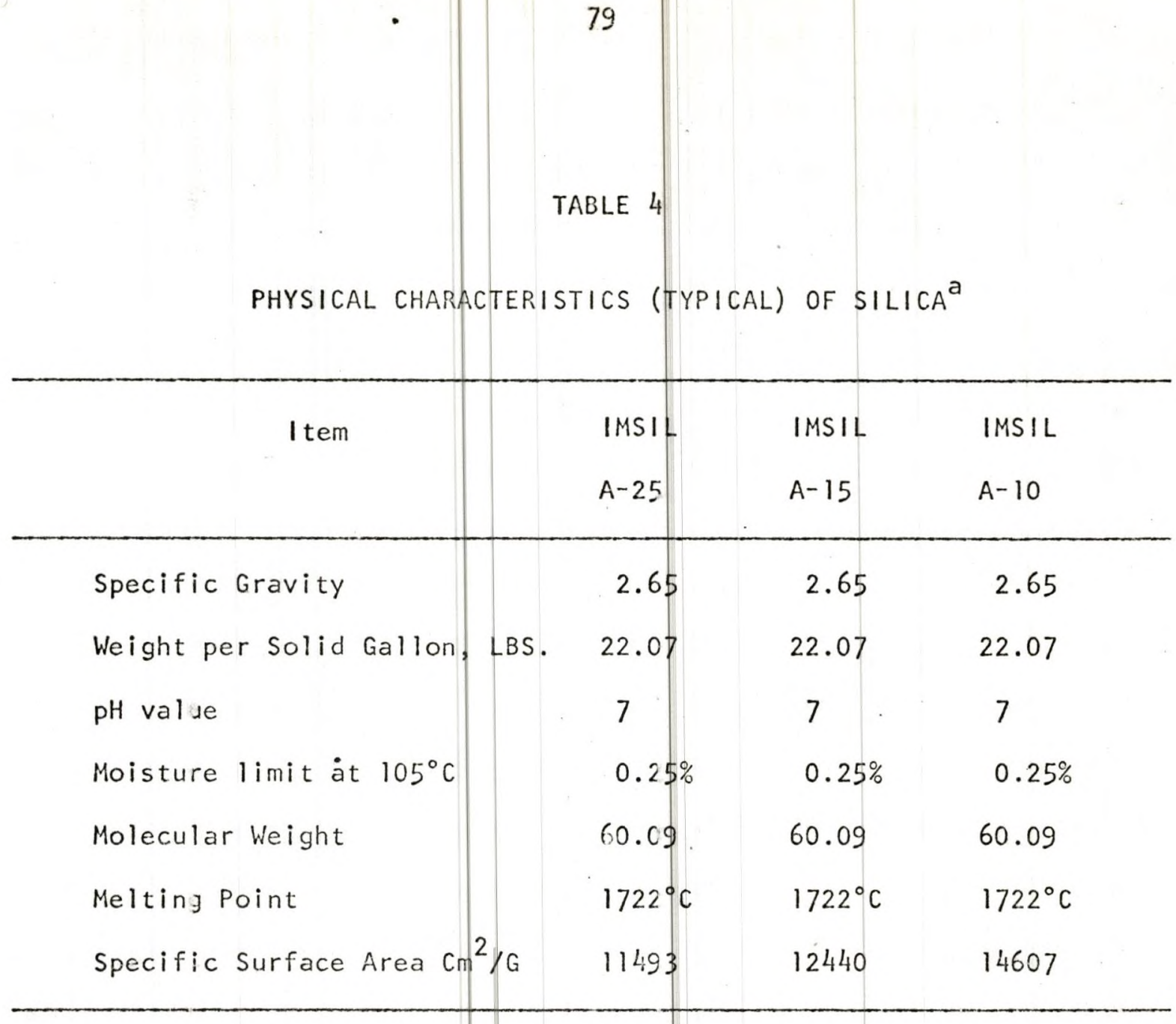

aspecified in manufacturer's brochure 
TABLE 5

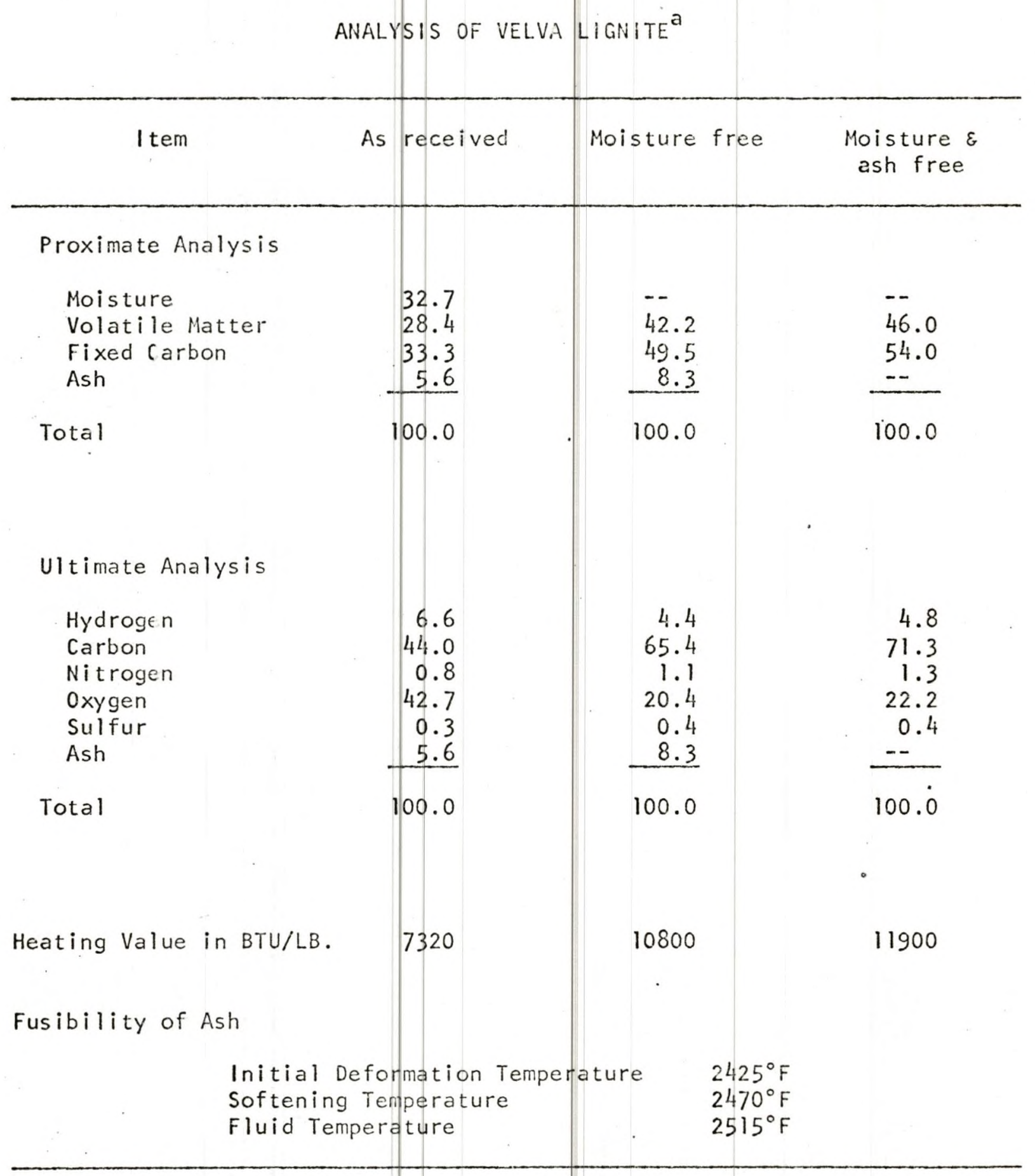

a Run by U.S. Bureau of Mines Laboratory at Pittsburgh 


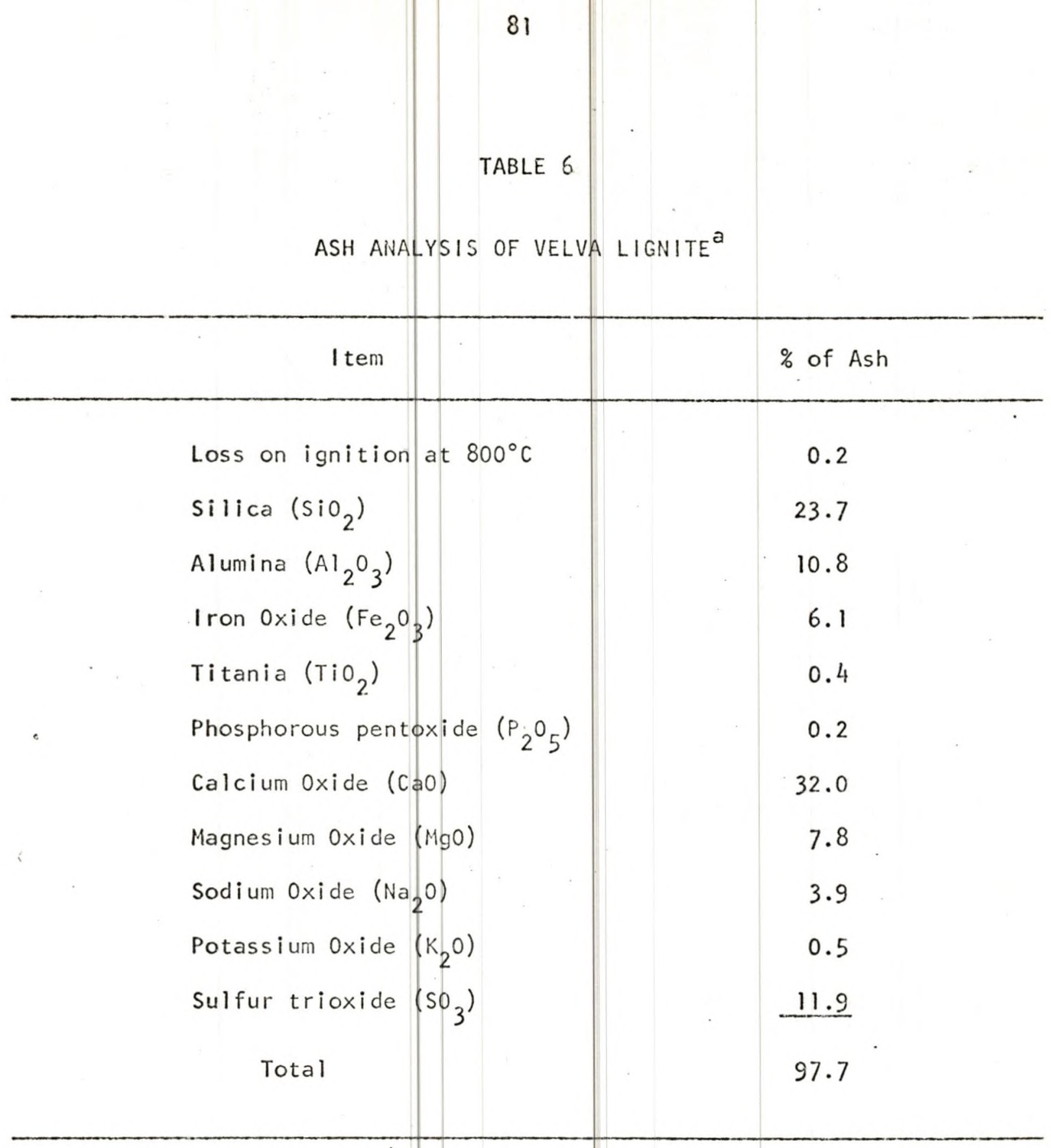

a Run by U.S. Bureau of Mines Laboratory at Grand Forks 


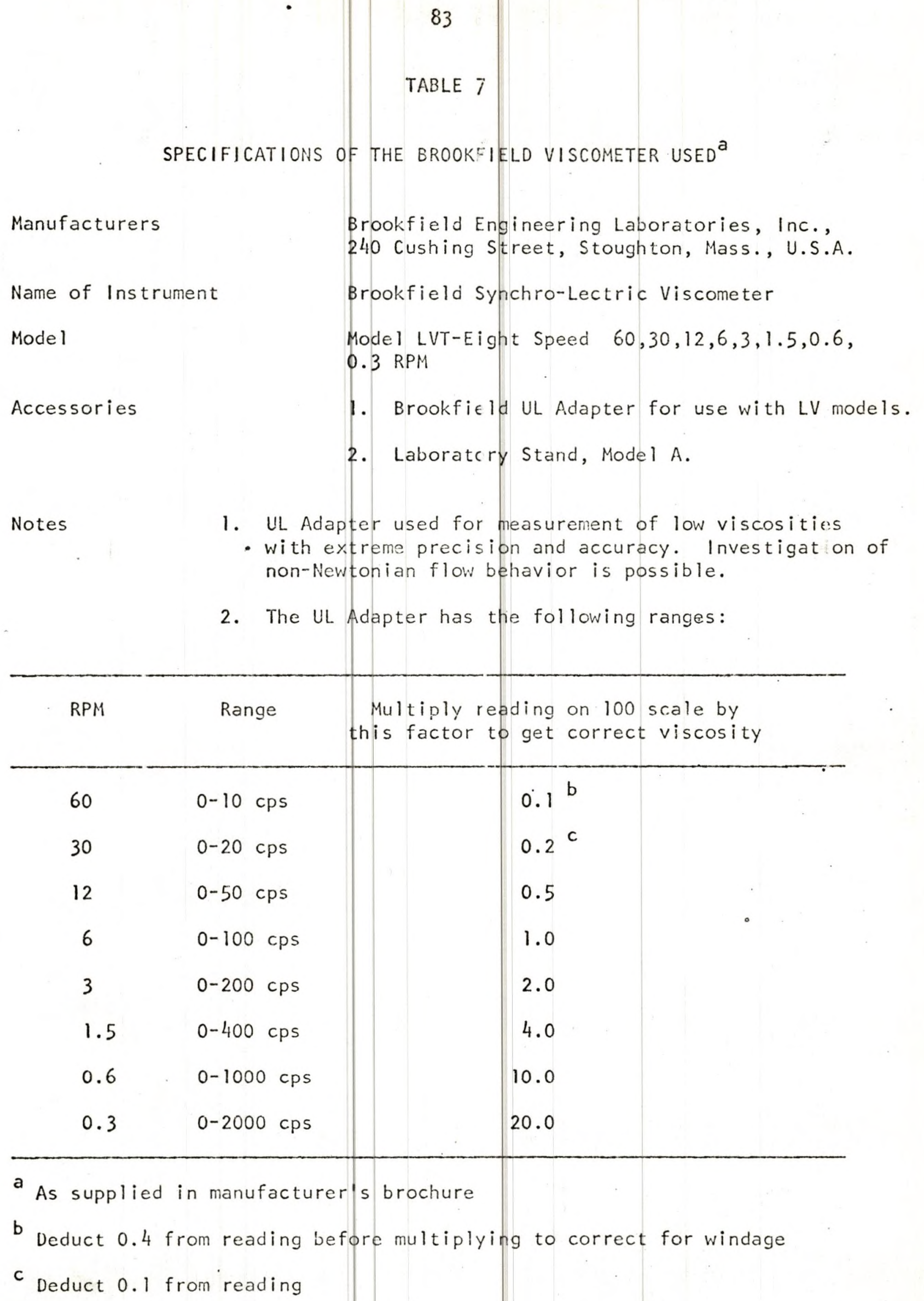


Name of instrument

Manufacturer

TABLE \&

STANDARD ZETA-METER SPECIFICATIONS ${ }^{a}$

Zeta-Meter

Zeta-Meter, Inc., 1720 First Avenue, New York, N. Y. 10028, U.S.A.

\section{A "Standard ZETA-METER" consists of the following items:}

1. Zeta-Mecer

a. Electrical input - $110-120 \mathrm{~V}, 60$ cycle, AC, 100 watts.

b. Output - continuously variable, 0 to $300 \mathrm{~V} D C$, 0 to $100 \mathrm{ma}, 0$ to $30 \mathrm{w}$.

c. Voltmeter and Ammeter - accuracy, $1 \%$ full scale, $4.6^{\prime \prime}$ scale, knife-edge pointer, mirror backed. Ammeter to $100,000 \mathrm{micro-amps}$ in four stages.

d. Electric Timer-micro-switch operated, 0 to 999.9 seconds in tenths.

e. Fuses - both $A C$ and $D C$ circuits.

f. DC Polarity - reversible by quick-acting lever swi ich.

g. DC Terminals - binding posts and cables with insulated clips.

h. Cabinet-size $18-1 / 4^{\prime \prime} \times 8-1 / 4^{\prime \prime} \times 9-1 / 2^{\prime \prime}$ high - equipped with carrying handle.

2. Cell llluminator

a. Adjustable type - jack-knife positioner.

b. Lamps - GE No. 1493.

c. Lenses - focus to $3 / 16^{\prime \prime}$ diameter beam.

d. Filters - one blue-glass and one heat-retarding.

e. Voltage - continuously variable, 0 to $10 \mathrm{~V}, 4$ Amp. max.

3. Stereoscopic Microscope

a. Precision grade, inclined binocular body, factory adjusted to the ZETA-METER cell.

b. Eye Pieces - 15X wide field, matched and coated, and eyeshields.

c. Paired Objectives $-4 x, 6 x, 8 x$ on revolving nosepiece.

d. Magnification - 60X,90x,120X.

e. Visible particle size - 0.2 to 1 micron and larger, depending upon shape and reflective properties of the colloid.

f. Mechanical Stage - designed for the ZETA-METER electrophoresis cell, integrally attached.

a As supplied in Zeta-Meter Manual (28). 
TABLE 8--Continued

g. Ocular Micrometer - designed for ZETA-METER electrophoresis cell (Tracking lengths for the standard scale are $120,160 \& 240$ microns). Quarter scale micrometers have scale lengths of 30,40 and $60 \mathrm{microns}$.

h. Portable carrying case.

4. Electrophoresis Cell and Components

a. New Circular Tube Type - can be emptied, cleaned and refilled in l'.

b. Effective length of cell $-10.00 \mathrm{~cm}$., precision reamed and polished.

c. Tube diameter approx. 4.40 millimeters.

d. Cell holder - polished plate-glass with electroplated silver backing - $3 / 4^{\prime \prime}$ thick.

e. Method of Illumination - reflected beam of intense blue-white light projected upward at an angle of approx. $50^{\circ}$.

f. Electrodes - iridium hardened platinum: one strip-type and one closed-tube type, for use with systems with a specific conductance not exceeding $1000 \mathrm{micromhos} / \mathrm{cm}$. (A special Molybdenun anode is included for higher SC values.)

g. Electrophoretic Mobility range - zero to the highest existing.

h. Specific Conductance range - 0 to $100,000 \mathrm{micromhos} / \mathrm{cm}$. at no dilution.

i. Time required to determine EM, ZP and SC - about 5 minutes.

j. Accuracy of ZP determination - approx. \pm 1 or 2 millivolts, depending upon the ZP of the colloid, and the particle charge cistribution of the system. 
APPENDIX E: 


\section{7}

TABLE 9

SAMPLE DATA FOR A FARTICULAR RUN

Suspension of $A-10$ Silica in water

$\mathrm{pH}=4.0$

Volume fraction of solids $=0.15$

Apparent Viscosity Measurements:

\begin{tabular}{|c|c|c|c|c|}
\hline RPM & Scale Reading & $\begin{array}{r}\text { Apparent Visco } \\
\text { Centipoises }\end{array}$ & $\begin{array}{l}\text { Mean } \\
\text {. }\end{array}$ & $\begin{array}{l}\text { Apparent Viscosity } \\
\text { Centipoises. }\end{array}$ \\
\hline $\begin{array}{l}60 \\
60 \\
60 \\
60 \\
60\end{array}$ & $\begin{array}{l}56.6 \\
56.4 \\
56.5 \\
56.6 \\
56.4\end{array}$ & $\begin{array}{l}5.62 \\
5.60 \\
5.61 \\
5.62 \\
5.60\end{array}$ & & 5.61 \\
\hline $\begin{array}{l}30 \\
30 \\
30 \\
30 \\
30\end{array}$ & $\begin{array}{l}39.4 \\
39.4 \\
39.6 \\
39.2 \\
39.4\end{array}$ & $\begin{array}{l}7.86 \\
7.86 \\
7.90 \\
7.82 \\
7.86\end{array}$ & & 7.86 \\
\hline $\begin{array}{l}12 \\
12 \\
12 \\
12 \\
12\end{array}$ & $\begin{array}{l}28.0 \\
27.8 \\
28.1 \\
28.2 \\
27.9\end{array}$ & $\begin{array}{l}14.00 \\
13.90 \\
14.05 \\
14.10 \\
13.95\end{array}$ & & 14.00 \\
\hline $\begin{array}{l}6 \\
6 \\
6 \\
6 \\
6\end{array}$ & $\begin{array}{l}23.2 \\
23.2 \\
23.2 \\
23.2 \\
23.2\end{array}$ & $\begin{array}{l}23.2 \\
23.2 \\
23.2 \\
23.2 \\
23.2\end{array}$ & & 23.20 \\
\hline
\end{tabular}




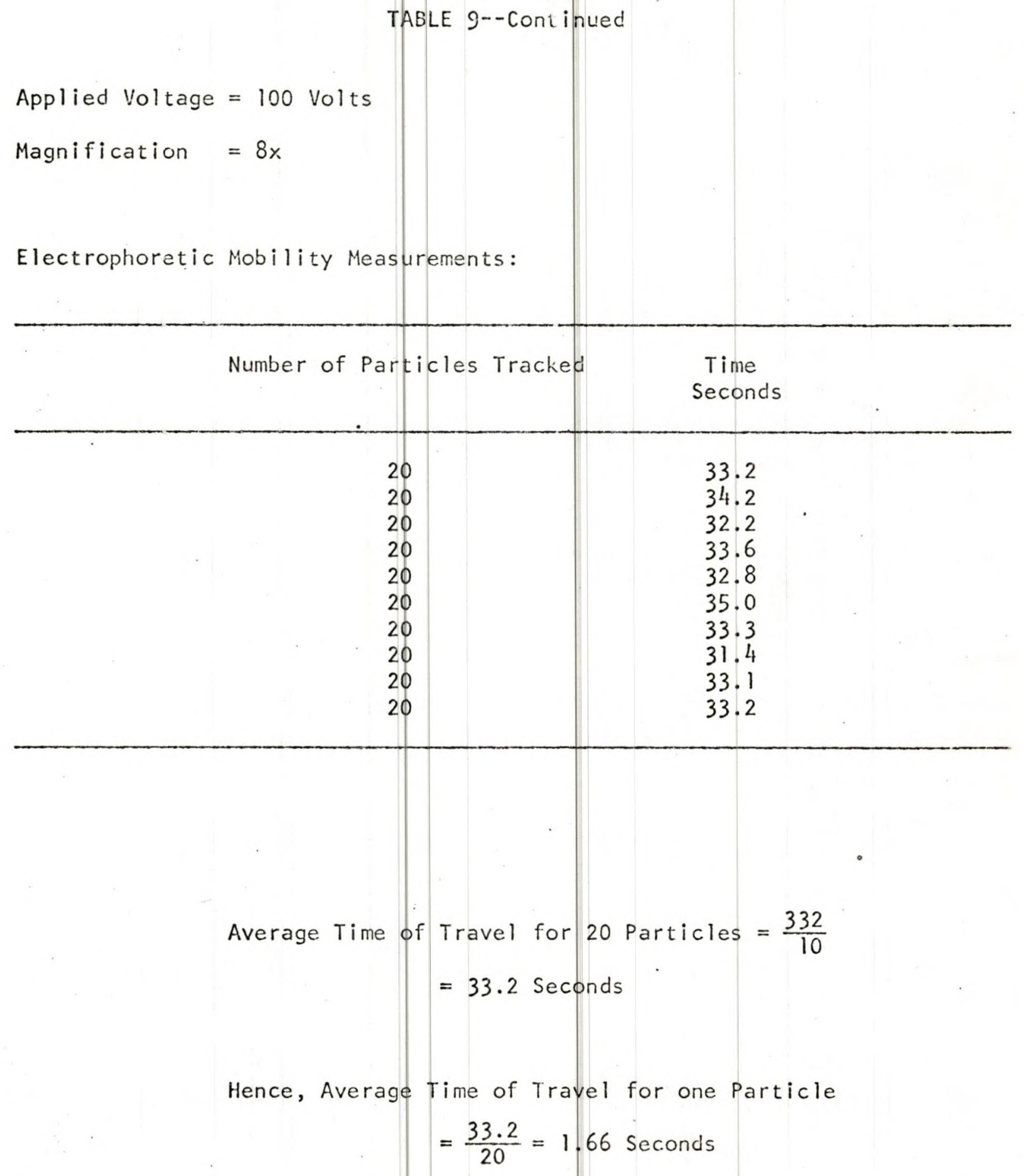




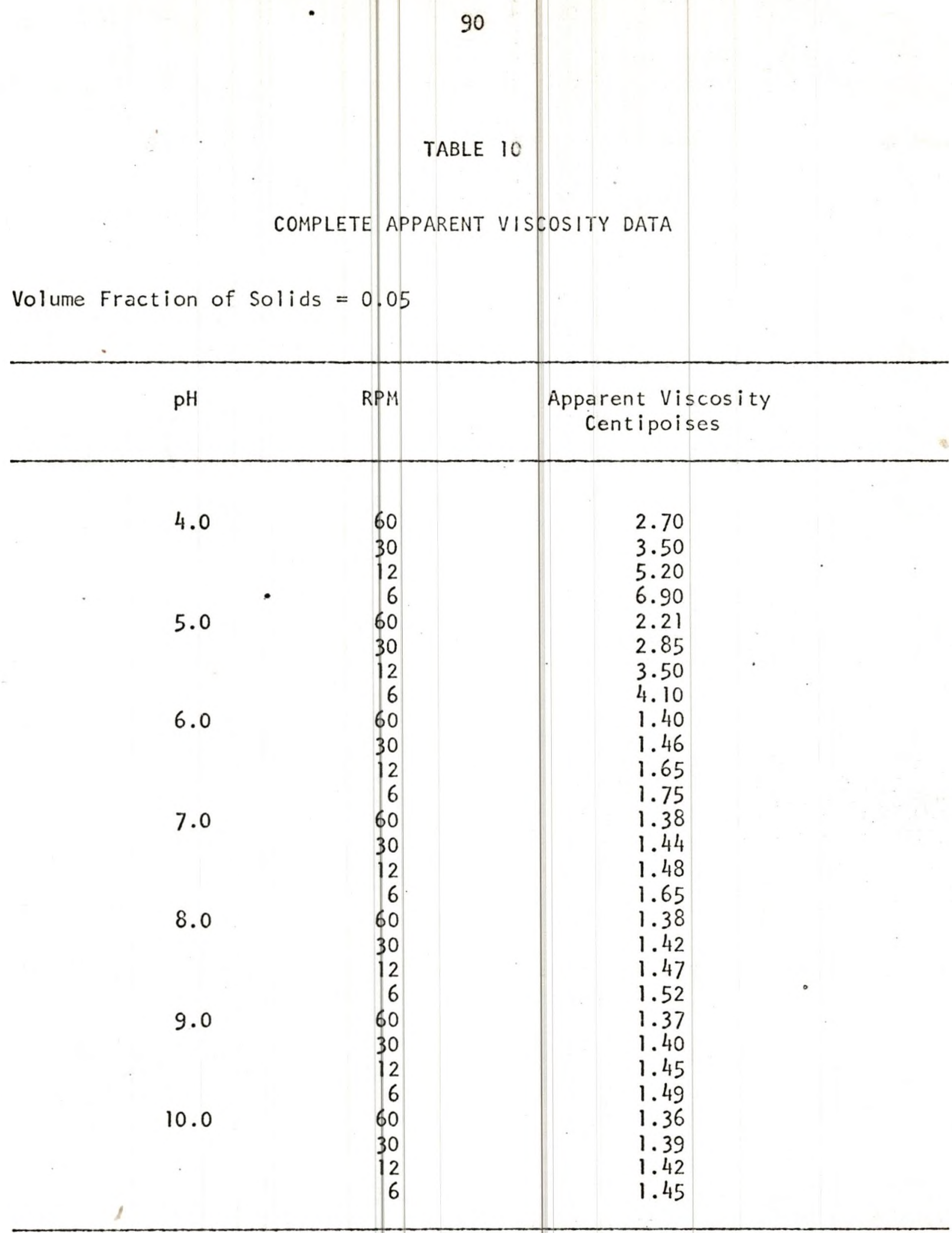


TABLE 10--Continued

Volume Fraction of Solids $=0,10$

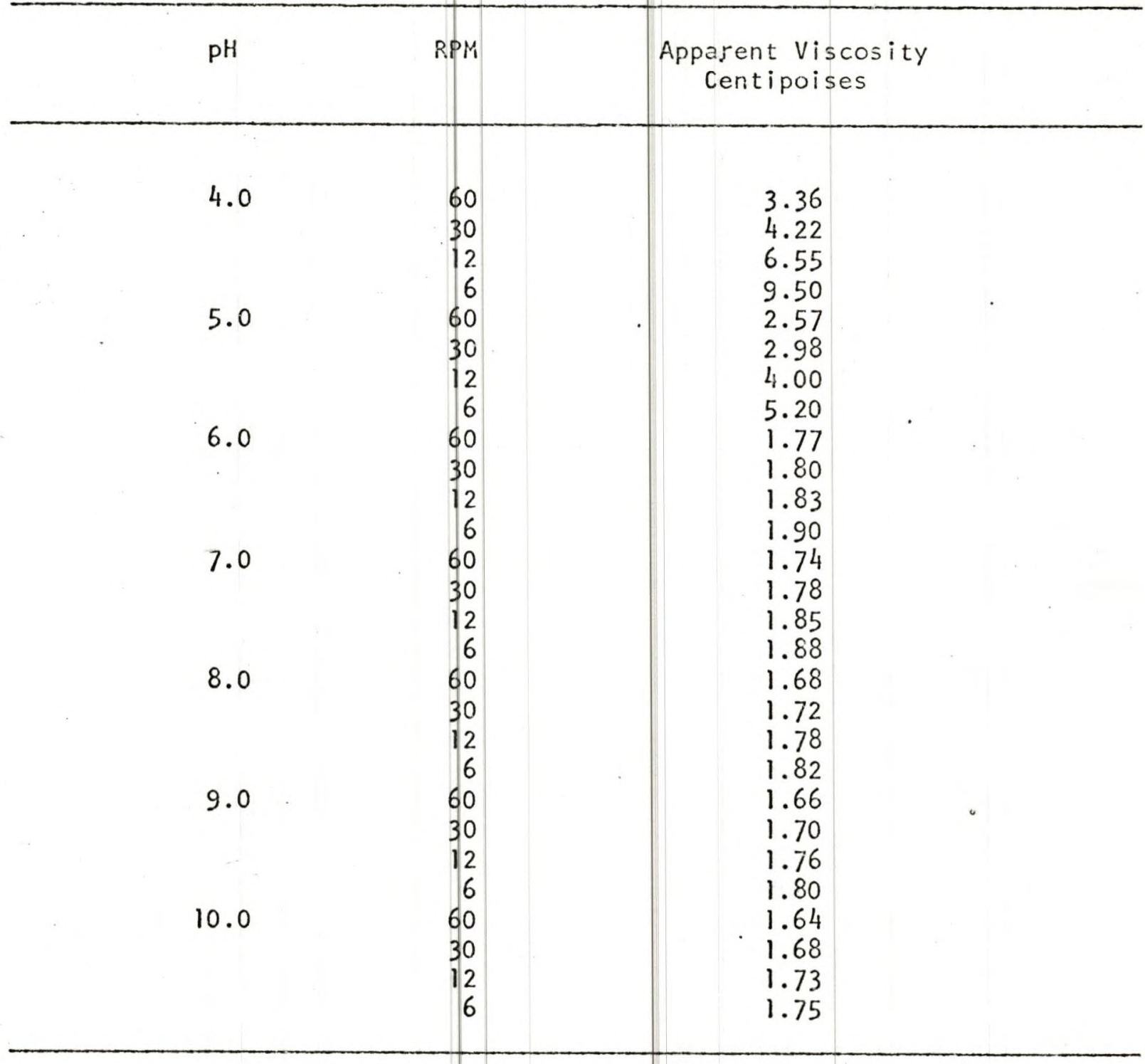


TABLE 10--Continued

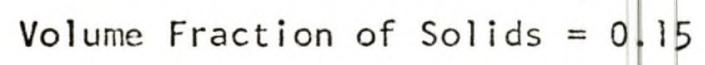

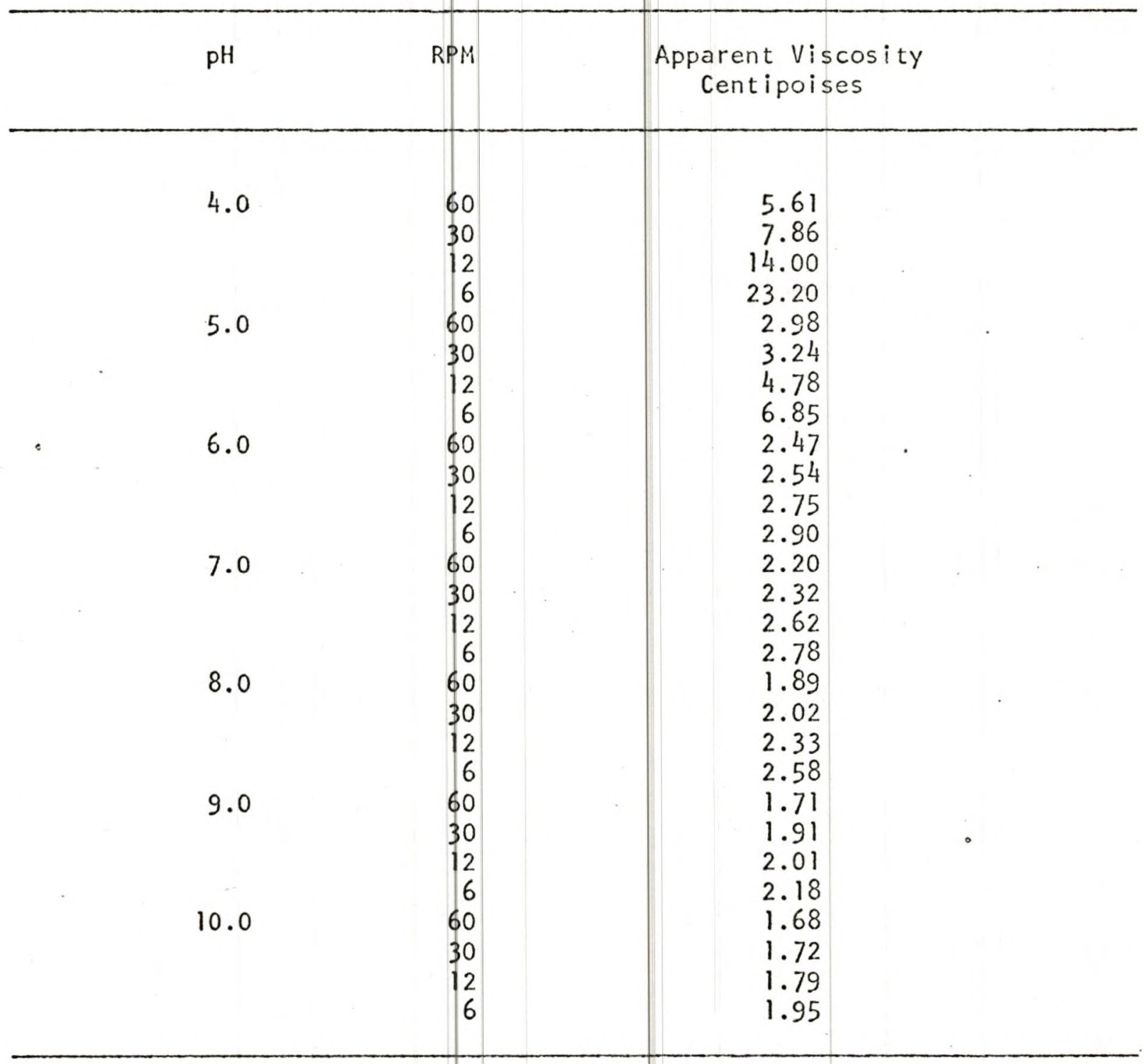


TABLE 10--Continued

Volume Fraction of Solids $=0.20$

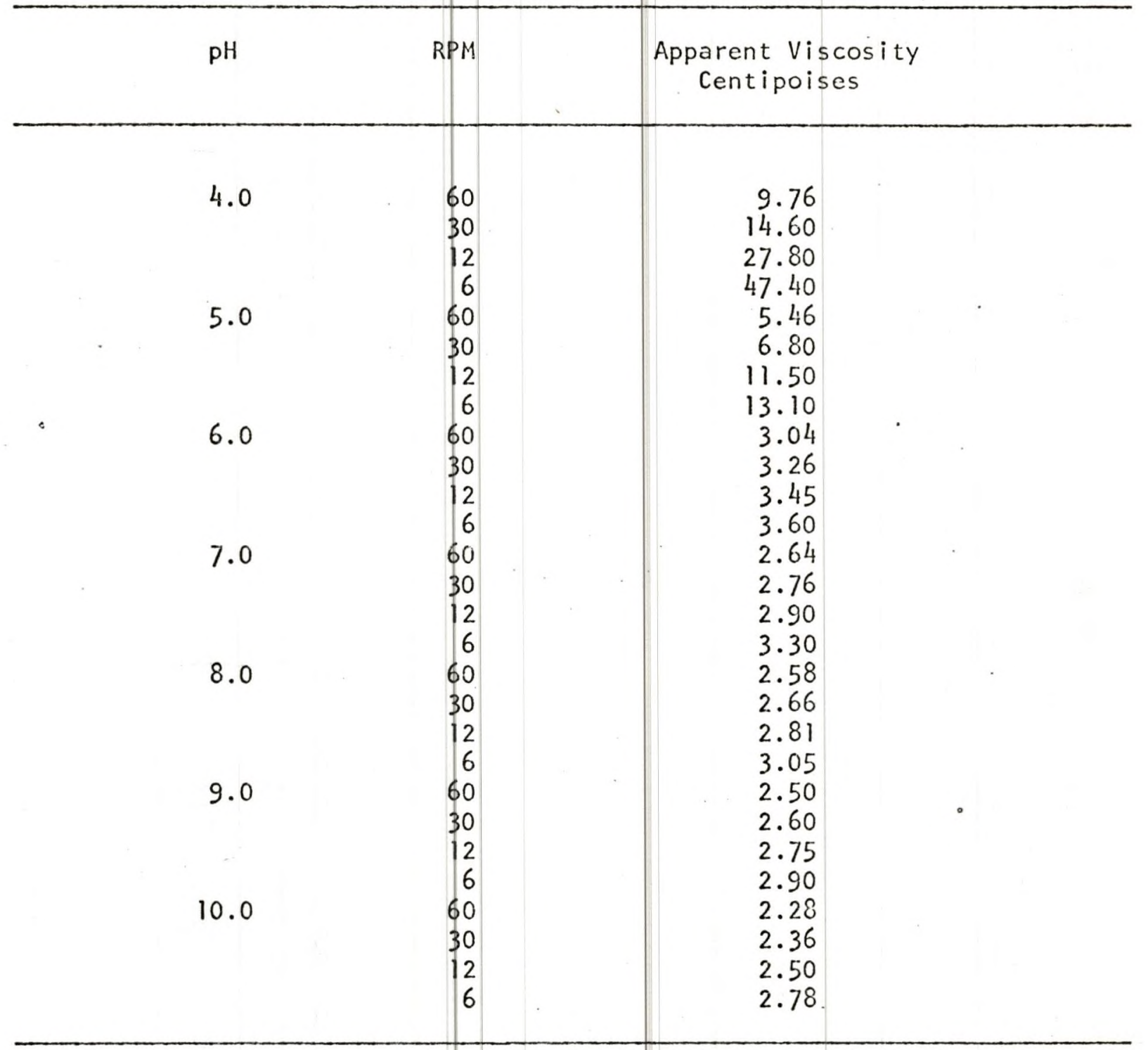


TABLE 10--Ccntinued

Volume Fraction of Solids $=0.25$

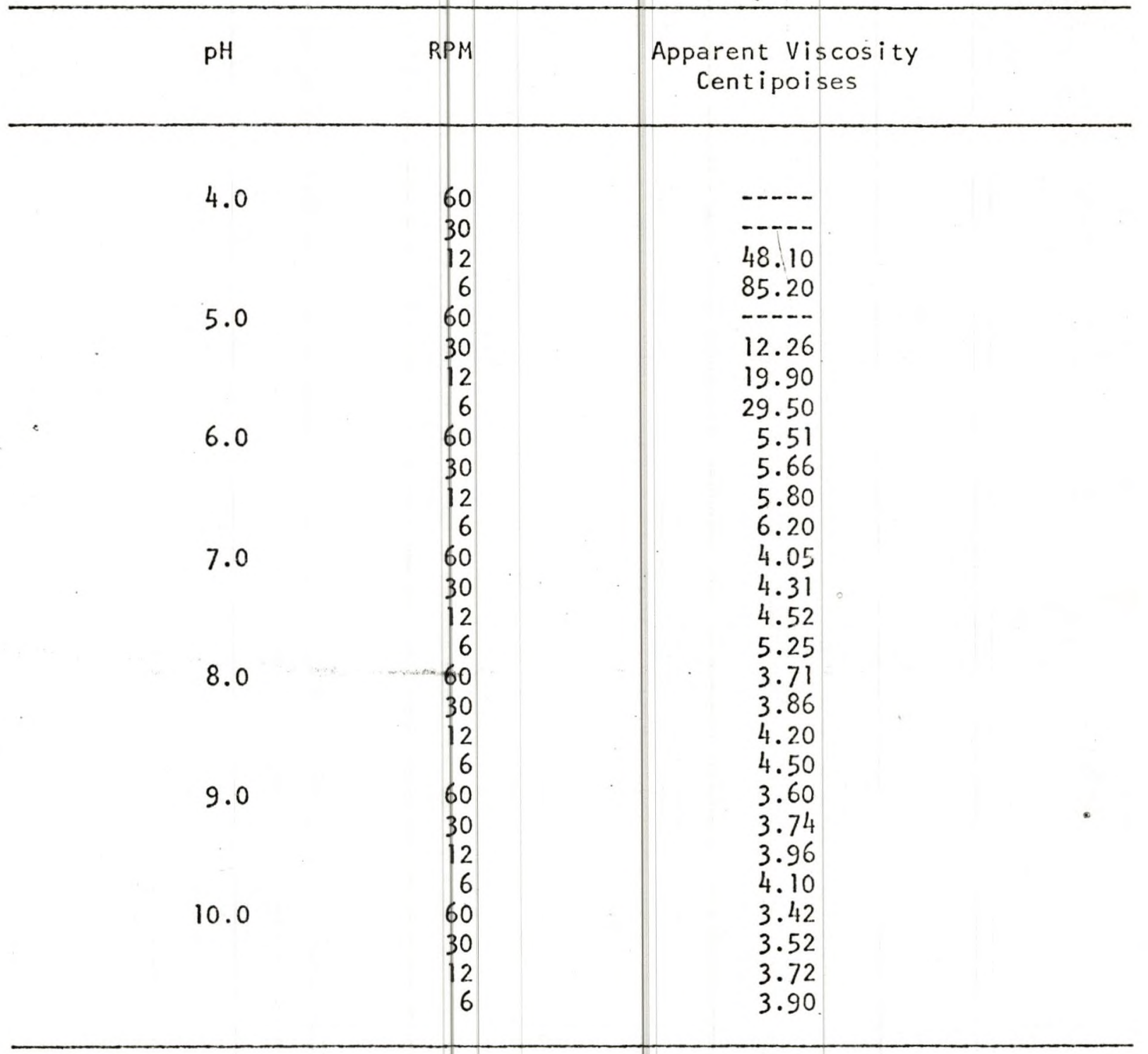


TABLE 10--Cortinued

Volume Fraction of Solids $=0.30$

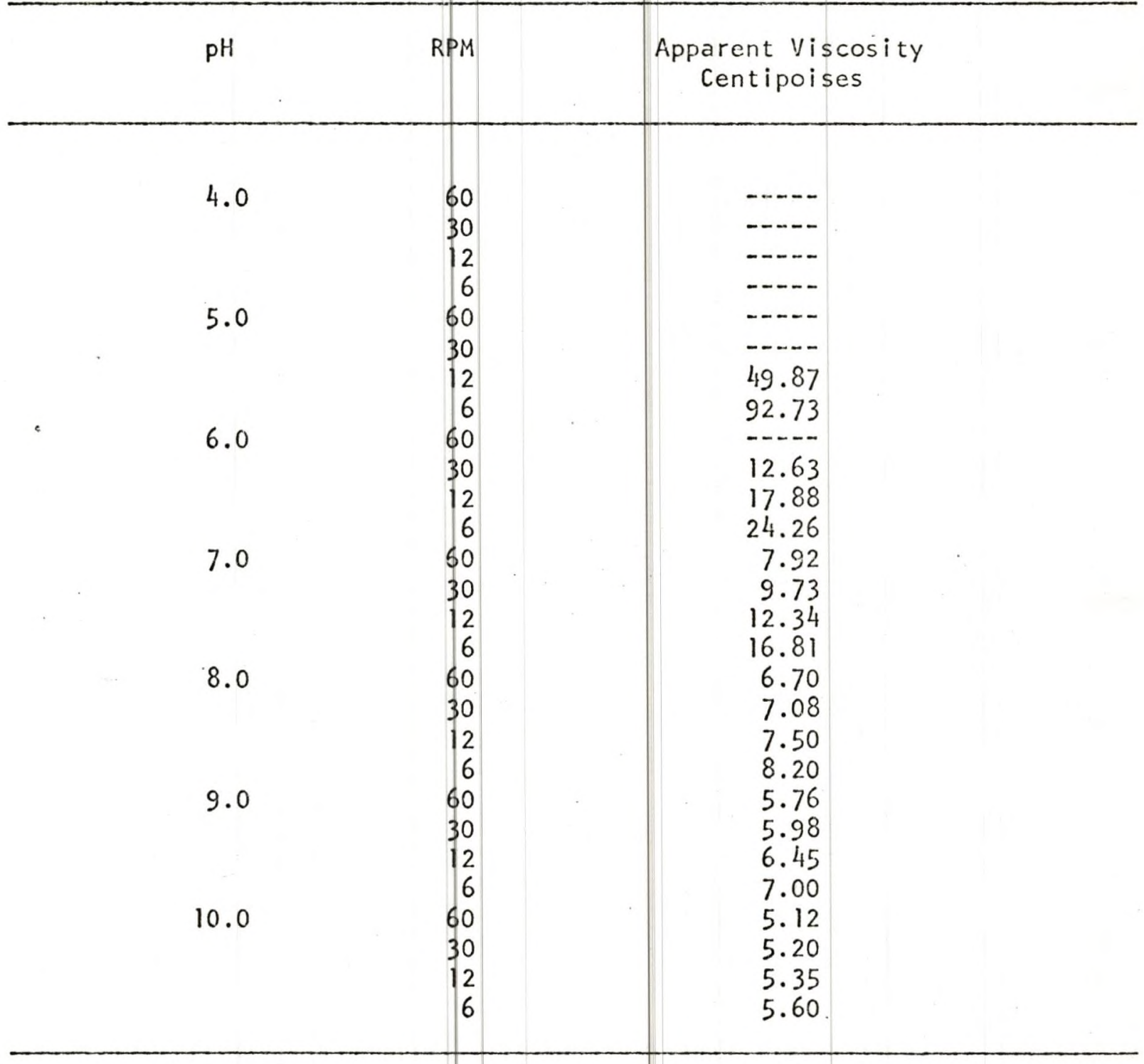




\section{AVERAGED ELECTROPHORETIC MOBILITY DATA}

Calculated Values of Zeta Potential and Electrophoretic Mobility for Different Values of $\mathrm{pH}$

\begin{tabular}{cc|c}
\hline $\mathrm{pH}$ & $\begin{array}{c}\text { Electrophoretic Mobility } \\
\text { Microns cm Volt }\end{array}$ & $\begin{array}{c}\text { Zeta Potential } \\
\text { sec } \\
\text { millivolts }\end{array}$ \\
\hline 4.0 & 7.23 & -102 \\
5.0 & 10.07 & -142 \\
6.0 & 12.55 & -177 \\
7.0 & 14.04 & -198 \\
8.0 & 14.89 & -210 \\
9.0 & 16.09 & -227 \\
10.0 & 18.72 & -264 \\
\hline
\end{tabular}




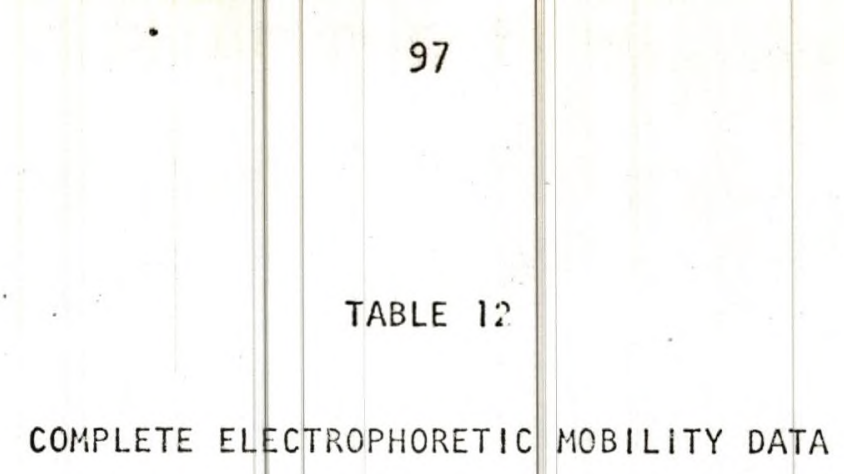

Electrophoretic Mobility Data for Different Solids Concentrations and $\mathrm{pH}$ $\phi=$ Volume Fraction of Solids

\begin{tabular}{|c|c|c|c|c|c|c|}
\hline $\mathrm{pH}$ & $\phi=0.05$ & $\begin{array}{l}\text { Electro } \\
\text { Microns } \\
\phi=0.10\end{array}$ & $\begin{array}{l}\text { horetic } \\
\mathrm{cm} \text { Volt } \\
\phi=0.15\end{array}$ & $\begin{array}{l}\sec ^{-1} \\
\phi=0.20\end{array}$ & $\phi=0.25$ & $\phi=0.30$ \\
\hline 4.0 & 7.28 & 7.25 & 7.18 & 7.27 & 7.21 & 7.19 \\
\hline 5.0 & 10.00 & 10.12 & 10.14 & 10.02 & 9.99 & 10.15 \\
\hline 6.0 & 12.52 & 12.57 & 12.58 & 12.55 & 12.55 & 12.53 \\
\hline 7.0 & 14.14 & 14.08 & 14.04 & 13.94 & 14.04 & 14.00 \\
\hline 8.0 & 14.81 & 14.87 & 14.89 & 14.97 & 14.85 & 14.89 \\
\hline 9.0 & 16.09 & 16.04 & 16.16 & 16.14 & 16.09 & 16.02 \\
\hline 10.0 & 18.72 & 18.82 & 18.72 & 18.79 & 18.62 & 18.65 \\
\hline
\end{tabular}




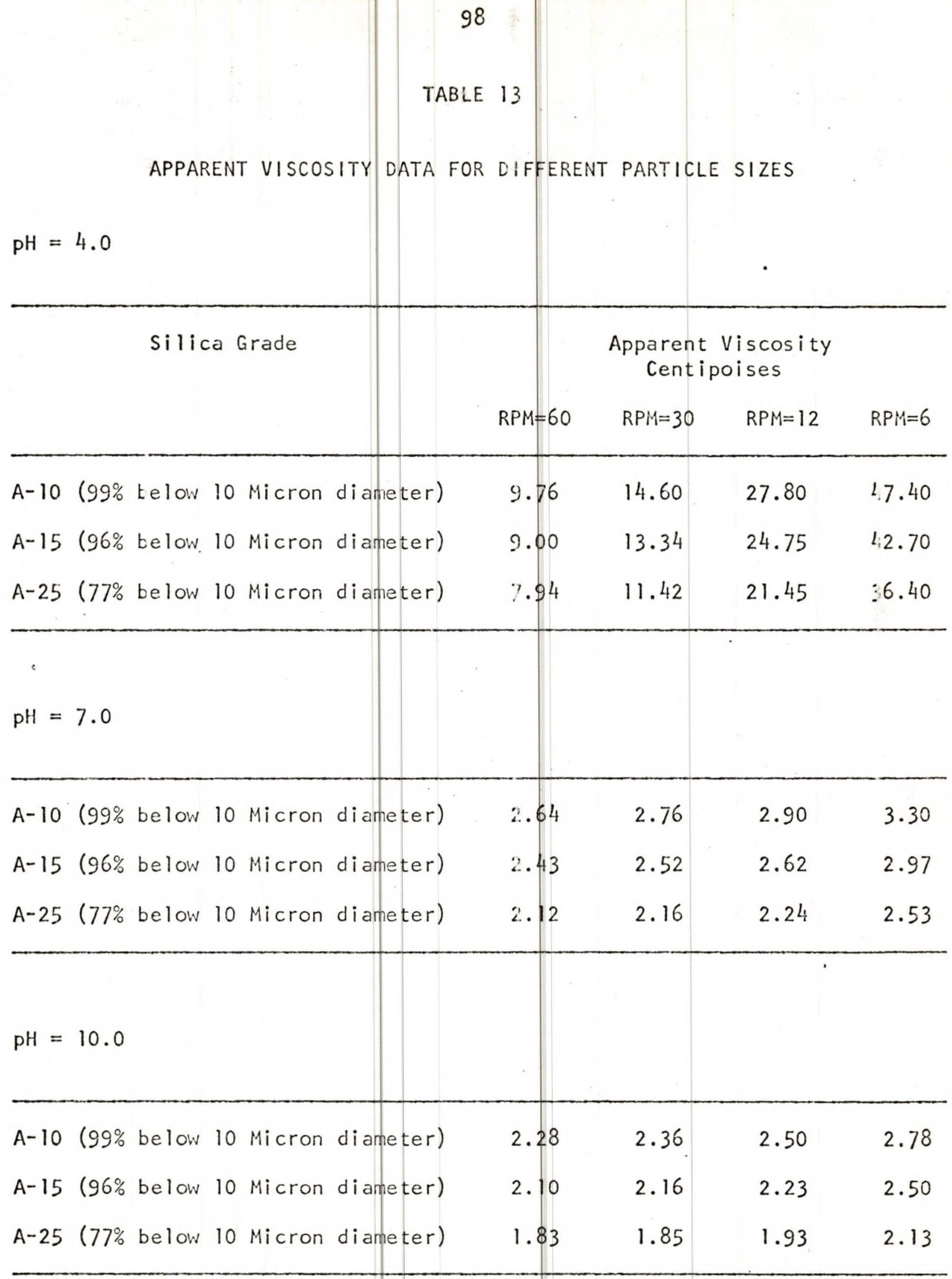




\section{0}

Electrophoretic Mobility

\section{SAMPLE CALCUI.ATIONS}

\section{From Table 9}

Average time of travel for one particle $=1.66$ seconds

Asplied Voltage $=100$ Volts

Magnification $=8 x$

Fron Table 8

Length of one micrometer division $=120 \mathrm{microns}$

Length of electrophoresis cell $=10 \mathrm{~cm}$

Henze,

Electrophoretic Mobility $=\frac{120 / 1.66}{100 / 10}$

Zeta Potential

In millivolts, the relationship between Zeta Potential and Electrophoretic Mobility is as follows (29):

$$
Z P=113,000 \frac{V t}{D t} \cdot E M
$$

where $V t=v i s c o s i t y$ of suspending medium at temperature $t$ and $D t=$ dielectric constant of suspending medium at temperature $t$

For the present case

$$
E M=7.23 \frac{\mathrm{microns} / \mathrm{sec}}{\text { Volt } / \mathrm{cm}}
$$




$$
\begin{aligned}
& V t=\text { viscosity of water at } 20^{\circ} \mathrm{C}=0.01 \text { poise } \\
& D t=\text { dielectric constant of water at } 20^{\circ} \mathrm{C}=80.0
\end{aligned}
$$

Hence,

$$
\begin{aligned}
\text { Zeta Potential } & =-113,000 \times \frac{0.01}{80.0} \times 7.23 \\
& =-102.0 \mathrm{millivolts}
\end{aligned}
$$

The negative sign indicates that the colloid is electronegatively charged.

Plastic Viszosity and Yield Stress

Froin Appendix $A$, equation $(A-12)$ is:

$$
\omega=\frac{T}{4 \pi h_{p}}\left(r_{1}{ }^{-2}-r^{-2}\right)+\frac{\tau_{0}}{\mu_{p}} \ln \frac{r_{1}}{r_{2}}
$$

which can be written as

$$
\omega=\frac{T}{4 \pi h \mu_{p}}\left(r_{1}^{-2}-r^{-2}\right)-\frac{\tau_{0}}{\mu_{p}} \ln \frac{r_{2}}{r_{1}}
$$

So, by using two values of $\omega$ and $T, \mu_{p}$ and $\tau_{0}$ can be determined.

If $T^{\prime}$ is the torque per unit height of cylinder, then

$$
\begin{aligned}
\mu_{p} & =\frac{T_{2}{ }^{\prime}-T_{1}^{\prime}}{\left(\omega_{2}-\omega_{1}\right) 4 \pi}\left(\frac{1}{r_{1}}-\frac{1}{r_{2}{ }^{2}}\right) \\
\text { and } \tau_{0} & \left.=\frac{\mu_{0}}{\frac{\ln \frac{r_{2}}{r_{1}}}{4 \pi \mu_{p}}}\left(\frac{T^{\prime}}{r_{1}{ }^{2}}-\frac{1}{r_{2}{ }^{2}}\right)-\omega\right] .
\end{aligned}
$$

First $T^{\prime}$ and $\omega$ are to be calculated. For $T$, we have equation (3.4).

from Chapter 3 as follows:

$$
T=\frac{4 \pi \mu_{a} h \omega}{\left(r_{1}^{-2}-r_{2}^{-2}\right)}
$$


So,

$$
T^{\prime}=\frac{4 \pi \mu_{a} a^{-2}}{\left(r_{1}^{-2}-r_{2}^{-2}\right)}
$$

where $\mu_{a}$ is the apparent viscosity.

Angular velocity can be calculated from the following equation:

$$
\begin{array}{rlrl}
\omega= & \frac{2 \pi R P M}{60} & \text { radians } \sec ^{-1} \\
\text { So, for } R P M & =60 & \omega=6.3 \text { radian } \mathrm{sec}^{-1} \\
R P M & =30 & \omega & \omega .1 \text { radian } \mathrm{sec}^{-1} \\
\mathrm{RPM} & =12 & \omega & \omega \\
\mathrm{RPM} & =6 & \omega & \omega
\end{array}
$$

Now, $T^{\prime}$ can be calculated since $r_{1}$ and $r_{2}$ are known

$$
\begin{aligned}
& r_{1}=1.25 \mathrm{~cm} \\
& r_{2}=1.40 \mathrm{~cm} \\
& \left(r_{1}^{-2}-r_{2}^{-2}\right)=0.1298 \mathrm{~cm}^{-2} \\
& \text { So, for RPM }=60 \quad \omega=6.3 \text { radians } \sec ^{-1} \quad \mu_{a}=0.0561 \text { poise } \\
& T^{\prime}=\frac{4 \times \pi \times 0.0561 \times 6.3}{0.1298} \mathrm{gm} \mathrm{cm} \\
& =34.1 \mathrm{gm} \mathrm{cm} \\
& \text { Similarly, } \\
& \text { for } \mathrm{RPM}=30 \quad \omega=3.1 \frac{\mathrm{rad} .}{\mathrm{sec} .} \quad T^{\prime}=23.9 \mathrm{gm} \mathrm{cm} \\
& \text { for RPM }=12 \quad \omega=1.3 \frac{\mathrm{rad} .}{\mathrm{sec} .} \quad T^{\prime}=17.1 \mathrm{gm} \mathrm{cm} \\
& \text { for RPM = } \quad \quad \omega=0.63 \frac{\mathrm{rad} .}{\mathrm{sec} .} \quad T^{\prime}=14.1 \mathrm{gm} \mathrm{cm}
\end{aligned}
$$

This data for torque-angular velocity has been plotted in

Figure 5 on page 31 . 
Now, for calculation of $H_{p}$
$T_{2}{ }^{\prime}=33.2 \mathrm{gm} \mathrm{cm}$ at $\omega=6.0 \mathrm{rad} . / \mathrm{sec}$.
$T_{1}{ }^{\prime}=20.0 \mathrm{gm} \mathrm{cm} \mathrm{at} \omega=2.0 \mathrm{rad} . / \mathrm{sec}$.

So,

$\mu_{p}=\frac{(33.2-20.0)}{(6-2) \times 4 \times \pi} \times 0.1298$ poise $=3.38$ centipoises

Now, for calculation of $\tau_{0}$

$T^{\prime}=26.6 \mathrm{gm} \mathrm{cm}$ at $\omega=4.0 \mathrm{r}$ dians $\mathrm{sec}^{-1}$

Also

$$
\ln \frac{r_{2}}{r_{1}}=\ln \frac{1.4}{1.25}=\frac{1}{5.4825}
$$

Hence

$$
\begin{aligned}
\tau_{0} & =\frac{0.0338}{\frac{1}{5.4825}}\left[\frac{26.6 \times 0.1298}{4 \pi \times 0.0338}-4.0\right] \\
& =0.71 \text { dynes } \mathrm{cm}^{-2}
\end{aligned}
$$

Parameters ' $m$ ' and ' $n$ ' for the power law model

Again, the $T^{\prime}$ versus $w$ data, calculated above, has been plotted on logarithmic coordinates in Figure 18 on page 46.

From Appendix $B$, equation $(B-10)$ is as follows:

$$
\omega=\left(\frac{T}{2 \pi m h}\right)^{1 / n} \cdot \frac{n}{2} \cdot\left(r_{1}^{-2 / n}-r_{2}^{-2 / n}\right)
$$

which can be written as

$$
\omega=\left(\frac{T^{\prime}}{2 m}\right)^{1 / n} \cdot \frac{n}{2} \cdot\left(r_{2}-2 / n-r_{1}^{-2 / n}\right)
$$

Taking $\log$ on both sides

$$
\begin{aligned}
\log \omega & =\frac{1}{n} \log \frac{T^{\prime}}{2 \pi m}+\log \frac{n}{2}+\log \left(r_{2}^{-2 / n}-r_{1}^{-2 / n}\right) \\
\text { or } \log \omega & =\frac{1}{n} \log T^{\prime}+c
\end{aligned}
$$


where

$c=-\frac{1}{n} \log 2 \pi m+\log \frac{n}{2}+\log \left(r_{1}-2 / n-r_{2}^{-2 / n}\right)$

So, a plot of $\log \omega$ versus $\log T^{\prime}$ should have a slope of $1 / n$ and intercept $C$ on the $\log w$ axis from which ' $m$ ' and ' $n$ ' can be calculated.

Now, making use of Figure 18 on page 46

$$
n^{\prime}=0.370
$$

Now, picking the point on the straight line at $\omega=4.8 \mathrm{rads} . / \mathrm{sec}$.

$$
\begin{aligned}
& \log 4.8=\frac{1}{0.37} \log 32+c \\
& c=-3.3738
\end{aligned}
$$

Hence

$$
\begin{aligned}
& -3.3738=\frac{-1}{0.37} \log 2 \pi \mathrm{m}+\log \frac{0.37}{2} \\
& +\log \left[(1.25)^{-2 / 0.37}-(1.40)^{-2 / 0.37]}\right. \\
& \text { 'n }^{\prime}=0.363 \mathrm{gm} \mathrm{cm}^{-1} \mathrm{sec}^{-0.37}
\end{aligned}
$$


APPENDIX H 


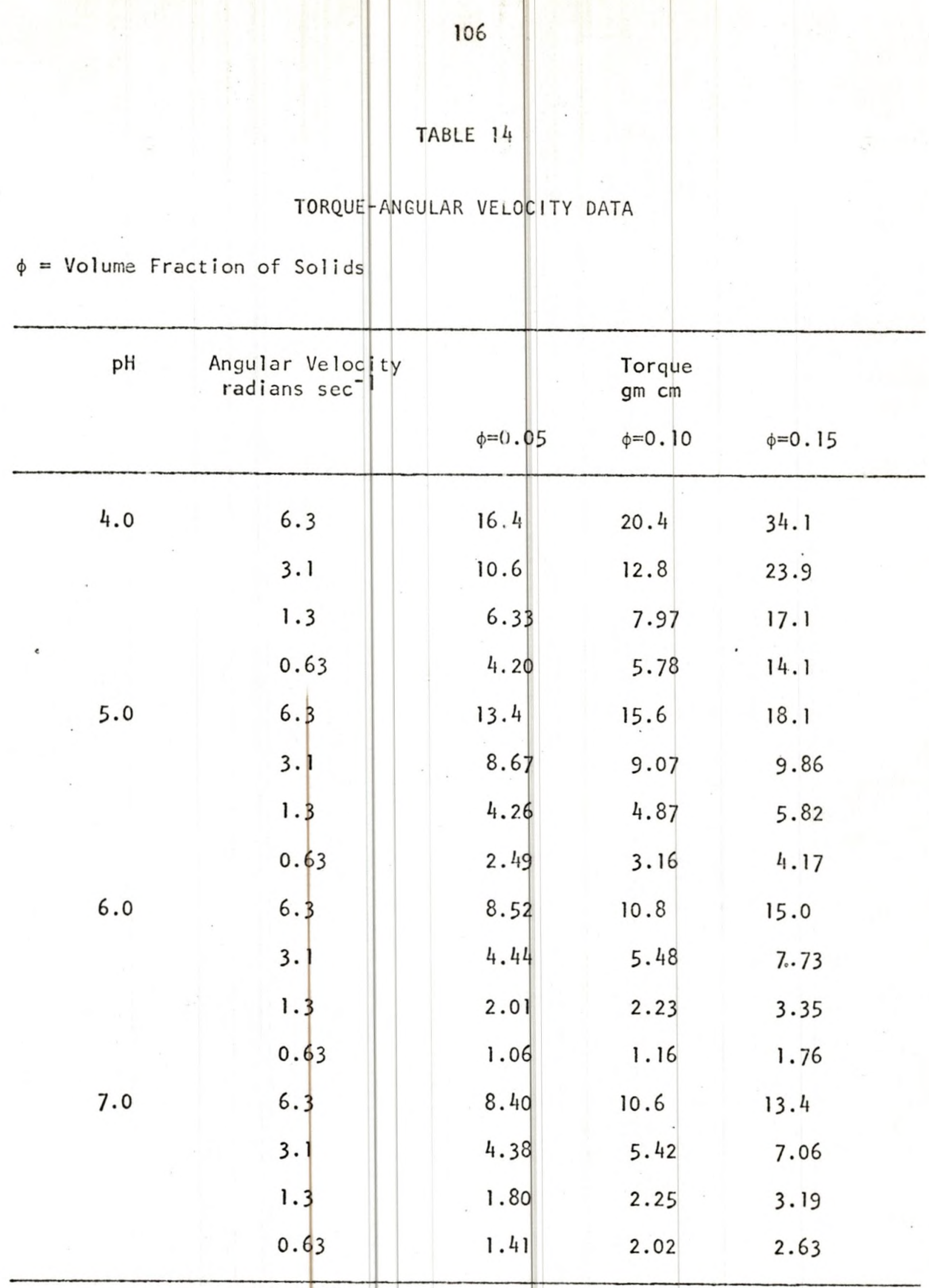


$\phi=$ Volume Fraction of Solids

TABLE 14--Continued

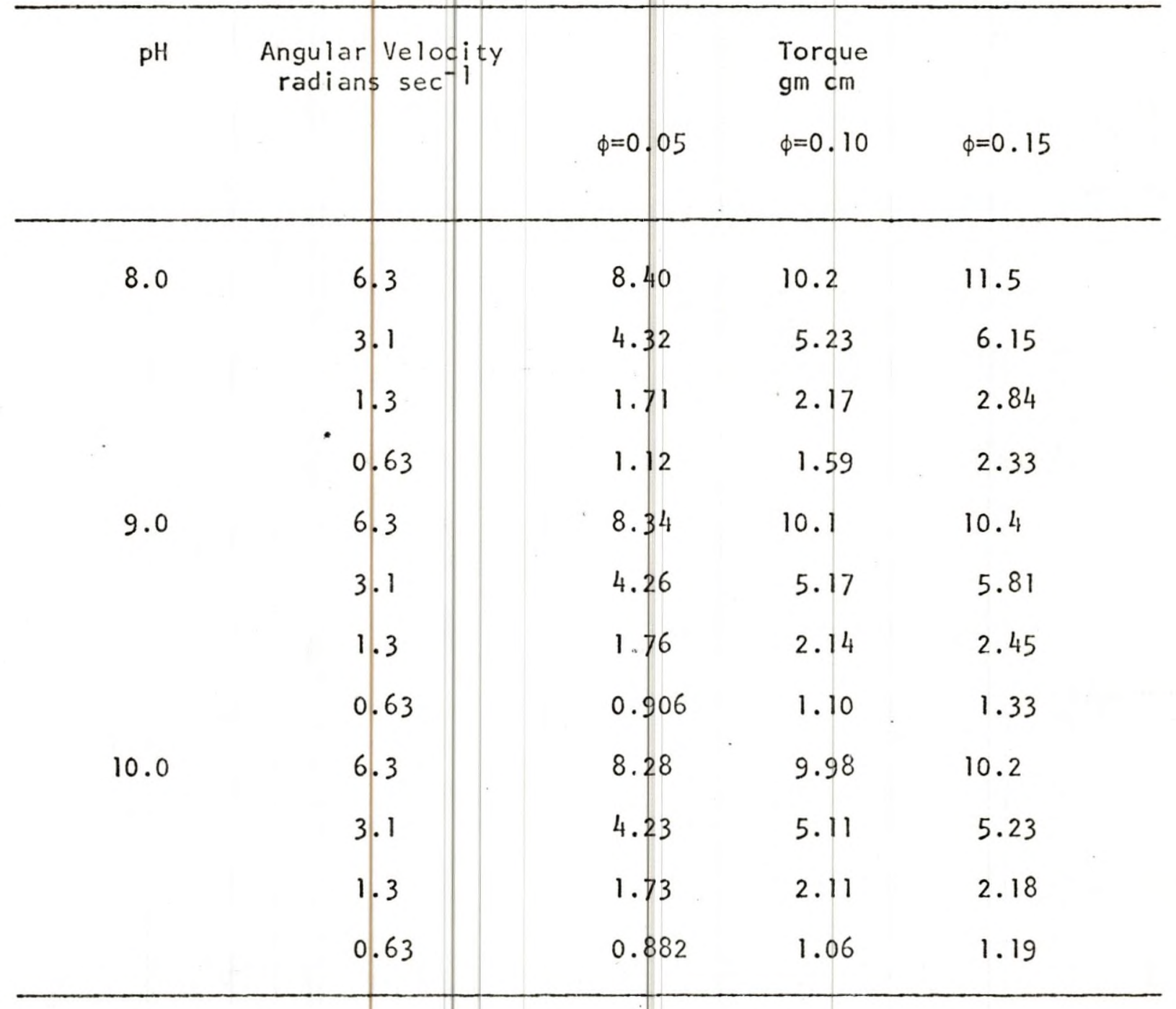


TABLE 14--Continued

$\phi=$ Volume Fraction of Solids

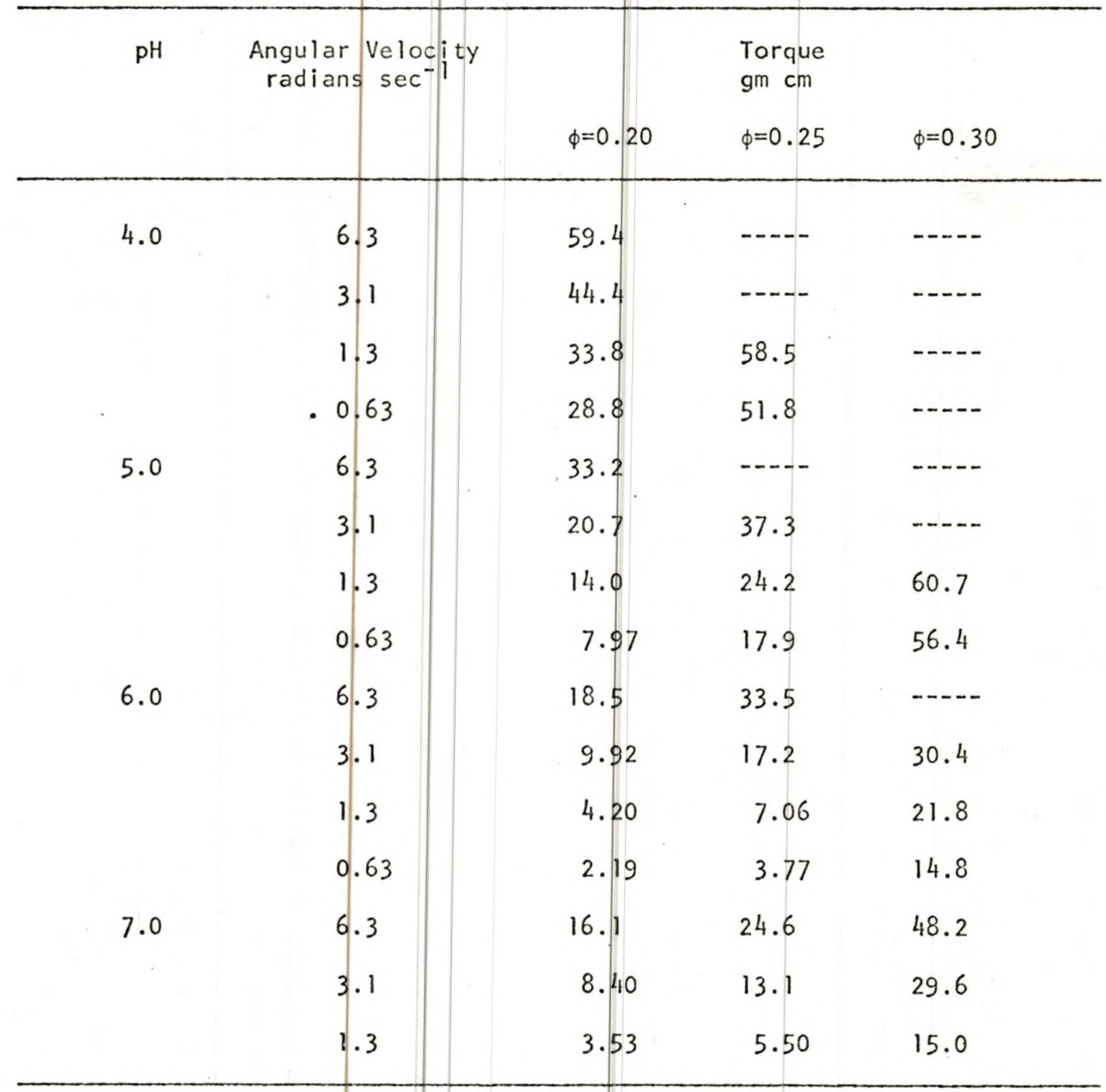


$\phi=$ Volume Fraction of Solids

TABLE 14--Continued

\begin{tabular}{|c|c|c|c|c|}
\hline $\mathrm{pH}$ & $\begin{array}{l}\text { Angular Veloci } \\
\text { radians } \sec ^{-1}\end{array}$ & ty & $\begin{array}{l}\text { Torque } \\
\mathrm{gm} \mathrm{cm}\end{array}$ & \\
\hline & & $\phi=0.20$ & $\phi=0.25$ & $\phi=0.30$ \\
\hline 8.0 & 6.3 & 15.7 & 22.6 & 40.8 \\
\hline & 3.1 & 8.09 & 11.7 & 21.5 \\
\hline & 1.3 & 3.42 & 5.11 & 9.13 \\
\hline & 0.63 & 1.86 & 2.74 & 4.99 \\
\hline 9.0 & 6.3 & 15.2 & 21.9 & 35.0 \\
\hline F & 3.1 & 7.91 & 11.4 & 18.2 \\
\hline & 1.3 & 3.35 & 4.82 & 7.85 \\
\hline & 0.63 & 1.76 & 2.50 & 4.26 \\
\hline 10.0 & 6.3 & 13.9 & 20.8 & 31.2 \\
\hline & 3.1 & 7.18 & 10.7 & 15.8 \\
\hline & 1.3 & 3.04 & 4.26 & 6.51 \\
\hline & 0.63 & 1.69 & 2.37 & 3.41 \\
\hline
\end{tabular}




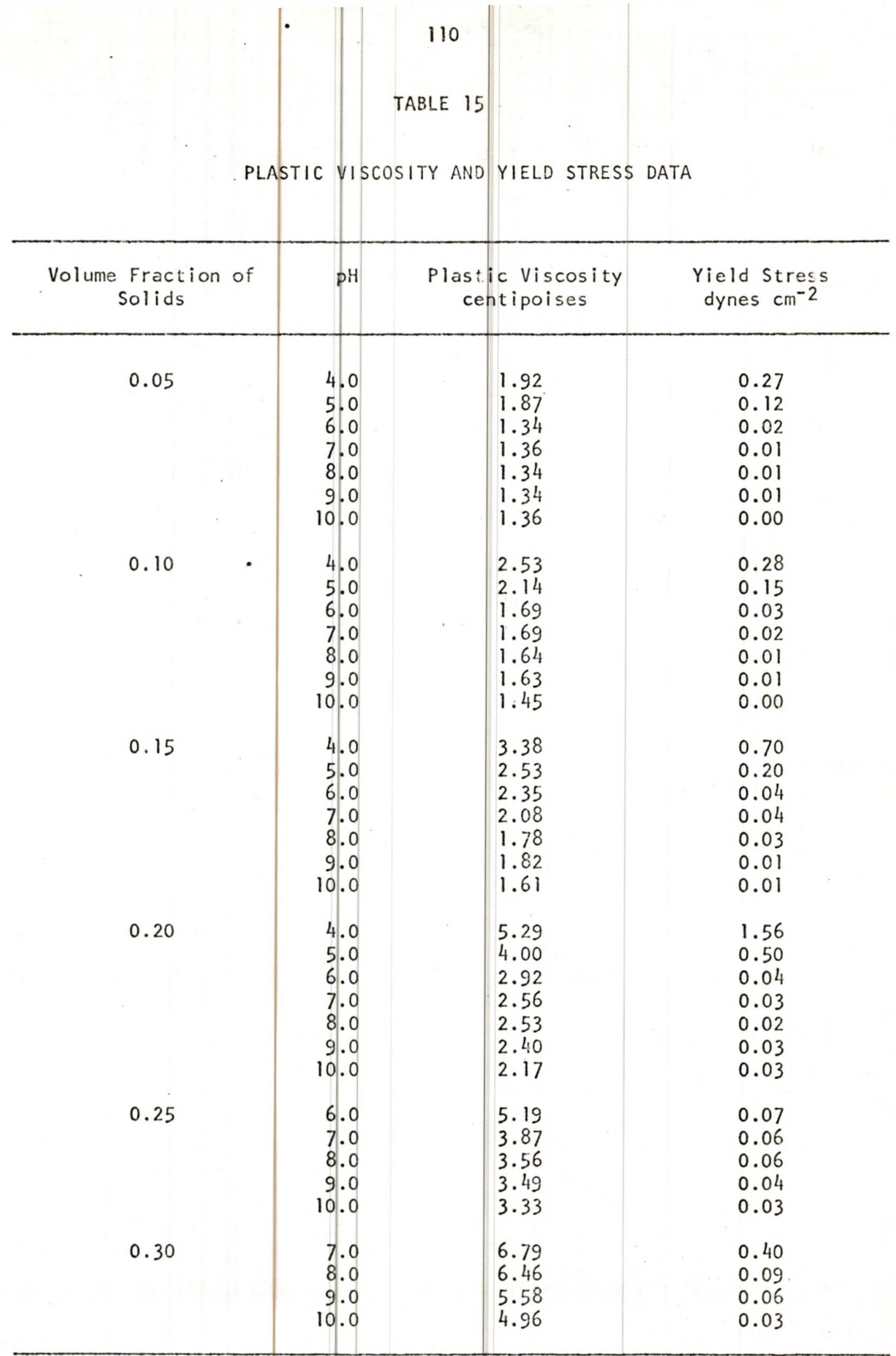


LIST OF SYMBOLS 


\section{LIST OF SYHBOLS}

A constant in Nernst equation, millivolts.

a factor in Ford equation, dimensionless.

$a_{1}$ crowding factor in Mooney equation, dimensionless.

B constant in Nernst equation, millivolts.

b factor in Ford equation, dimensionless.

bl factor in ottewill equation, dimensionless.

$b_{2}$ factor in 0ttewill equation, dimensionless.

c. artivity of a particular ion in solution, dimensionless.

c) factor in Conway Dobry-Duciaux equation, dimensionless.

$c_{2}$ factor in Conway Dobry-Duclaux equation, dimensionless.

$c_{3}$ factor in Conway Dobry-Duclaux equation, dimerisionless.

F Faraday charge, Faradays.

f factor in Thomas equation, dimensionless.

$f_{1}$ electroviscous contribution factor, dimensionless.

h height of inner cylinder in Brookfield UL Adapter, cm.

Kl first electroviscous effect factor, dimensionless.

$\mathrm{K}_{2}$ second electroviscous effect factor, dimensionless.

$\mathrm{K}_{3}$ third electroviscous effect factor, dimensionless.

k Einstein shape factor, dimensionless.

$k_{2}$ collision time constant, dimensionless.

' $\mathrm{m}$ ' power law model material characteristic parameter, $\mathrm{gm} \mathrm{cm}^{-1} \mathrm{sec}^{-\mathrm{n}}$

' $n$ ' power law model material characteristic parameter, dimensionless 
Q hydrodynamic interaction constant, dimensionless.

$r_{1}$ radius of inner cylinder in Brookfield UL Adapter, cm.

$r_{2}$ radius of outer cylinder in Brookfield UL Adapter, cm.

$T$ torque at inner cylinder in Brookfield UL. Adapter, gm cm.

$\gamma$ shear rate, $\sec ^{-1}$.

$\mu_{a}$ apparent viscosity of fluid, poises or centipoises.

$\mu_{0}$ absolute viscosity of Newtonian fluid, poises or centipoises.

$\mu_{p}$ plastic viscosity of fluid, poises or centipoises.

$\tau$ shear stress, dynes $\mathrm{cm}^{-2}$.

$\tau_{0}$ yield stress of fluid, dynes $\mathrm{cm}^{-2}$.

$\phi \quad$ volume fraction of solids, dimensionless.

$\phi_{\infty}$ volume fraction of solids, when relative viscosity is infinite, dimensionless.

$\omega \quad$ angular velocity, radians $\sec ^{-1}$. 


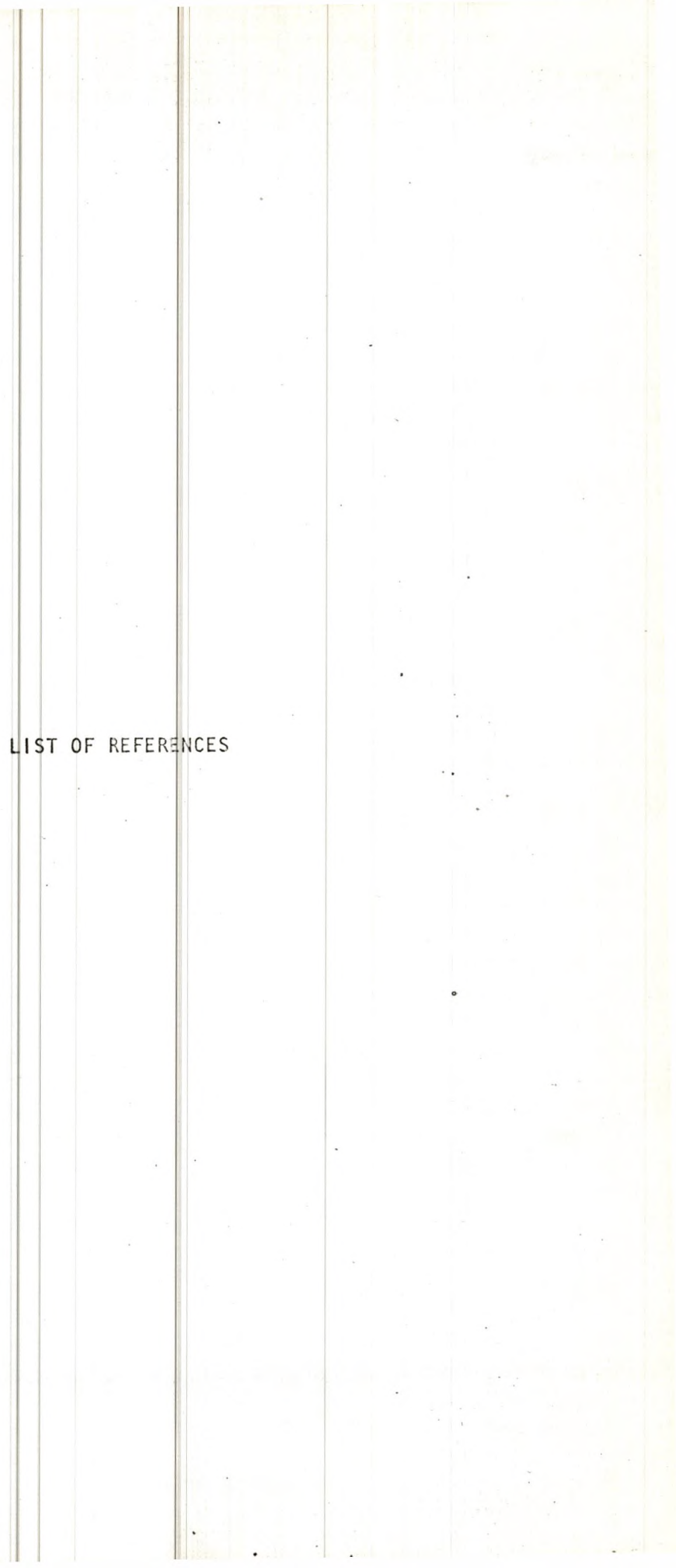




\section{LIST OF REFERENCES}

1. News Article, Chemifal Engineering, (Feb. 24, 1969), pp. 40.

2. Sharp, A. N., "Cral by Pipeline," Coke and Gas, (Aug. 1961), pp. $336-338$.

3. Weisman, J., "Minimum Power Requirements for Slurry Transport," A.I.Ch.E. Journal, 2, No. I (Jan. 1963), pp. 134-138.

4. Thomas, D. G., "Non Newtonian Suspensions: Part 1: Physical Properties and Lami rar Transport Cha acteristics," Industrial Engineering Chemistry, 55, No. II (Nov. 1963, pp. 18-29.

5. Kambe, H., "Rheolog of Concentrated Suspensions," International Chemical Engineerin,, 9, No. 1 (Jan. 1969), pp. 164-171.

6. Ellis, H. S., Redbe ger, P. J., Bolt, L. H., "Transporting Solids Jy Pipelines: Slurrie; - Basic Principles and Power Requirements,"

- Industrial Engineering Chemistry, 55, No. 8 (Aug. 1963), pp. 18-26.

7. Frisch, H. L., Simhp, R., Ed. Eirich, F. R., "Rheology, Theory and Applications," Vol. 1, Academic Press, Inc., New York (1956).

8. Schaller, E. J., "Electroviscous Effects in Suspensions of Monodisperse Spherical Particles," University of Pennsylvania, Ph.D. Thesis, (1965).

9. Chong, J. S., "The Rheology of Concentrated Suspensions," Doctoral Dissertation, University of Utah, (1964).

10. Ting, A. P., Luebbers, R. H., "Viscosity of Suspensions of Spherical and other Isodimensional Particles in Liquids," A.I.Ch.E. Journal, $\underline{3}$, No. I (March 1957), pp. 111-116.

11. Vand, V., "Viscosity of Solutions and Suspensions, 11," Journal of Physics and Colloid Chemistry, 52, (1948), pp. 300-314.

12. Eirich, F. R., "Rheology, Theory and Applications," Vol. I, Academic Press, Inc., New York, (1956).

13. Mooney, M., "The Viscosity of a Concentrated Suspension of Spherical Particles," Journal of Colloid Science, 6, (1951), pp. 162-170.

14. Shaheen, E. 1., "Rheological Study of Viscosities and Pipeline Flow of Concentrated Slurries," University of Tennessee, Ph.D. Thesis, (1967). 
15. Moreland, C., "Viscosity of Suspensions of Coal in Mineral 0il," Canadian Journal of Chemical Engineering, (Feb. 1963), pp. 24-28.

16. Ford, T. F., "Viscosity-Concentration and Fluidity-Concentration Relationships for Suspensions of Spherical Particles in Newtonian Liquids," Journal of Physics and Colloid Chemistry, 64, (Sept. 1960), pp. $1168-1174$.

17. Huber, 0., Penzkofer, A., "The Rheological Behavior of Coating Clays and Aqueous Clay Dispersions," International Chemical Engineering, 8 , No. I (Jan. 1968), AP. 92-99.

18. Ottewill, R. H., "Studies on the Viscrsity of Concentrated Sols of Silver lodide," Unplblished Report, (1956).

19. Conway, B. E., Dobry-Duclaux, A., Ed. Eirich, F. R., "Rheology, Theory and Applications," Vol. 3, Academic Press, Inc., New York, (1960).

20. Sennett, P., Oliviel, J. P., "Colloidal Dispersions: Electrokinetic Effects and the Concept of Zeta Poten ial," Industrial and Engineering Chemistry, 57, 10. 8 (Aug. 1965), pp. 32-50.

21. Overbeek, J. Th. G. Ed. Kruyt, H. R. "Colloid Science," Vol. 1, Elsevier Publishing Company, New York. (1952).

22. Bird, R. B., Stewar,, W. E., Lightfoot, E. N., "Transport Phenomena, "' John Wiley and Sons Inc., New York, (1960).

23. Caldwell, U. H., Babbitt, H. E., "Flow of Muds, Sludges and Suspensions in Circula. Pipe," Industria Engineering Chemistry, 33 , No. 2 (Feb. 1941), pp. 249-256.

24. Brodkey, R. S., "The Phenomena of Fluid Motions," Addison-Wesley Publishing Company, Reading, Massachusetts, (1967).

25. Christiansen, E. B., Ryan, N. W., Stevens, W. E., "Pipeline Design for non-Newtonian Fluid; in Streamline Flow," A.l.Ch.E. Journal, 1, No. 4 (Dec. 1955), pp. $54+-548$.

26. Black, A. L., "How to get more information from Readings of Rotational Viscometers," Rubber Age, (Jan. 1959).

27. Bowles, R. L., Davie, R. P., Todd, W. D., "Interpretation of Brookfield Viscosities," Moder Plastics, (Nov. 1955).

28. Zeta-Meter, Inc., "Zeta-Meter Manual," 2nd ed., (1968), pp. 12.

29. Riddick, T. M., "Cohtrol of Colloid Stability through Zeta Potential," Vol. I, Livingston Publishing Company, Wynnewood, Pennsylvania, (1968), pp. 14. 